\title{
The Grammar of Knowledge in the Concrete
}

\author{
Egotism is true modesty. \\ J. H. NEWMAN \\ Each one must examine his own work, \\ and then he will have reason to boast with regard to himself alone, \\ and not with regard to someone else; \\ for each will bear his own load.
}

Gal 6:4

I think that the most important contribution of Newman to European tradition was that, firstly, he sought to redefine the modern tradition, reaching back to British empiricism and drawing on Christian antiquity. This redefinition meant a revolt against the mechanistic vision of the world in which the individual, within the confines of the independent intellect and limited only by sheer logic, expands the space of his absolutist choices; the individual must subdue himself to the metaphysics of reality and the metaphysics of his own being. There are rules which have not been conceived by the agent and so must be respected. At the time when the applied sciences ruled, traditional views were being undermined, and the revolutionary turmoil seemed to have spread over all the continents, Newman stood up first in defence of the person, and then of the Church with her transcendent claims and her dogmatic structure. Philosophical reflection made him come up with an extended conception of what is rational and personal; a historical reflection on Christianity brought him to the gate of the Catholic Church. It was indeed an enormous task in the nineteenth century, which I have called in this book a laboratory to demonstrate, that the human person can peaceably march the paths of intellectual and moral developments and, above all, be actively engaged in the fascinating world of scientific endeavours and firmly stand by traditional values. In other words, that there is no contradiction between faith and reason, modernity 
and tradition, assuming they are properly understood. Newman had no fear of the "brave new world". The human person in his rich abundance covers all dimensions and, in fact, is an inexhaustible source of variety. Generally speaking, as Meriol Trevor stresses, Newman was especially predestined to confront modernity, he "was an expert, perhaps the greatest Christian expert of the modern age." And the author explains why: "All his ventures were undertaken to assist the formation of a truly Catholic mind - the University, the School, the Magazine itself were all part of this campaign; so was the Oratory, since it was meant to mediate to the people understanding in the practice of their faith." I would summarise that as follows: to build a citadel of certitude inside the human person, indeed, inside the Catholic mind. To build a citadel amidst the maelstrom of the rapid panorama of successive events.

The British historian William A. Clebsch counts John Henry as one among the apologists who "expanded the capacity of self-conscious people for assenting to and apprehending a complex of Christian doctrines whose development he traced back to the original, simple idea of Christianity evoked by Christ's incarnation." ${ }^{2}$ There were two pillars of this new approach, two pillars designed to buttress the new construction of religious belief in the nineteenth century: real assent (including: personal assent) and historical development. The human person is neither an expressivist paradigm nor Locke's punctual self. Each approach that would assume some individualistic elements and subject them to analysis is bound to fail to comprehend him. The person is capable of amassing all sorts of data and creating a system. Therefore, in this chapter I would like to devote much time to Newman's concept of assent. It must also be noted that in the numerous debates held with a view to decide whether Newman was a philosopher or not, it is the category of assent that should be taken into consideration. With his analysis of assent, Newman enters into the philosophical tradition.

Modernity, as we know, ushered into the history of mankind the problem of certainty of knowledge. How can we make the process of knowing certain and indubitable? The dilemma of rationality-irrationality pertains primarily to our mode of acquiring knowledge. Here the key term since at least the time of Augustine has been "assent." It is at the moment of passing judgements that we are exposed to our errors. And our interpretation of judgements decides our definition of rationality. This is a very crucial point, since the kind of rationality we propose brings forth weighty consequences in the area of religion

1 M. Trevor, Light in Winter, London: MacMillan \& Co Ltd, 1962, 201.

2 W. A. Clebsch, Christianity in European History, New York: Oxford University Press, 1979, 267. 
and morality. If, for instance, "rational" is reduced to "demonstrable," religion gets whittled down to a mere naturalistic approach and private opinion. The world becomes an area of mechanistic manipulation in which-as Hegel predicted - the rational can be identified with the real. Therefore, to put it in somewhat simpler terms that may speak to the reader's imagination, as long as something can be logically justified, it can be accepted. The individual history of a single person can then be explained away and ignored by the History of humankind. The age of intellect and the machine naturally has no empathy for the devious paths of personal fortunes. It is in the steady and unrelenting currents of History that our individual histories are immersed and made sense of, but individually and privately they are of no consequence.

As I have already remarked in Chapter 1, we can trace the concept of assent from Augustine's assentior, through Descartes' l'assentiment, down to Locke's assent. In Augustine's works, especially in his dialogue De Magistro (On the Teacher), we find this oft-repeated statement "assentior et video" (I assent and I see, I agree completely). The way we define human judgements is informative of our theoretical position: whether we are rationalists, empiricists, or realists. In other words, whether we reduce human freedom to intellectual cognition or we are open to broader personal knowledge. Newman's main problem was not "to pursue the definition, organization, and systematization of theological truth, but, rather, to study the birth, the life, the death, and the revival of real assent to dogmas in the minds of concrete and existing men."3 In other words, the question was how people really arrive at judgments in the concrete. Indeed, it is worth examining how come, to repeat Stein's example, that a young Jewish intellectual, and an atheist at that, was so ready to assent to the truth of a Christian text, and one written by a mystic. One thing must be noted here: Stein's assent to what she had read in Teresa of Avila was not yet certitude, a remark that is very much in accordance with Newman's explication of real assent. It is not certitude, but may lead to it. This moment of assent can be understood as an initiation in a certain way. It is then followed by reasoning, by scrutinizing what I have assented to, i.e. I examine the object of my assent. Newman went on a path towards the source of his assent, testing whether he could find more confirmation. And Stein, having assented to the truth of the text, set off on a journey to the source of her-most probably even unexpected to herself-assent. At the moment of this assent, she could not yet embrace all the consequences of her decision. She did not yet know what it was to be a Christian, let alone a Carmelite sister, that is, a very committed Christian.

3 J. H. Newman, Grammar, 2 . 
A radical position on assent is presented by the rationalist (Descartes) and empiricist (Locke) traditions. In the view of these traditions, assent must be well-grounded or else it can be censored as irrational. The history of philosophy calls this process "disenchantment". It is true that a certain amount of disenchantment is found in the Aristotelian-Thomistic tradition, but Locke's disenchantment is radical and thoroughgoing. We read his ferocious criticism of what rationalists called enthusiasm: "How a man may know, whether [he is a lover of truth for truth's sake], in earnest, is worth inquiry; and I think, there is this one unerring mark of it, viz. the not entertaining any proposition with greater assurance than the proofs it is built on will warrant. Whoever goes beyond this measure of assent, it is plain it receives not truth in the love of it; loves not for truth-sake, but for some other by-end."4 Newman, for his part, respected Locke and did not feel like arguing with his fellow-citizen, retorted in his Essay on the Development of Christian Doctrine:

It does not seem to have struck him that our 'by-end' may be the desire to please our Maker, and that the defect of scientific proof may be made up to our reason by our love of Him. It does not seem to have struck him that such a philosophy as his cut off from the possibility and the privilege of faith all but the educated few, all but the learned, the clear-headed, the men of practised intellects and balanced minds [...]. The 'enthusiasm' against which Locke writes may do much harm, and act at times absurdly; but calculation never made a hero. ${ }^{5}$

It follows clearly from the above that, for the author of these words, man cannot be reduced to a kind of inductive-deductive creature who is triggered to act only by the force of arguments and would never accept anything that cannot be demonstrated. Newman was alarmed by what was happening in the Church of his birth. Religious truths being diluted to several principles of gentleman's conduct and comprehensive belief ended up with a shocking realization: man can establish a church in which there is no need for God. All such dangerous processes of enlightened modernity induced Newman to come up with his own theory of knowledge. The author of Apologia seems to be saying: you must be talking about man in general, one that does not exist save in books, but let us actually look closer at what man in concrete circumstances is doing.

4 J. Locke, Works, Repr. Darmstadt: Scientia Verlag Aalen, 1963, vol. III, chap. XIX, par. 1, 147.

5 J. H. Newman, An Essay on the Development of Christian Doctrine, 328. 
In the Introduction to Newman's Grammar we read: "If it is a question of achieving a scientific knowledge of the Christian faith, theology alone, as being notional, can do it; but religion is both personal and real, and, unless we content ourselves with a vague religious sentiment, the only way to restore Christianity in the hearts and minds of men is to teach them how to assent to dogmas as to so many real and particular objects. This lack of real assent which Newman was already deploring in England and in Europe [...] does not seem to have grown less common in our own days. On the contrary, it frequently happens that, in nominally Catholic countries, countless baptized men and women not wholly ignorant of their religion seem to live, to behave and to think as though they were wholly foreign to the truth of Christian dogma. This is precise the evil which Newman has attempted to define and for which he has sought a cure in the notion of assent." 6

\section{Notional versus Real Assent}

Before I embark on a characterization of assent (notional and real alike), let me first define its basic trait, which is substantially contradistinctive to the empiricist view. According to Newman, and contrary to Locke, assent is unconditional. As we know, the British empiricist admitted to a gradation in assent: one can assent to something insofar as one is persuaded to it by respective arguments on the part of the object of assent. In the rationalist-empiricist sense therefore, assent would be coequal to inference, whereas for Newman, as we shall see, assent is distinct from inference. Such is the rationalist-empiricist position: a rational man cannot accept more than he can comprehend (i.e. explain, demonstrate), therefore, here is the essential divergence from Locke's rationalist-empiricist view of assent, and the essence of the personalist perspective. Assent (notional and real), in Newman's view, as an act is one and indivisible, and differs essentially from inference. The latter is stronger or weaker, depending on its premises. Externally, for instance, it is difficult to distinguish a notional act from a real one, since, as we consider them from the outside, they look similar, i.e. the subject's verbal response sounds similar. Therefore, in order to examine the true nature of an assent, one would have to embark on introspection, and — naturally — on the practical effects. And this introspection must be carried out by the self itself.

6 J. H. Newman, Grammar, 19-20. 
Let us stress this point of absent gradation in assent, for, if such is the case, we realize that there is an essential discrepancy between the knowing subject and the known object; in other words, the subject can accept more than he can comprehend, and his assenting is not entirely exhausted by the amount of arguments brought forth on behalf of the object presented for comprehension. This is a very important statement because it protects human expanded rationality from a narrow rationalism (in which only argumentation and demonstration are valuable instruments of rationality), and, obviously, it provides rational grounds for the Catholic belief in dogmas. Dogmas, as we know, are not objects of free deliberation, but tenets of faith.

All in all, there is no contradiction between Newman's criticism of the Lockean gradation of assent and his claim that assents are unconditional, although they can be weaker or stronger. For Newman, assent either is or is not. Two elements converge here: antecedent probabilities and the agent's personal preparation to assent to them; the agent is not determined by the probabilities. It is like shaking someone's hand. There is no denying that I have shaken someone's hand if I have done it. But I can still do it in a stronger or weaker manner.

In this case even mistakes play, paradoxically, their constructive function. They simply prove that the whole construction is grounded on solid foundations because despite centrifugal forces it still persists and resists diverse disruptions. The Church persists despite the so-called modernizing attempts and schisms and apostasies (and defections). So if we cannot assent to something we do not comprehend at first, this is because we are not prepared to fill in this surplusage with personal readiness.

\section{$2 \quad$ Notional Assent}

Human beings are very active in formulating opinions, holding views, and declaring something; all such kinds of activity belong to the world of notions. This is how we commonly understand our rationality, i.e. the rational being should be ready to express opinions and hold views on any matter. Notional assents are the weakest types of assent. Among these, Newman enumerates profession, credence, opinion, presumption, and speculation. A notional assent lacks the power to possess the mind, which can distance itself and become disengaged, analyzing the matter at hand the way a scientist looks at an interesting species through a microscope. As Newman rightly observes, while comparing the notional with the real, "It is in human nature to be more 
affected by the concrete than by the abstract."7 Moreover, there is a parallel between the thing apprehended and apprehension, an interrelation that we know from our personal experience. ${ }^{8}$ At this point, let us note that because of this nature of notional apprehension, it is Newman's manifest intention to investigate the process of translating the general into the concrete. How and when does the general turn into the concrete? The point is that when a man translates the general into the concrete, he makes it personal; as I have mentioned dogmas above, the question is how a dogma can become a personal principle.

Notional assents are often confused with inferences and, judging from without, we do not know whether one has no doubts about something or whether one is certain. Notional apprehension is congenial to inference, and real apprehension is congenial to assent. And at this point let it be noted that there is a profound discrepancy, even an inverse proportionality, between inference and assent. Newman calls it the true paradox, "that, when Inference is clearest, Assent may be least forcible, and, when Assent is most intense, Inference may be least distinct $[\ldots] .{ }^{m 9}$

I have already mentioned this basic discrepancy between the knowing subject and the object of knowledge. We could also call this moment a moment of human freedom, or a gap of uncertainty in which a person, confronted with an indubitable inference, gives only a weak assent; and when the same person is presented with a weak inference, his assent is surprisingly stronger. Therefore, Newman concludes in his Grammar that we do not automatically assent to something when given a reason, or else that we abstain from assent when strong reasons are provided. On the contrary, assent may be "withheld in cases when there are good reasons for giving it to a proposition, or may not be withdrawn after it has been given, the reasons remaining, or may not remain when the reasons are forgotten, or must always vary in strength, as the reasons vary; and this substantiveness [...]," as Newman calls it, "of the act of assent is the very point which I have wished to establish."10 In other words, our minds are not always inclined to the conclusions to which inferences point; and there are numerous cases when they incline to conclusions not pointed to by our inferences.

Professions are very weak. Assents are made here upon habit. We follow certain tastes or surrender to stereotypes. We hold that we are behoven to conduct

\footnotetext{
7 Ibid., 5 o.

8 Cf. J. H. Newman, ibid., 49.

9 Ibid., 52.

$10 \quad$ Ibid., 145
} 
ourselves well in good company, or we choose the kind of literature that is fashionable in our day. We tend to share the most popular views because others do the same, or we want to be regarded as sophisticated and well-educated. The beliefs we thus hold are transitory; we take them up one day, and then abandon readily, sooner before we have even realized what they mean. Here comes what Newman called formalism, which happens when one asserts and accepts a view on authority. It is "professing to understand without understanding," and words are used as "war-cries, nicknames, and shibboleths" without a more profound apprehension. ${ }^{11}$ The multitude keeps repeating them because they want to be regarded as men of the world or sound well-bred. They are mere assertions.

In credence, we spontaneously assent to the many messages we receive from our daily contacts, from reading newspapers or consulting other media (in Newman's time the press was in its heyday). The kind of assent that is present here furnishes our minds with respective cultural information. It is characteristic of the social milieu in which we grow up. This kind of information makes up our national uniqueness, for instance, by which we can be distinguished from other social and cultural groups. Such assents are notional and, consequently, superficial, because the ideas thus provided are too complex. They provide some practical information for conversations on various topics, but do not make us professional, for their range is too broad. The reality is fragmented into too many pieces for us to master.

While analyzing notional assent, we must be all the time aware of its basic characteristic, i.e. its theoretical distance to reality. In this sense, for instance, religion, just like theology, can be regarded as notional. Theology is a science, therefore it provides theoretical knowledge, but even religion can be a subject of notional assent. In like manner, even here we can find a superficial (a merely theoretical) attitude to religion. Newman approves of Evangelicalism and other denominations which practice the reading of the Bible. Nevertheless, he deems it insufficient to be content with reading and living a correct life, for, as such, "it is not a religion of persons and things, of acts of faith and of direct devotion; but of sacred scenes and pious sentiments."12

Opinion is a similar assent to that of credence. It is an explicit assent to the probability of a proposition. Being an assent, it is independent of premises. Therefore, unlike credence-which is implicit-opinion is explicit. We are

\footnotetext{
11 See J. H. Newman, ibid., 53, 54.

12 Ibid., 63.
} 
forming an opinion when we reflect upon our credence. It is notional because we assent to abstract probability.

In presumption, we assent to first principles. We know that we have certain faculties of reasoning and memory. Newman writes: "We are what we are, and we use, not trust our faculties. [...] Our consciousness of self is prior to all questions of trust or assent. We act according to our nature, by means of ourselves, when we remember or reason."13 Therefore, trusting the faculties of reason or memory cannot be regarded as a first principle. We simply use ourselves - and this element of his, let us say, realistic theory of knowledge will often be repeated. Therefore, he undertook this meticulous task of examining how a single person comes to know something concrete, or under concrete circumstances. The existence of things external to ourselves can be considered a first principle and such that "is founded on an instinct." ${ }^{4}$ We have an instinct that informs us about the existence of the world without. This instinct accompanies each object that is given to us in experience. We then generalize the collection of such instincts and come up with a general statement that the external world exists.

General names are abstractions as they are conclusions from particular experiences. Likewise assents to the so-called first principles are notional assents to the propositions containing abstracts terms. When the question of Newman's alleged nominalism is raised, one must be aware of the fact that he was hardly interested in deciding on behalf of idealism or realism. The problem appeared to him to be fairly theoretical and — as he frequently repeated — his principal interest was man's conduct in the concrete circumstances. In the concrete circumstances, the acting person never considers the reality or unreality of the world, but rather has to grapple with what is good or bad, what is proper or improper to do. From this point of view, we may easily understand that even the first principle of our conscience, i.e. "there is a right and a wrong"-wellknown as the principle of synderesis-is notional and theoretical, unless it is followed by a personal struggle towards a concrete choice under given circumstances. Therefore, Newman has a point here, for the general principle does not confront us with the practical choice of a good or a bad action, unless it is potentially, until we are actually confronted with some existential dilemma. In other words, the principle of synderesis is abstract for us before we start to act. We know, theoretically, that there are these two fundamental aspects of reality, but we realize their presence when we are called upon to act.

\footnotetext{
13 Ibid., 66, 67 .

14 Ibid., 67.
} 
As we learn about the external world through our senses, likewise we learn about God through the dictates of our conscience. Here is an analogy between the knowledge thus gained about the external world and the knowledge of God gained through the dictates of conscience. We learn about the existence of a world external to us by way of induction from a recurring experience of objects. In like manner, we realize that there must be a Being superior to us from the recurring dictates of our conscience.

And Newman provides an adequate explanation of the abstract (notional) nature of this principle when he writes that "in proportion as we obey the particular dictates which are its tokens, so are we led on more and more to view it in the association of those particulars, which are real, and virtually to change our notion of it into the image of that objective fact, which in each particular case it undeniably is." ${ }^{15}$ Indeed, this is one of those wonderful ways in which Newman brings home to his readers his true meaning of such confusing statements. We may be aware of good and evil in theory, but only our adjustment to the practical claims of our consciences, when theory is translated into an image, makes us actually realize good or evil. Obedience to the dictates of conscience in the aforementioned quote is an excellent example of Newman's key interest, namely, the practical translation of a theoretical tenet into a practical principle of action.

Another example of a notional assent-presumption-is the belief in causation, an example which Newman might have taken from Hume's exposition of the problem. We can understand causation in two senses: when something causes something else to exist and when something follows something else, i.e. when A is prior to B, or when B follows A. We observe a sequence of antecedents and consequents and we "confuse causation with order," but we should rather speak about "a cause to be an effective will; and, by the doctrines of causation [...] or first principle, [Newman means] that all things come of effective will; and the reception of presumption of this notion is a notional assent."16

The same goes for causation understood as a temporal succession of antecedents and consequents. If they belong to the order of nature, and we have approved of the thus established causation, there is a notional assent to the repetitive pattern of certain events. On the basis of this homogeneity of nature physicists construct general laws. Naturally, Newman is still referring to the Newtonian vision of nature in which the laws are universal. For the sake of

\begin{tabular}{ll}
\hline 15 & Ibid., 70. \\
16 & Ibid., 71, 72.
\end{tabular}


our considerations, let us note that it suffices for his argumentation, namely, that he wants to say that, inasmuch as the laws in question are universal and embrace all phenomena that fall under their operation, the phenomena themselves are always unique and individual. Therefore, he claims that the doctrine of the uniformity of the laws of nature is an abstract conception, which is "more perfect than the recurrent phenomenon itself [...], and the variations which accompany the repetition are of the nature of exceptions."17 His argumentation exhibits the consequence in his thinking. The point he is driving at is to show that there is an essential discrepancy between the general laws and the concrete events which these laws have been designed to describe. Concrete events are always different in their detail from the general outlines. ${ }^{18}$ We may speak only about approximations rather than adequate descriptions. Obviously, science accounts for these aberrations by the interaction present in nature. We must not, however, confuse facts with reasoning, for "the confusion is a fact, the reasoning processes are not facts." ${ }^{19}$

We are dealing with hypotheses rather than with experienced phenomenal facts. We take the unfailing uniformity of nature for granted. For Newman, it is not a cause that makes things happen but Will, for "we have no experience of any cause but Will." ${ }^{20}$ In view of this, speaking about moral luck is even more absurd. A cause implies a will, and the order of nature implies a purpose. The order of nature can be changed by "that which willed it, [...] and the invariableness of law depends on the unchangeableness of that Will."21

It follows from the above considerations that general laws are never adequate tools for the descriptions of individual facts. Rather, they are simplified approximations and should be regarded more as probabilities than exact representations of experienced facts. Particular events happen not by the scheme of some deterministic laws, and yet they still happen, hence they must have been willed by Someone. Newman denounces the modern vision of mechanistic laws that rule over nature; for him, the Creator of nature is ever present in His creation. Is our situation as Newman describes it? We have a network of laws and a complex agglomeration of facts. And now we seek to express these facts by means of those laws. As the network is inadequate, we resemble a fisherman who is trying to catch small fish with a net whose grids are too big.

\footnotetext{
17 Ibid., 73 .

18 From the point of view of contemporary physics, Newman's conclusions are obvious. Today, physicists speak merely about the probability of physical events.

19 J. H. Newman, Grammar, 73.

$20 \quad$ Ibid., 74.

21 Ibid., 74-75.
} 
In speculation, which is another kind of notional assent, we include our conscious acceptance of propositions as true. Here we list some general truths, maxims, mathematical investigations, legal judgements "the determinations of science; $[. .$.$] the principles, disputations, and doctrines of theology"22 Because$ they are expressed as general propositions, they are subjects of notional apprehension. This does not mean that they cannot be received by real assent as well. Generally speaking, all of our notional assents can be made real and assented to in our experience, as I shall try to demonstrate further. Let us now turn to real assent.

Real Assent

What is notional and what is real exert a force on the mind, but the real, being concrete, exerts a much more powerful force. In the case of the real, our apprehension is stronger than in the case of the notional. Mere abstract terms or some general knowledge do not stimulate the mind in the same manner and to the same degree as a concrete influence does. General deliberation about death does not have as equally potent an impact as the concrete (and actual) death of a close relative. Inference and notional assent are often treated as one class of concepts, with the exception that assent is always an unconditional acceptance of a proposition, whereas in inference we must first accept its premises and only afterwards the conclusion. In notional assent, the mind contemplates its own creations. In real assent, the mind is directed towards things. They inculcate impressions on the imagination. Things create images, which, in turn, exert influence on individuals. Here, we are talking about minds which have long acquainted themselves with certain subjects. Images need not be true, but they exert a vivid apprehension. Images evoke something in us, they call for a prompt response. They are like anchors holding us fast to a certain reality, like seals on our minds. Come and see for yourself, touch me and see. ${ }^{23}$ Images are witnesses to what we have gone through; it does make a difference when we say "I understand it," and "I know because I have seen it." Images leave behind some indelible traces that will not permit us to forget. Images admit no room for deliberation. Let us consider an example.

Several years ago Randy Pausch, the late computer science professor at Carnegie Mellon, published a book entitled The Last Lecture (2008). And this

$\begin{array}{ll}22 & \text { Ibid., } 76 . \\ 23 & \text { Cf. Lk 24:39. }\end{array}$


book is indeed about his last lecture; it was literally his last lecture. The word "last" was not only the last element in a set of like terms in which there is not any "next." The word "last" meant that the lecturer would not give any further lectures, for he would not exist any longer. Thus, it took on a very radical meaning. The reason was not his retirement (he was still young) or his decision to move to another university, as one might expect, but the diagnosis of his terminal condition (he had been diagnosed with a very malignant type of pancreatic cancer). I think that Pausch's book (and his very idea to deliver this lecture) is a splendid recapitulation of what we are talking here about. Existential philosophers say that the human being is a Being-toward-Death (Heidegger), in itself a clever term that covers our gradual passing away, but the connection between being and death rendered by this term is merely theoretical, and therefore abstract. Likewise, one may consider the death of any representative of homo sapiens as a consequence of biological development (birth, growth, and decay). The situation takes on an entirely new turn when one is struck by the sudden realization that his or her death is indeed imminent, that it is - so to speak metaphorically — standing at the threshold. A diagnosis is a visible sign of something concrete, something that has almost been calculated. At that moment, words implode, they appear desperately inadequate to comprehend that truth, they fail to render the meaning, when, safely embedded within semantic and syntactic wholes, they are dimmed by the unknown; do not we express this feeling by saying that we are desperate for words, that words fail us, that we are short of words? Indeed, this is the situation when I learn that it is I who am about to die. And this is what Newman meant by realizing, by assenting to something real. The truth speaks itself, it shines through the human being; we experience the fact that the time for guided discourse has ended. Only real assent is meaningful and effective, although one may hopelessly search for words to describe it. And real assent at such moments may also denote silence. ${ }^{24}$

General truths and great maxims, as Newman says, float on the surface of society. They are waiting to be born, i.e. to be given life by some individuals. First, they are regarded as abstract truths with self-evident acquiescence, but then transformed into practical expression. They are hardly ever realized by society at large. Usually, there is an individual mind, like that of Wilberforce's, that becomes operative in translating the notional into the real. And William Wilberforce (1759-1833), as we know, won a successful battle over the abolition

24 When Job's friends had realized their friend's enormous suffering, they remained silent for seven days and seven nights. 
of slavery in Britain in the nineteenth century. Of course, there was general outrage against slavery among many, but only Wilberforce was practically inspired to take concrete steps that proved so successful in Britain.

Many classes of people acquiesce in general truths, but only some minds are aroused to action. To these minds, words speak of things, not merely of notions. Hence, they serve not merely for embellishing our speeches, but for acting. The first thing for something to be real, Newman claims, is that it must be presented in the form of an image. The question as to the reality of images is another matter, for, as we have said, an image may be very impressive yet without being real. Very often we deviate "from the line of reason and duty," especially in the case of "an idiosyncratic sagacity," that is, in the case of men with outstanding intellectual gifts. ${ }^{25}$ Such people are prone to be carried off by the lively productions of their concepts. Imagination, let us stress, does not produce assent, but only intensifies it. An image is like, say, a connatural reflection in someone's mind; it is a response of the person, not merely an acquiescence of the intellect.

Imagination and Images versus the Response of the Person

The role of the imagination in the nineteenth century became proverbial; it was set in opposition to the intellect of the Enlightenment. Imagination does not cause action, but only stimulates our motive powers "by providing a supply of objects strong enough to stimulate them." ${ }^{26}$ When we consider such things as future life, reward or punishment, it matters much whether these objects create some images in us or whether they are mere notions for the construction of propositions. There is a correspondence between a future action and the thought about this action. The latter is initiated on condition that in our minds there is something "congenial to it" or, as Newman explains it, if "there is that preparation of mind, the thought does lead to the act."27 This is what I call "a connatural reflection." No wonder, then, that we may have a group of people exposed to the same contents, and yet only some of them, or, in fact, only very few of them, are ready to give their real assent. We hardly ever come across a situation in which all the subjects are affected in the same manner. Ultimately, however, it is the person's fiat that causes action, not a clear and distinct concept or persuasive reasoning. And this conclusion agrees perfectly

\footnotetext{
25 See J. H. Newman, Grammar, 81.

26 Ibid., 82.

27 Ibid.
} 
with Newman's understanding of causation, in which the will is the motivating factor.

Another important trait that has a bearing on real assent is its personal nature. Unlike notional apprehension, which corresponds to our common nature, real assent is always personal. When we turn to abstractions, we can easily establish a common measure between two minds. Thus, learned discussions are plausible because the object of discussion is made intelligible and intersubjectively comprehensible. Real assents in which we assent to images are unique, but we cannot secure the same images in experience for any two persons, or, we should more correctly say we cannot assure the same responses to equivalent images.

The problem of imagination in Newman causes certain doubts. We know that, for him, imagination does not determine action, but can stimulate the agent to action. It provides images and they are more powerful than mere theoretical concepts in initiating action. Insofar as this point is relatively clear, it is difficult to understand the role of imagination in belief and knowledge. In his philosophical notes, the Cardinal writes that "imagination is the habit of the act of making mental images." Imaginations, however, "cannot be matter of judgment, i.e. of assent or dissent, because you cannot affirm or deny without grounds - and hence there is no basis of knowledge at all. What one cannot assent to \&c, one cannot believe or disbelieve; is not the subject of faith. ${ }^{28} \mathrm{He}$ then makes a distinction between Imagination and Conception. The two should not be mistaken, for "we can imagine things which we cannot conceive."29 So far so clear, but later on we learn "we can believe what we can imagine, yet cannot conceive [...], you can believe what you [-imagine] $<$ cannot conceive >; «understand» means «imagine» and certainly I do not believe (except implicitly) what I do not imagine." ${ }^{30}$ Are these two pages contradictory? First, we learn that if we cannot assent to imaginations, they cannot be the subject of faith; now we learn that we cannot believe what we cannot imagine. The conclusion is all too clear: we can assent to what we can imagine; and there is another conclusion: we cannot believe if we cannot imagine. Is belief possible at all? We may account for this apparent contradiction by referring to a passage from Newman's Grammar. Here, the author relates imagination to experience. Perhaps the best answer to this difficulty would be Newman's method of arriving at the truth, which is a process of development. In the Grammar of Assent, the author explains the intrinsic discrepancy between

28 E. Sillem (ed.), The Philosophical Notebook, vol. 2, 152.
29 Ibid., 153.
$30 \quad$ Ibid. 
notion and image in favour of the image. Although an image can be incomprehensible, we can still assent to it. This is the case in which indeed "understand" can mean "imagine", but not "to explain." Therefore, when a person says "I see," he, in fact, acquiesces: "I understand." And this is how the phrase is understood in the English language. The interesting fact here is that the verb "see" is naturally used in another context in which it is related to the sense of sight.

Of course, the question is how abundant our imagination is. If our imagination is subdued to the intellect, it is limited only to what can intellectually be conceived. If it is guided by the heart, it is open to much vaster vistas of reality. The heart can see more than that which can be explained, it goes beyond the world of concepts. As if to confirm our suggestions, Newman hastens to explain this in his Grammar: "As notions come of abstractions, so images come of experiences; the more fully the mind is occupied by an experience, the keener will be its assent to it, if it assents, and on the other hand, the duller will be its assent and the less operative, the more it is engaged with an abstraction; and thus a scale of assents is conceivable, either in the instance of one mind upon different subjects, or of many minds upon one subject varying from an assent which looks like mere inference up to a belief both intense and practical [...]."31

Indeed, I can imagine what I can experience. Does the Cardinal reduce knowledge to the empiricist view? I think he is simply saying that experience broadens our horizon, and if I want to understand religion in its real-not merely notional - form, I must be deeply immersed in religious life, I must be open to religious experience and religious practice. Religion and morality are not primarily areas of theoretical knowledge. This is what Aristotle understood so perfectly in his exposition of virtue: we need not know what virtue is, but we need to be virtuous people. I can see what I understand, and I can understand what I can see. To be open to religious experience means to be fully aware that, in this encounter between the transcendent and infinite Being on the one hand and the finite on the other, there is much to accept without comprehension. In any case, even the finite being - and I shall elaborate on this-has, deep down, an immeasurable and incommunicable reservoir of mystery. This requirement of being real crops up all the time in Newman's writings, i.e. instead of being satisfied with knowing what virtue is, one should practise virtue. How can a man talk about virtue if he has never sought to be a virtuous man? How can a man talk about religion if he has never attempted to be religious? Therefore, the American Newman 
scholar, John Crosby, is right in saying that Newman "sought rather to make people realize the truths that they were so fruitlessly professing. He sought to make the sources of religious experience flow for them again. He sought to awaken the religious imagination. He sought to appeal not only to the intellect but also to the heart, and in this way to stir up his listeners to action. He preached in a way that 'pierced' the existence of his hearers, which means that he energized them existentially. That was the secret of his power." ${ }^{2}$ I can only enhance one of these points by adding that Newman primarily sought to appeal to the heart, this enlivening centre of images that may stimulate action. For instance, instead of just talking about suffering we should see those who suffer and rush to their aid.

It is not the act of assenting to something that should be the focus of our criticism, but the object to which we assent. In general, it is good that we are capable of assenting, especially that we are capable of assenting to things we do not comprehend. The fault is in the object, not in the assenting. When we assent to bad things, it is not the act of assenting that is at fault - an act which was the object of criticism for Descartes made him suspend his judgement-but the object to which we assent. The fault is not in the assenting itself, so that it should be self-evident, as if we could withdraw from assenting and become non-judgemental. This is the surest way to non-commitment and scepticism. The rationalist suggests suspending our judgement until the object presents itself as a clear and distinct idea, i.e. as an intellectually clear object. In such a case, we could remain in withdrawal and suspension forever. Assenting has its source in the person as a whole, not only in his intellect; the task of our reason and conscience is to analyse the object of assent. The more integrated we are, the more spontaneous and intuitive such processes are.

When the undivided person is assenting to something, he stands a chance of finding the truth. Therefore when Newman was criticised for being hypocritical, he set about writing "the closely reasoned pages of the Apologia where he shows his unerring logic at the best advantage."33 Its purpose was to prove that he had never intentionally made a mistake, adding simultaneously that he had never "sinned against the light," that is, he had never sinned against his conscience, that his words had never been unreal.

32 J. F. Crosby, The Personalism of John Henry Newman, 34.

33 L. Sheppard, Spiritual Writers in Modern Times, 33. 
How can we communicate if there is no common measure between us? Let us repeat that we are now talking about real assents in their capacity for communication; in the case of the notional, communication is far more plausibleoften superficial, yet plausible; we can observe how scholars notionally communicate. It may happen that their understanding of the terms in question do not match, but they can make up for this by providing respective definitions. What we are doing here, then, is to translate the individual and idiosyncratic into words (into abstract notions), i.e. into a shared linguistic system of communication. Here we have to mention another key word in Newman's "system," namely the word "realize." In notional assents we readily assent to contents we do not realize. In his Parochial and Plain Sermons, Newman describes this situation as follows: "When we are told a thing, we assent to it, we do not doubt it, but we do not feel it to be true, we do not understand it as a fact which must take up a position or station in our thoughts, and must be acted from and acted towards, must be dealt with as existing: that is, we do not realize it."34 In notional assents, we express many lofty words, but "we do not in any good measure realize them." ${ }^{35}$ We need to see the reality behind the notions, we need to gradually gain knowledge of ourselves and the world until we realize, that is, until "we shall give up shadows and find the substance."36

Obviously it is difficult to grasp what is meant here and put it into a comprehensible definition, for realization will mean something different in each particular case. Our real assent is always personal in terms of its intensity and of its time. The process of growing is of utmost importance for Newman. It must also be stressed that the word "personal" should not be taken to be synonymous with the word "private." If our understanding of a religious matter is personal, this does not mean that everybody can have their own private judgement on religion. Such an outcome would mean that, in fact, religious truth is relative. No, the personal means here that I have to make religious truth my own, and as such it must always be adjusted to my individual life, not in the sense that I tailor it to my life, but that I shape my life according to this truth; such is the ultimate meaning of realization. And this is what, in Newman, can be called subjectivity, as distinct from subjectivism. In other words, the general religious tenets should be apprehended in an individual manner in a concrete person.

\footnotetext{
34 J. H. Newman, Parochial and Plain Sermons, San Francisco: Ignatius Press, 1987, 1236.

35 Ibid., 1238.

$36 \quad$ Ibid., 1239 .
} 
Accidents happen to us according to general laws, but why they happen to this or that person is a mystery. Individual accidents fall within a scheme of contingency we do not understand. Therefore, the same contents may be attached with different images because we have different backgrounds and upbringing, the individual circumstances of our lives. Hence, "the image in the mind, with the experiences out of which it is formed, would be a personal result $[\ldots]$ would in each case be so idiosyncratic in its circumstances, that it would stand by itself, a special formation, unconnected with any law; though at the same time it would necessarily be a principle of sympathy and a bond of intercourse between those whose minds had been thus variously wrought into a common assent [...]."37 Newman is all the time referring to the fact that, in the process of knowing, we use ourselves as we are, while the universal logical rules are only a part (oftentimes not so decisive) in our personal endowment. At the same time, general schemes are always inadequate instruments to render precisely what is concrete and individual.

Real assents, inasmuch as they are individual and unique, can bring about a common understanding. By way of illustration, we may be attracted by the same view, i.e. a splendid waterfall, and yet in each case the experience is unique. The beauty of the water cascading down a rock is reflected in a hundred mirrors. And the sight of this waterfall is much stronger than a mere literary description of the same event read by a hundred people. Descriptions are abstractions, and "an abstraction can be made at will, and may be the work of a moment; but the moral experiences which perpetuate themselves in images, must be sought after in order to be found, and encouraged and cultivated in order to be appropriated." ${ }^{38}$ The teaching of the New Testament is told in stories appealing to listeners. The Samaritan took the wounded traveller, put him on his donkey, then carried him to an inn, and eventually paid for his recovery. All the listeners present could imagine the whole situation. This is an excellent example of a moving story turned into a moral lesson that appealed to the imagination of the listeners.

Real assent, also called belief, can affect our conduct, although it does not lead to action directly. Newman calls it "an intellectual act" whose "object is presented [...] by the imagination" and, as such, can stimulate "those powers of the mind from which action proceeds." ${ }^{39}$ Not abstractions or hasty generalizations, but real assents or beliefs have the means to stimulate the mind to action. Real assent or belief lives in images. It is the power of the concrete that

37 J. H. Newman, Grammar, 85 .

38 Ibid.

39 Ibid., 86. 
appeals to us. The concrete allows for no hesitation, i.e. this concrete suffering human being is in need of help. Belief is like presence, for faith is enlivened by presence, faith lives and feeds on presence. In real assent, we need to apprehend the things believed (apprehension is presupposed), unlike in notional assent or inference. In the latter case, we are dealing with mere surfaces or aspects. In inference, for instance, we simply proceed from premises to conclusions and it suffices to satisfy the formal requirements for an inference to occur. We proceed from premises to conclusion by virtue of the inherent logical procedure of the inference.

The question of what is real would be of particular interest to scholars of the phenomenology of religion, a phenomenology of religious belief. I mean in particular this special, peculiar relationship between a proposition and real assent. What makes us really assent to a proposition? Is it in the proposition, in its formulation, in the recipient of the proposition or in the utterer of the proposition? And, of course, real assent to a religious proposition is entirely different than other propositions, for instance a mathematical proposition. Let us assume that someone tells us that, in a right-angled triangle, the square of the hypotenuse is equal to the sum of the two squared legs. The fact of assent depends to a large extent on the recipient of this message. Usually, there is a sort of tension between the proposition and the recipient. Here are the basic conditions for assenting. (1) Let us assume further that I have some general knowledge of mathematics and am acquainted with its basic principles, especially such basic formulae as the Pythagorean theorem. I was a diligent student in college and have a good memory. Therefore, I can simply assent to the truth of this proposition. (2) I am totally ignorant in mathematics, yet at the same time I know that the statement comes from someone who is a well-known mathematician, someone who is knowledgeable about its theorems. In the latter case, I can assent to the theorem on trust, on the grounds of someone's authority. (3) Now let us consider yet another case. This time I meet someone within the premises of an institute. In our example, this may be an Institute of Mathematics. Therefore, it is the authority of the institution that impels me to assent to the given formula.

Now, which of the above conditions is used in the case of a dogma? The situation is more or less similar to the second and third examples. In other words, its truth is guaranteed by the authority of the person and the Church. In the case of mathematics, I may feel encouraged to assent by the authority of a specialist or the authority of an institution. When a dogma is at stake, it is the testimony of a believer and the authority of the Church that provide support. What is originally only felt by many believers as true is later translated into a dogmatic form. Obviously, in the case of religious truths we take into 
consideration not only their theoretical wording, but also we look at the lives of those who live them. It follows from the above examples of assent that - as Gilson rightly observed - "real assent does not automatically follow from valid notional inference" and this statement "opens a wide and fruitful field to phenomenological investigation." 40

The big question that arises in this context is how to turn theoretical principles into living guidelines in individual human beings. In the case of mathematics, we are ready to trust someone who is familiar with mathematics; in the case of a religious truth in a dogmatic form we have the authority of the holy men and the authority of the Church. Of course, there is yet another step that we have to take. And this is something in which Newman is fundamentally interested. Obviously, the acceptance of the Pythagorean formula may have little significance to our real life, whereas the acceptance of certain moral truths is vitally important for us.

In example (1) it is the sheer logic of the proposition that appeals to us. We do not need to refer to other sources. It is enough to understand the categories in question in order to assent to a proposition. Rationalism follows this narrow path. The point is to reduce all the formulae to their most simple constructions, so that their inherent clarity impels us to assent to them. Dogmas have their history, living human principles have their personal circumstances. Therefore, it would be far too little to reduce their force of impact to only their theoretical formulations. More often than not they even lack formulations. The main reason for Newman's opposition was that rationalism, especially narrow rationalism, relies entirely on the speculative products of the immanent self. In this personal quest, when intellectual prowess is the only criterion for investigation, the ultimate outcome is most uncertain. Lost in the intricate interplay of premises, the individual may arrive at any solution, but hardly at the truth.

Thus, we apprehend propositions in two ways: notional and real. Newman says that real apprehension is closer to assent: "Now assent to a real proposition is assent to an imagination, and an imagination, as supplying objects to our emotional and moral nature, is adapted to a principle of action $[\ldots] . .41$

\footnotetext{
40 E. Gilson, Introduction, in: Grammar, 20-21.

41 J. H. Newman, Grammar, 176.
} 
Newman discussed this issue at length in his Discussions and Arguments on Various Subjects, in which he argued that being enlightened by bookish knowledge does not suffice for moral improvement. A mere theoretical acquaintance with various subjects on ethics does not create an ethical man. Contrary to the positions held by ethical intellectualism, whose source - as we know-is traditionally attributed to Socrates, and the enlightened views of the French philosophes, Newman disavows a mere notional apprehension as sufficing for human edification, let alone sufficing for moral action.

Let us observe that such rationalistic views fit well into the picture of a disenchanted world, a world of free choice based on the hypertrophy of the intellect and the atrophy of morality. In this deistic and naturalistic milieu there is no need for any personal conversion or transformation, any personal effort at obedience, let alone liberation from sin. Sin does not exist in the rationalistic vision of the world; there are only errors in reasoning, which can be remedied by the employment of the appropriate method. The human being is formally prepared to think for himself and absolutely free to choose whatever values come in handy. Education is all we need in order to learn about our whereabouts.

The Cardinal summarizes their arguments as follows: "Education is the cultivation of the intellect and heart, and Useful Knowledge is the great instrument of education. It is the parent of virtue, the nurse of religion; it exalts man to his highest perfection, and is the sufficient scope of his most earnest exertions.

Physical and moral science rouses, transports, exalts, enlarges, tranquilizes, and satisfies the mind. Its attractiveness obtains a hold over us; the excitement attending it supersedes grosser excitements; it makes us know our duty, and thereby enables us to do it; by taking the mind off itself, it destroys anxiety; and by providing objects of admiration, it soothes and subdues us.

And, in addition, it is a kind of neutral ground, on which men of every shade of politics and religion may meet together, disabuse each other of their prejudices, form intimacies, and secure co-operation." ${ }^{22}$ The ironic overtones are evident here, and the quote perfectly recapitulates the secularized and deistic heritage of the Enlightenment.

42 J. H. Newman, Discussions and Arguments on Various Subjects, London: Longmans, Green, and Co., 1924, 255-256. 
The description of the "brave new world" reads like a joyful message concerning the person's puzzle. If the knowledge of our duty suffices in order to be dutiful, everything else becomes redundant. Knowledge induces us to fulfil our duties. Apparently, Descartes' dream, i.e. the right method, has thus become a reality. Theoretical knowledge elevates us. Indeed, the prospect that is unfolding before our eyes resembles a situation in which a man placed amid a collection of books becomes enlightened by the very presence of this noble company. Newman's critical remarks were actually a reaction to Sir Robert Peel's ${ }^{43}$ address on the opening of a reading room at Tamworth in 1841. Newman's critical edge is primarily aimed at Peel's enlightened thesis that, while becoming wiser, we are automatically becoming better. One thing is obviously presupposed in the description above, namely that the human self is a theoretical construction that is ruled by some external, common, universal, and intelligible rules; and in the case of disobedience and unruly behaviour, only sufficient knowledge is wanting. And these rules exhaust whatever we need to know in order to understand the human person. Therefore, the key to learn the self is outside, not inside. Both Newman and Stein held contrary views. It is true that there are certain aspects of the self that can be viewed from outside, analyzed and expressed in some general terms, otherwise we would not be able to say anything sensible about the person at all, but such knowledge is never exhaustive and can never aspire to a complete view of the person.

In such desperately foreshortened beliefs not only is knowledge the key to understanding the person, to know his or her duties, but it also becomes the safeguard of social peace. Religion is definitely deprived of its supernatural dimension, unless it provides some practical rules for the sustenance of social decorum. Useful Knowledge is its nurse. We can understand that the rationalist needs religion as a kind of embellishment. If it fails to play this role, it may be abandoned. After all, what is religion for, if knowledge is designed to cater for all social needs? Indeed, in the enlightened perspective religion becomes co-equal with knowledge, and the latter is sufficient for moral improvement. Human nature has no need of conversion, it suffices to acquire respective knowledge. The latter secures cooperation, forms intimacies, and eliminates prejudices. Newman rightly observes that "to know is one thing, to do is another; the two things are altogether distinct [...]" and "the consciousness of a

43 Robert Peel (1788-1850), British prime minister in the years 1834-1835 and 1841-1846; in the 184 os he enacted free-trade regulations which were designed to relieve the then economic crisis. 
duty is not all one with the performance of it." ${ }^{\text {"4 }}$ Autonomy furnished by mere theoretical knowledge is insufficient.

Providing different theoretical contents in the form of education will not automatically bring about any practical changes in human conduct, because "the human mind is at best in a very unformed or disordered state; passions and conscience, likings and reason, conflicting, - might rising against right, with the prospect of things getting worse." 45 This is what I shall later call chaos; therefore, the first step is to examine one's own self and its circumstances. We may call this introspection or diagnosis of the individual situation. What is significant is inward change, not a change of external objects, "the mere lulling of the passions to rest by turning the course of thought; not a change of character, but a mere removal of temptation." ${ }^{\prime 6}$ One should not wonder at this proposal by the utilitarians, if their major belief is that true excellence comes from without, not from within. Now that we are living in a culture of advertisements, this "philosophy of expedients" 47 has become even more popular. Once the criteria of good and bad are removed, and each lifestyle finds its proponents, all obstacles must be removed from its path. There is a remedy for every problem.

\section{$7 \quad$ Examples as the Sources of Proper Conduct}

In addition, Newman argues that mere theoretical knowledge, notional apprehension, is incapable of changing man. Expedients are no good here; we need to renovate the heart and the will. In our education, we should begin with faith, conscience, and practice. We need common sense and practical experience. We must approve of differences, because differences are the backbone of Christianity, i.e. of faith, but they are subject to judgements. Differences mean to learn to be judgemental. Contrary to the modern trend towards uniformity, man must learn to evaluate. Since we cannot prove every single aspect of our daily lives, since our knowledge is imperfect, we must begin with faith. And faith also means reliance on someone else's words or examples. Examples appeal to the imagination. There is no power in deduction; we must reach the heart, and the heart is reached "through the imagination, by means of direct impressions, by the testimony of facts and events, by history, the description.

\footnotetext{
44 J. H. Newman, Discussions and Arguments, 262.

45 Ibid., 263.

46 Ibid., 264.

47 See ibid., 266.
} 
Persons influence us, voices melt us, looks subdue us, deeds inflame us." ${ }^{48}$ And Newman repeats his ever recurrent argument, namely that it is not enough to know something, we must be certain of it, we must realize it. It must not be "a thing which is, but which we are 'certain about' [...]," people must "realiz[e] their high maxims in the concrete." ${ }^{49}$ We can be indifferent to what we know; we must be touched by it from within in order to be moved. We must realize what we are certain of.

Newman ridicules what he calls "a religion of inferences," for "man is not a reasoning animal; he is a seeing, feeling, contemplating, acting animal. He is influenced by what is direct and precise." 50 This does not mean that the author of these words is against reason. He is simply saying that mere intellectual argumentation is insufficient in dealing with such a complex being as the human person. Moreover, we find here the same affective element that is consistent with Edith Stein's writing. As her commentator writes, "The center of the individual $[. .$.$] lies in the personal layer, the home of the personal care, the will,$ and our affective life." 51 Therefore, each person is so complex and no external observer can help him, if he does not make efforts to retrieve all the discordant elements of his very being. More often than not, there is no evidence on which to proceed. In his action he cannot start with proof, rather he must act on faith. We should rather rely on images that come from impressions, and these can be drawn from commitment. If we insist on proofs, we shall be doomed to reasoning ad infinitum, whereas we are called to act and "to act you must assume, and that assumption is faith." 52

In line with the new (romantic) spirit of the age, Newman focuses on the concrete, on images that lead to action. Faith is the first principle of our action, something self-evident that the author is not going to demonstrate. We read: "Why we are so constituted that Faith, not Knowledge or Argument, is our principle of action, is a question with which I have nothing to do; but I think it is a fact, and if it be such, we must resign ourselves to it as best we may, unless we take refuge in the intolerable paradox, that the mass of men are created for nothing, and are meant to leave life as they entered it. So well has this practically been understood in all ages of the world, that no Religion has yet been a Religion of physics or of philosophy. It has ever been synonymous with Revelation. It never has been a deduction from what we know: it has ever

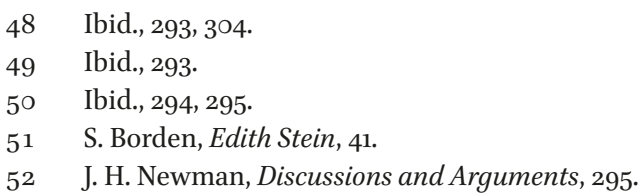


been an assertion of what we are to believe. It has never lived in a conclusion; it has ever been a message, or a history, or a vision. No legislator or priest ever dreamed of educating our moral nature by science or by argument."53 Examples help us emulate others by giving images and by stirring emotions. As the British writer and playwright William Somerset Maugham (1874-1965) astutely observed, "emotion speaks a language that all may understand." 54

This is indeed a very profound recapitulation of Newman's main message. We should rely on instances and patterns, on examples and testimonies. Christianity is a supernatural history, it is almost scenic - as Newman puts it beautifully - in order to appeal to human imagination, in order to touch the human being in all the dimensions of his being. Interestingly enough, Newman is also referring to the dissenters - those Protestants who would not join the Anglican Church. Those radical believers left Britain and set sail for the New World, i.e. America. He rightly observes that dissenting teaching was dissipated because it was based on the speculations of logic rather than on the dogmatism of faith. If there is no centre, no common point, speculations diverge in various directions. They succumb to the centrifugal forces of various centres of attraction. Speculations that have no unifying centre-like the dogmas of the faith - are propagated away in their independent circles and revolve around some temporary forces of attraction. Such transitory centres are, again, shortlived because they are ruled by the same principles of speculation. Newman sets the instruction of the Church in opposition to this pathetic outcome, because this instruction, "with all its defects and mistakes, comes to some end, for it started from some beginning." 55

\section{The Power of the Particular}

Science, as it is, does not lead to religion, although in some particular cases it may. This, however, does not come from the nature of science, but from the nature of a concrete human being whose mind is of a religious turn. Henceforth, the science of nature may lead to religion just as much as to atheism. A speculation is ruled by its inherent cohesion of antecedents and consequents, and, as such, can serve any kind of argumentation, for its only criterion is exactitude.

\footnotetext{
53 Ibid., 296.

54 S. Maugham, The Moon and Sixpence, Harmondsworth: Penguin Books, 1963, 6.

55 J. H. Newman, Discussions and Arguments, 297.
} 
If we consider a dogma, it can be assented to, and appropriated as a reality "by the religious imagination; it is held as a truth, by the theological intellect," 56 for theology is primarily occupied with notions. What we need for action is not a mere notional knowledge, but imaginative apprehension. We have a representation of things which is true, but not adequate. We learn about the existence of things that leave impressions on us "by instinct." ${ }^{\text {" In }}$ this instinctive manner, the existence of physical objects is brought home to us. We learn about the Creator through the sense of moral obligation. It is from our mental phenomena that we deduce the existence of the external world. And from the experience of moral obligation we deduce the existence of some first principle, and this first principle is, for Newman, the fact "that we have by nature a conscience" 58 with its attendant judgments of approbation or blame. And here is the room "for the real apprehension of a Divine Sovereign and Judge."59

Newman outlines his position in the Grammar of Assent when he attempts to define the difference between theology and religion; in other words, between notional and real assent. We read the following: "Religion has to do with the real, and the real is the particular; theology has to do with what is notional, and the notional is the general and systematic. Hence theology has to do with the dogma of the Holy Trinity as a whole made up of many propositions; but religion has to do with each of those separate propositions which compose it, and lives and thrives in the composition of them. In them it finds the motives for devotions and faithful obedience; while theology on the other hand forms and protects them by virtue of its function of regarding them, not merely one by one, but as a system of truth." 60

Behind propositions there must be enlivening principles, and it is to these principles that the believer should assent. Newman decided to quit the Anglican Church when he realized that "she had no life." ${ }^{\text {"1 }}$ Theology can help us attain a scientific knowledge of the Christian faith, for in theology we acquire notions, "but religion is both personal and real, and, unless we content ourselves with a vague religious sentiment, the only way to restore Christianity

\footnotetext{
56 J. H. Newman, Grammar, 93.

57 Ibid., 96.

58 Ibid., 98.

59 Ibid.

6o Ibid., 122 .

61 Edith Stein, in her remarks on civilization, also notes that "it owes its existence" to individual people and their authentic response to values. When we say that civilization "withers away," we mean that it is individual people who have betrayed "the souls upon whom the civilization should be bestowing life" (E. Stein, Philosophy and Psychology of the Humanities, 219).
} 
in the hearts and minds of men is to teach them how to assent to dogmas as to so many real and particular objects." ${ }^{\prime 2}$ Rather than to propositions, we assent to realities, to images, to people.

The question now is obviously whether we have this religious imagination as our natural endowment or whether we can develop it. Religious imagination makes one capable of grasping theological truths and keep them alive in the novelty of individual expression "by habits of personal religion." ${ }^{63}$ In other words, when we practice religion. There is no immediate relationship between religious imagination or the vivid apprehension of supernatural objects and theoretical knowledge; that is why absorbing a considerable amount of knowledge does not necessarily bring about an experience. On the contrary, theoretical speculation may blunt its sharpness, as reflection often does. The same proposition which is expressive of a religious truth may serve two purposes: notional and real. Theology, being a theoretical knowledge, "deals with notional apprehension; religion with imaginative." ${ }^{4}$ Hence, there is no contradiction between a dogma and personal belief, even though the rationalists claimed there is, because the real apprehension is in the recipient, not in the proposition. A dogma is only a mediatory stage that proceeds to a vivid grasp of the reality hidden behind the notion. We have no other way but to use propositions in our intellectual intercourse. Otherwise, we would not be able to communicate at all. And, contrary to those who might argue that Newman was an anti-intellectualist, let us put it bluntly "that in religion the imagination and affections should always be under the control of reason."65 Indeed, this is the Anselmian fides querens intellectum. I may admire the lofty and aweinspiring ceilings of cathedrals with the most solemn and rapturous words, but emotional reaction does not contradict the marble solidity of the columns upon which the ceilings rest. The intricate shapes of the Baroque style must be supported by solid frames. Religion and theology go hand in hand. In other words, we could say that those people who claim that they would accept religion without its institutional garb are naïve.

It is interesting to note that, after so many appreciative words written on behalf of the imagination and its importance for real apprehension, Newman should protect reason. He does this to the extent that he writes that imaginative or emotional sentiment falls "back upon the intellect for its stay, when sense cannot be called into exercise; and it is in this way that devotion falls

62 E. Gilson, Introduction, in: J. H. Newman, Grammar, 19.

63 J. H. Newman, Grammar, 106.

64 Ibid., 108.

65 Ibid., 109. 
back upon dogma." ${ }^{\prime 6}$ The lofty rib-vault ceiling or fan vaulting are our sentiments, and the dogma is the pillar. Or, to take another example, let us consider late medieval altarpieces. For the onlooker, they present a complicated network of geometrical figures, facial grimaces and bodily postures expressive of emotions (e.g. the Veit Stoss altarpiece in Kraków, Poland). They seem to be hanging in the air and living an independent existence, yet their sculptor has pinned them down to their background of larch wood. We have long noticed that Newman uses the words "intellect" and "reason" alternately. In some contexts he treats them synonymously, in others as being different.

Before proceeding further, I would like to turn the reader's attention to a linguistic example which I myself find especially illuminating. This time I shall have to refer to another language. The word "assent" in the Polish language is translated as "przyświadczenie." This word is, in fact, composed of two components: "przy" (at) and "świadczenie" (testimony). Because these two components are, in themselves, meaningful, let us separate them and write it with a separating hyphen, i.e. "przy-świadczenie," and define real assent as "being at something in order to testify to it." Such a definition, I am convinced, renders exactly the meaning of real assent. If we really assent to something, we are ready to testify to it, since we are drawn to it; the intellect and emotions are united in one action. And here is the power of the particular, the enticing force of an edifying example, of a history, of a message, for they encourage their witnesses to imitate them. And their force surpasses that of arguments.

\section{$9 \quad$ Assent versus Inference}

As we have said, assent is unconditional and inference is conditional. This distinction is of the utmost interest, for inference, being conditional, precedes assent, which is unconditional. How come that something that is conditional can precede that which is unconditional? If we wish to carry out a logical proof of Newman's exposition, we shall easily understand it, and the reasoning may run as follows: assent is not the last moment in a series of inferential steps, hence it does not automatically result from a string of antecedents and consequents, but is the agent's own decision, or - to repeat Newman's phraseis the personal result. Ultimately, it is the person who decides, not the logical processes. Inference is a conditional proposition in which, on the basis of premises, a conclusion is implied. A classic example of an inference is the form

66 Ibid. 
of implication: if $\mathrm{p}$, then $\mathrm{q}$, which in logical notation is written as $\mathrm{p}>\mathrm{q}$. If $\mathrm{p}$ occurs, then q takes place; if it rains, I'll take an umbrella. Inference is conditional, because the certainty of the conclusion is measured by the certainty of the premise. ${ }^{67}$ Newman makes a definite distinction between inferences and assents. Inference, being conditional, allows for degrees; assent, being unconditional, does not allow for degrees. We have already mentioned that, for Newman, there is no gradation in assent. If assent had degrees, it could only ratify demonstration or induction. And if that were the case, one would be permitted to assent only to such propositions which had strong evidential proof attendant on them, i.e. based either on rationalistic grounds (some selfevident truths) or intuition. Let me put it this way: if there is no gradation in assent, and assent is distinct from inference, then it could be metaphorically understood as a picture of the person at the moment of decision. At the moment of assent the person reveals what he is; it is like a momentary reflection in a mirror, but, of course, preceded by the personal history of maturation.

When man is acquainted with a particular area, his imagination opens up to cover what cannot be demonstrated. Thus, we can speak about mathematical, physical or poetic imagination. Naturally, we are not expected to be specialists in mathematics, physics or poetry, unless we have long been acquainted with the areas in question. No-one is expected to predict what happens when mercury is immersed in water if they do not have respective knowledge. What is interesting to note in this context is the fact that familiarity with some areas expand our imagination. Inasmuch as mathematics and physics can be treated as areas fairly limited to some groups of people, and no-one feels guilty if he cannot answer questions which pertain to these areas, the situation is entirely different when they concern what commonly belongs to all. And such is the case with moral and religious matters. One element, however, is common to, say, physics and morality. In both of them, one needs practice, but of a different kind. Generally, we are not expected to have a specialized knowledge in mathematics or physics unless we are employed as mathematicians or physicists. We lack the respective keenness of the ratiocinative faculty. But, conversely, we are expected to know what is good or bad conduct with our fellow citizens in daily matters.

An interesting example is presented by Jacques Hadamard (1865-1963), a French mathematician and psychologist, in his book An Essay on the Psychology of Invention in the Mathematical Field. He refers to a report on Friedrich Gauss's

67 See P.J. Hurley, A Concise Introduction to Logic, Belmont: Wadsworth Publishing Company, $1988,18 \mathrm{ff}$. 
experience that was mentioned in a Poincaré's 68 lecture. This German "prince of mathematicians," as Gauss (1777-1855) is commonly called, had unsuccessfully been trying to prove an arithmetical theorem. Seeing all his efforts in vain, the mathematician abandoned his ventures. Then, as Gauss himself reports, "two days ago, I succeeded, not on account of my painful efforts, but by the grace of God. Like a sudden flash of lightning, the riddle happened to be solved. I myself cannot say what was the conducting thread which connected what I previously knew with what made my success possible." ${ }^{69}$ I think Gauss's example excellently shows what Newman meant, namely that the human mind always thinks in its own way. Owing to his long acquaintance with the subject, the German mathematician found a solution at the level of his tacit ratiocination. It is not the brain alone, empowered by logical structures, that thinks, but the person. And assent, indeed, was not the last stage of inference. There was rather a gap between the last antecedent and the final conclusion. This is what happens to a mind immersed in a concrete reality - it acquires the ability for a special kind of intuition, the elements of which have no explicit form, of supra-logical judgement, of unperceived impressions. In other words, the mind is drawn into a silent dialogue-if I may express it metaphoricallythe ingredients of which unfold to the degree to which it is engaged, being found rather than constructed. These points will be dealt with further on.

Gauss's example exemplifies not only mathematical minds in which "the truth flashes at once [...] and [they] see the truth all of a heap, by one act."70 In like manner, we think in our own individual way, therefore it is difficult to establish one measure between two minds. The reason why person A views a fact in his own way depends on how he looks at it. Newman identifies reasoning with intuition. He is even willing to relate intuition to our internal acts, to relate it "to our own operations."71 In this sense, Newman follows Dugald Stewart rather than Locke. What Newman is driving at is the kind of unity that is unmediated. I grasp something with one act instead of being divided into a string of reflections: I think A and reflect on the one who thinks A. Now, if we recall again the example of Gauss, we may come to a similar conclusion. The solution appeared as a flash in Gauss's intellect, but it was preceded by an arduous process of ratiocination. It is an open question and, apparently, impossible

68 Jules Henri Poincaré (1854-1812), French mathematician, astronomer, and philosopher of science.

69 See J. Hadamard, An Essay on the Psychology of Invention in the Mathematical Field, New York: Dover Publications, Inc., 1954, 26.

$70 \quad$ E. Sillem (ed.), The Philosophical Notebook, vol. 2, 73, 75 .

71 Ibid., 2, 77. 
to answer: what is the relationship between the process and the flash? Is there any causality? The only thing we know is that the process was prior to the flash. We may, certainly, claim that the flash was caused by the process but we would not be able to demonstrate this. As I repeat here and elsewhere, we have these two elements at work: intuition and process (reflection). Intuition seems to be safer and more reliable (depending on the intellectual and moral character).

In abstract matters, it is easier to imagine conclusions that must be unconditionally accepted, but in concrete matters we are dealing with probabilities. If I am going to sign a business contract with person X, I can never be a hundred percent certain that $\mathrm{X}$ will agree, or that he interprets the conditions of the contract in the same way as I do, let alone his future conduct.

Locke's view of what is rational is limited to inference, in which the transition from premises is strictly guided and controlled by reason. Let us note in passing that this approach is typical of enlightened modernity, i.e. to have everything under control, to be the master and author of one's life. This guidance and control is, in fact, reduced to a mechanical process in which the conclusion is implied by self-evident premises. Thus, inference is an event within an immanent logic, and there is no effort on the part of the acting agent. Newman criticizes Locke in that he approves of absolute assent only when premises inevitably lead to an infallible conclusion, and he calls someone who would accept something that has no such grounds an enthusiast, but on the other hand he allows a conclusion which rises to the degree of assurance on the basis of probabilities near to certitude. Whatever is added to the conclusion on the part of the agent that rises above evidence is called surplusage.

Leaving the details aside, let it suffice to pinpoint the main difference between the rationalist-empiricist approach and Newman's personalist approach. For Newman, the human person is not determined by the premises in his assent, principally because - as we have said — assent is distinct from inference. It must be separate from the latter if it is not to be merely a superfluous act. For if the person is called upon to assent to something, there must be - and I think we feel it — a kind of effort on the part of the agent, otherwise agreement comes automatically from the mere sequence of premises. Moreover, as we have said before, we often give assent to opinions and views that become the furniture of our minds. Such activity is frequently devoid of any reflection; they are "self-sustained in our minds, and have been so for long years; they are in no sense conclusions; they imply no process of thought."72 
Newman's basic contribution to our theory of knowledge is his thoroughgoing analysis of acquisition.

Contrary to the rationalist-empiricist view, the depository of our minds is not composed of clear-cut concepts for which we can always account, thus being acquitted of enthusiastic censure, but rather it is a deposit of living moments of our lifetime that gradually (and often imperceptibly) accumulate. We are not perfect or impartial constructivists of our own minds who reign supreme over them and can account for every idea they hold true or are much attached to. We may have clung to some concepts and then discarded them when new reasons appeared. Newman has observed a certain regularity with regard to inference and assent, and if we evaluate his observation in an unbiased manner, we shall admit that he is right. Indeed, we often assent to many things before we deign to examine them. Quite frequently, we stick to views that are contrary to what we otherwise theoretically hold or practically implement. And, in practice, inference works differently than assent. As we know, inference is composed of premises and conclusions, whereas in daily life we assent to propositions, images, persons, and testimonies. Such is our abundant inheritance. And, contrary to Locke's view, the ideas we hold in our minds are not all a close-knit network of elements the self can account for. Each time we rather contact the person who holds certain ideas. The only thing we can say is secretum meum mihi.

If we consider this matter historically, we indeed find examples of philosophers who defended views that contradicted their philosophical positions. And I think that this is an evident argument that contradicts Locke's view, namely the fact that we find in our mental repository ideas which are at variance with one another. Plato and Aristotle approved of slavery, and Locke himself supported Britain's imperial ambitions. Even his Letter Concerning Toleration, that was supposed to defend religious freedom, in fact only ossified religious intolerance, for he proposed the State Church and the ruler's denomination as the mainstay for social peace, a view that resulted from the rationalist tenets, i.e. one ruler and his religion are like the same idea held by all citizens' minds. It took quite a while for Americans to come to grips with racial discrimination and slavery. Many a time Christians could be accused of hypocrisy throughout their history, and the scribes and Pharisees were called outright hypocrites. In our own twentieth-century, Stein's colleague and Husserl's disciple, Martin Heidegger (1889-1976), was an ardent proponent of Nazi ideology.

Such being the case with inference versus assent, therefore Newman rightfully underwent a careful study of the grammar of assent, i.e. how we come round to accepting certain truths and how we hold them in our minds. It is not so rare a case when the inferential reasons for the recognition of our assent 
remain, but the assent dies down. We seem to have lost our belief in what can still, logically, be defended. Sometimes our convictions change imperceptibly, so even we cannot account for this rapid change. In this context, let me make a digression that is very supportive of the heroes of my book. In view of what I have said so far about the distinction between inference and assent, it seems clear that both Newman and Stein had to reformulate their assents. They arrived at a turning point in their lives where they had to take an entire new direction much to their surprise, and yet in line with their inner calls. As new circumstances appear, the reasons for the old arguments remain the same, nevertheless we feel obliged to make a new assent. There are frequent cases where people loudly profess truths they have never thought of practicing. They "may believe without practising." ${ }^{33}$ Ratiocination does not always lead to a belief. Arguments may be as strong as ever, but they do not secure assent. We hold a truth, for we do not find arguments to refute it, or, conversely, we may refute a truth, but cannot muster arguments to explain why, or else we come to accept it after a long while.

All the time, therefore, we have been talking about a certain inherent incongruity between arguments and minds. There is much more to an argument to be assented to than its mere logical cohesion. For Stein, we remember, the moment when she might have started to ponder Christianity was the way Reinach's wife reacted to her husband's untimely death. She demonstrated no despondency or despair, yet braved the predicament with composure. Stein did not know what it was, or whence this unexpected and dignified peace came from.

Even strong arguments may prove futile in inclining our minds to assent to them, even though we can find no fault with them from the logical point of view. In the area of mathematics, we come across truths that are irrefutable for the sake of their self-evidence (as, for instance, in geometry). Nevertheless, one can find people who still resist assenting to them, although they cannot counter them. In the case of elementary mathematical theorems, the situation is much simpler, and it usually elicits our prompt assent. Newman suggests, however, "long and intricate mathematical investigations" in which "every step $[. .$.$] requires a specially sustained attention and an effort of mem-$ ory to have in the mind all at once all the steps of the proof, with their bearings on each other, and the antecedents which they severally involve [...]." ${ }^{\prime 4}$ At this point we may refer to Gauss's example. I have been constantly repeating

$\begin{array}{ll}73 & \text { Ibid., 142-143. } \\ 74 & \text { Ibid., 144. }\end{array}$ 
Newman's perception that the nature of assent, unlike as Descartes believed it to be, is primarily personal, not logical. I do not want to say thereby that it is straightforwardly illogical, but that it calls for some personal logic, a subjective context, an implicit mode of thinking, not merely its explicit form for its explanation.

Let us take another example. We may find some primitive tribes who still hold to their own belief, long refuted by modern science. Medieval man believed that the Earth was flat and that the stars were quite near. The Copernican revolutionary ideas, despite abundant and convincing evidence, were long opposed by those who had assented to the view that the Earth was in the centre of the universe. Or let us think about the advent of new technology in farming. The new equipment that appeared undoubtedly facilitated the job, but was opposed due to the attachment to manual work. Distinct though inference and assent are, it is true that they have something in common. Arguments in favour of a certain conclusion, which naturally lead to the latter, naturally facilitate assent; they do not determine it, but facilitate it. Newman himself is in favour of such a view, that there must be some preliminary reasons for assenting. Therefore, he makes a distinction between apprehension and understanding; we can apprehend things we do not understand. But assent may be withdrawn despite the fact that the reasons still remain and hold water, or may be sustained, as I have already mentioned, when the reasons are missing.

And then we arrive at the final definition of assent, which reads that "assent is the acceptance of truth, and truth is the proper object of the intellect, and no one can hold conditionally what by the same act he holds to be true, here too is a reason for saying that assent is an adhesion without reserve or doubt to the proposition to which it is given."75 I think this definition is clear. We hold something as true, which does not mean that our belief is infallible, and that when new evidence comes the old beliefs may be abandoned. Newman is simply trying to illustrate the activity of life in which we are performing numerous acts of assent, some of them are just passing experiences, others stay longer in our minds. Frequently, we do not reflect upon our acts; we behave spontaneously, rather than, like in inferences, ponder on the premises. Indeed, we adhere "without reserve or doubt" to a given proposition, although, naturally, we submit those acts of assent to reflective evaluation. It appears, then, that they can either be confirmed, or must be abandoned on a careful analysis; they do not hold up to criticism. 
There are many cases where we do not assent at all. Hence, Newman claims that assent, if it does exist, is always unconditional, as I have already said. We naturally assent to things which are reasonings, not demonstrative, for our nature makes us "think or act [with] the acceptance of truths, not intuitive, not demonstrated, yet sovereign." They "lie outside the narrow range of conclusions to which logic, formal or virtual, is tethered; nor has any philosophical theory the power to force on us a rule which will not work for a day."76 Thus, we can daily assent to things which do not follow from intuition or demonstration; we naturally take them for granted. We need to distinguish between a mental act - the unconditional assent — and a scientific rule, e.g. a reflection on the act of assent. Newman is trying to grasp and elaborate on what the mind is actually doing when assenting. And he holds that there is nothing mediating between the mind and the object of assent. There is only a dynamic tension between the person that is supposed to acquire a belief, and the belief itself. Therefore, the most important thing is the position of the mind towards the proposition, not the relationship between a conclusion and its premises. In any case, there are concomitant circumstances attendant on each assent, but these should be distinguished from assent itself. When assent is associated with some strong emotions, like love or hatred, we express it respectively, but the attendant emotions have nothing to do with the alleged degrees of assent.

We assent to propositions differently, which does not mean that there is a gradation in assent, but that assent is relative to our preparation. This preparation may result from external circumstances or concomitant factors of our character, e.g. "in the emotions, in the ratiocinative faculty, or in the imagination." 77 We may, for instance, be prejudiced towards certain things presented for our assent. After all, as Newman summarizes his stance on human nature, "man is not a reasoning animal; he is a seeing, feeling, contemplating, acting animal. He is influenced by what is direct and precise." ${ }^{78}$ Therefore, assenting is not merely an intellectual act, and if so, it is an intellectual act of a special kind. Even in the case of notional assent, we, living in concrete circumstances, are surrounded by a complicated network of sentiments and resentments, likings and dislikings, so that the outcome can never be taken for granted and must at each time be attempted anew.

\footnotetext{
76 Ibid., 15 o.

77 Ibid., 154 .

78 J. H. Newman, Discussions and Arguments, 294.
} 
Simple assents are distinct from complex assents, and the force of assent depends very much on whether it is impressed upon the imagination or entertained by the intellect. Newman summarizes what he understands by simple assent as "the mental assertion of an intelligible proposition, [...] an act of the intellect direct, absolute, complete in itself, unconditional, arbitrary, yet not incompatible with an appeal to argument, and at least in many cases exercised unconsciously."79 It turns out that many of our assents result from habit, from our nature. We agree to proposals because they are conducive to our self. Newman is not satisfied with that stage of assenting. Many assents are unconscious because we are ignorant of our selves, i.e. we have not reflected yet on what truths we are going to hold. One might say that, for instance, we mechanically agree to numerous things which we find pleasurable. Here, again, the ancient principle "know thyself" acts as a precondition for comprehending assent. In other words, know yourself if you wish to understand why you assent to $\mathrm{A}$ rather than $\mathrm{B}$.

Complex or reflex assents are made consciously and deliberately. In complex assent, we reflect upon something we have previously assented to. We investigate our assent, trying to prove it. The whole structure that Newman is now laying open before our eyes reminds us of Locke's primary and secondary ideas. Inference may lead to an assent and may follow it as a kind of feedback upon its truth. There is no incompatibility between assenting and demonstrating, but there is a distinction between inquiry and investigation. Inquiry contradicts assent, for it denotes doubt. We cannot doubt something we are assenting to. We may assent to something, which we hold as true, and then investigate the grounds of our assent. Eventually, we can reflectively assent again to that which we have previously spontaneously assented. Hence, there is no inconsistency between assenting to something as being true and trying to prove it at the same time. Indeed, when Edith Stein assented to the truth of Teresa of Avila's book, she embarked on investigating it afterwards. Let us observe that the first step is assent, although I may not yet know why. Then, I take the next step and ponder over what I have read and found myself compelled to assent to.

What is typical of Newman's exposition here, is his stress on impression and image. Firstly, I can see the truth, or I find myself obliged (though I do not yet comprehend the cause of my obligation) to assent to it, and then I feel 
naturally compelled to ask: what is it that has stirred my emotions? I found it true. What is the nature of this truth? Why do I feel obliged to pay attention to it? It is all the more interesting when we assent to propositions we would have not even considered worthy of our slightest attention before. What is in them that we find so appealing?

We cannot be, as Newman writes, "believers and inquirers" at the same time, we cannot "be both inside and outside of the Church," and if we are "seeking" we have "not found." 80 This point is interesting in the context of comparing Newman with Stein. In a sense, he was in a more complicated situation because, when he began to doubt that the Anglican Church was the true Church, he was an insider and outsider simultaneously. Stein's position was entirely different. She was not a Christian; therefore, she was a radical outsider, even more radical for her declaration of disbelief. Perhaps Newman was an inquirer when he began to doubt the truth about the Anglican Church. And when the truth about the Catholic Church gradually began to dawn on him, he turned from an inquirer into an investigator.

I hope that the reader will understand my reservations that I am constantly making when positing some conclusions about Newman's intentions. He himself is full of such reservations, knowing that when we are considering something in theory, i.e. abstractly, focusing on certain aspects, we are always in danger of simplifications and generalizations. Such being the case, then it is possible that there are people on the borderline in individual cases, both inquirers and investigators, as if they were standing on the threshold without making any resolution either to enter or to leave. It seems to me that the situation of being in-between is becoming all too common a case, rather than a rarity. We are living in a world where inconsistency and hesitation have become the rule; there are many people who state something one day and deny it another. Being non-judgmental has become the rule, for such a position seems to satisfy political correctness.

The truth and the conclusion are two aspects of a given proposition. A conclusion does not need to be true, and we may try to find the conclusion of a true proposition. Newman is constantly reminding us that inference and assent are distinct acts, for he proposes a nineteenth-century paradigm aimed against its enlightened predecessor; nevertheless, they are not contradictory or exclusive, i.e. we may set about inferring a proposition in order to prove it to someone who disagrees with us, while at the same time we assent to its truth. Thus, inference and assent are two aspects of the same proposition, consistent

8 o Ibid., 159 . 
with each other. Only "inquiry is inconsistent with assent," 81 whereas investigation is a plausible procedure.

The individual is often besieged by incompatibilities and inconsistencies, so this is why Newman rightly considers observing the individual in concrete circumstances. We may investigate the credibility of a doctrine whose truth we assent to, for, in an investigation, there are no doubts as in an inquiry. It seems that we need to realize what we have assented to, and realization can be carried out through investigation. What is characteristic of belief is "the utter absence of all thought, or expectation, or fear of changing" and "a spontaneous resolution never to change is inconsistent with the idea of belief; for the very force and absoluteness of the act of assent precludes any such resolutions." ${ }^{\prime 2}$ In like manner, Newman consistently defends his idea of development and evolution, because to live means to change. And we must remember that throughout all this Newman does not want to solve a merely theoretical problem, but is constantly probing into the phenomenon of assent; he is constantly wondering what we are actually doing when we are assenting to something. We need to revise our first assents; such is the logic of our growth, to examine their grounds, since they are very often nothing more than prejudices. A complex assent, i.e. an assent to an assent, becomes a conviction.

\section{The Lazarus Case}

In order to exemplify once more the distinction between inference and assent and to demonstrate that there is no gradation of assent, i.e. we either assent to something or we do not, but assent can be stronger or weaker, I propose the following illustration. Let us consider the three sentences below:

1) Lazarus came to work very early today.

2) Lazarus did not come to work today because he died yesterday.

3) Lazarus died yesterday, but Jesus visited his home and brought him back to life, so he came to work today as usual.

We can assent to all three sentences, but the force of our assent varies according to their attendant probabilities; we, at least, apprehend them. Naturally, our assent is strongest in sentence (1) because here the antecedent probabilities are the most numerous. We know Lazarus, we know that he is very committed and conscientious; he likes his job and he usually arrives early. He is

$\begin{array}{ll}81 & \text { Ibid. } \\ 82 & \text { Ibid., 16o-161. }\end{array}$


a punctual person with a natural sense of duty. Sentence (2) is still probable, though subjectively less plausible. We only saw Lazarus yesterday and he was in good form. Generally, he is not obese and we have no information of any history of crippling or dangerous diseases in his family. He loves sport and has healthy eating habits. When we saw him yesterday, he emanated enthusiasm. He was full of energy and kept telling us about his future plans. He could not help waiting to see them realized. Now, sentence (3) to which we are invited to assent, seems least likely. It is true, human beings are mortal, so that-even though we know that Lazarus is very fit - we can still accept the message as probable, but very unlikely. Therefore, we think it highly incredible, as our general knowledge concerning human nature tells us that people die, their otherwise healthy constitution notwithstanding. The fact, however, that someone came to Lazarus and brought him back to life is very improbable. People do not rise from the dead after they die. We have not heard of any like events. Nevertheless, we can still assent to it, but this assent presupposes our belief in Jesus' power over death, His power restoring other people's lives.

Let us take other examples that we know so well. I am constantly trying to show this specific character of notional apprehension versus real apprehension. There are numerous mysterious encounters in the New Testament which, however, are understood only notionally. Otherwise, they should bewilder us rather than create a comfortable acquiescence. It suffices to visualize one such scene. A stranger approaches two men casting their nets into the sea. And he addresses them thus: "Come, follow me," and they immediately leave their nets and follow him, just like other two who are mending their nets- they leave their job and their father at the stranger's calls and comply with the proposal. ${ }^{83}$ Is this not amazing? Should it not be read with one eyebrow raised? They might have heard about the stranger. There have been widespread rumours about his extraordinary deeds and his outlandish teaching; nevertheless, this all seems insufficient for such a radical decision. The moment we assent to it, and perhaps whisper in bewilderment "I don't understand," this is paradoxically the moment of real apprehension. In all other cases, we try to rationalize and extrapolate some events we know about that particular encounter from before the ages. And it is in such cases that we begin to comprehend the difference between notional and real assent. When one ceases to argue and begins to feel, imagine, and see the event, then one is open to accepting the reality. In such cases, we can observe the essence of real assent, and that it is distinct from notional assent, i.e. from speculation and from inference. 
In one of his university sermons, Newman writes: "All is dreary till we believe, what our hearts tell us, that we are subjects of His Governance [...]." We must bear in mind that Newman understood the term "believe" in a very broad sense, not merely reduced to the sphere of religion. For him, believing was the fundamental element of our being in the world, our basic attitude in knowing the world. Inasmuch as our knowledge is imperfect and our ignorance irremediable, we need to take many things for granted, i.e. to believe that they are as they present themselves to us. This "belief attitude" is not in the least our surrender to some kind of irrational or antirational positions. On the contrary, it is merely the result of the sober estimation of our human condition. Let us observe in passing that we find this kind of attitude as the anthropological foundation of the twentieth-century Austrian School of Economics. In the writings of one of its prominent representatives, the economist Friedrich von Hayek, we read these memorable words: "our whole civilization in consequence rests, and must rest, on our believing much that we cannot know to be true in the Cartesian sense." ${ }^{\text {85 }}$ In other words, Hayek, like Newman, propounds the modification of the enlightened paradigm of human knowledge. Let us note that they are both opponents of the authoritarian vision of society. If each person is the special centre of his own actions and master of his own knowledge, any external attempts at general planning should be regarded as unjustified usurpations. Such is the romantic heritage and remodelling of seventeenth-century rationalism. The person is a centre in himself, striving to gain knowledge, and making use of all his personal endowments. Limited as he is, he can still possess certitude.

There are two conditions with which to prove certitude: $a$ priori-from the nature of the case, and a posteriori-from experience. As regards the former, certitude results from a reflex act of assent which pronounces that the proposition is "objectively and subjectively true:- then the assent may be called a perception," it "is the perception of a truth with the perception that it is a truth, or the consciousness of knowing, as expressed in the phrase, 'I know that

84 J.H.Newman, Fifteen Sermons Preached Before the University of Oxford, London:Longmans, Green, and Co., 1872, 348. (Further referred to as University Sermons).

85 F. Hayek, Law, Legislation and Liberty, vol. I, London: Routledge \& Kegan Paul, 1982, 12. Let us also observe that Hayek is more identified with the liberal position in philosophical thinking. 
I know'" ${ }^{\prime} 6$ We arrive at the moment of seeing something, of which mention has already been made. I cannot deny what I have seen with my own eyes or heard with my own ears. On the other hand, we are all too familiar with the not-so-rare experience that the same fact is interpreted in entirely different ways. At times, we are even shocked that others baulk at what we take as only obvious and natural; they find it hard to understand or believe. There are four elements that come to point at certitude: perception; the one who perceives (I perceive something to be true); conviction that a proposition is certain; and knowledge (I know that it is true).

Newman characterizes the true nature of certitude in the following manner: its characteristic is that we are "confident indeed that that certitude will last" and "if it did fail [...] [,] the thing itself, whatever it is, of which we are certain, will remain just as it is, true and irreversible." ${ }^{87}$ Thus, if we shrink away from any speculation on the topics we hold as false or even dangerous, it is not that we are uncertain about their being false or dangerous, but because we are afraid of ourselves lest we should be fooled into accepting them. Therefore, it is not a mark of certitude if we hold on to something, but then, when confronted by the opinion of another person, we hesitate and become unsteady in our views. One basic feature of certitude is tranquility of the mind and an unwillingness to become engaged in controversies, or to be drawn into proving that which we hold to be true. People who are certain are reluctant disputants. The intellectual anxiety that we may feel, however, is the opposite of certitude. If we are really certain, we do not have to assure ourselves by multiplying ever newer arguments on behalf of our alleged certitude.

Newman emphasizes the role of the imagination, but in his argumentation he seems to assign a greater role to the intellect. The imagination is powerful, but the intellect is more reliable. Here is how he beautifully describes it, in words worthy of sublime poetry, there are vacillations of someone who has not yet reached the stage of certitude: "anxieties and alarms may be merely emotional and from the imagination, not intellectual; parallel to the beating of the heart, [...] that trembling of the limbs, of even the bravest men, before a battle, when standing still to receive the first attack of the enemy [...], that palpitating self-interrogation, that trouble of the mind lest it should not believe strongly enough [...]."88 All these symptoms are evident proofs that the individual mind has not yet reposed in certitude. Newman calls them "the meteorological phenomena of the mind," which interfere with certitude because "to be certain of

86 J. H. Newman, Grammar, $162,163$.

87 Ibid., 165 .

88 Ibid., 167. 
a truth is to be careless of objections to it [...]." 89 Such being the nature of our certitude, we may legitimately ask whether Newman, at the time when he was an Anglican, was certain of the truths he held and which were in contrast to his later views. One explanation that can be proposed would read as follows: it was a time of assenting, not yet of certitude, and we know that assent is distinct from certitude. Thus, the fact that Newman joined the Oxford Movement is the best proof that he had not found certitude yet, the many truths he kept assenting to notwithstanding.

Certitude is different from assent, as we have noted. It is more like a reflection on assent, or a complex assent, a series of assents. Like in a mathematical series, we come closer and closer to the ultimate conclusion, a conclusion that is unlike the conclusion in inference. In certitude, not only do we assent to something, but we are aware of ourselves as assenting. Apart from tranquility, of which mention has already been made, there are other symptoms of certitude, such as "a feeling of satisfaction and self-gratulation, of intellectual security [...], a sense of success, attainment, possession, finality"; it is "united to a sentiment suigeneris in which it lives and is manifested." ${ }^{\prime 0}$ Therefore, certitude is not spontaneous, on the spur of the moment; rather, it is an arduous process of going somewhere, travelling to an unknown harbour. Through a tangle of successive assents followed by reflections, I eventually reach my goal. We have this double meaning in certitude, i.e. reaching something and the awareness of having reached it. I arrive at a goal and feel satisfaction from having arrived. In other words, I have not reached the truth until I feel satisfaction, but satisfaction in the form of intellectual security is entirely distinct from the truth. I do not seek the truth in order to feel satisfaction, for the latter is attendant on my having arrived at the truth. We can see, therefore, in certitude both the intellectual and emotional moments. This conclusion is important, especially when we consider Edith Stein and her concept of empathy. For the Carmelite saint, our intellectual life depends on how we respond to values. Therefore, as Sarah Borden notes, "It is not our thoughts which reveal most intimately our person, but our affective life."91 This is an excellent recapitulation of Newman's heritage in Stein's doctrine, or at least could be understood as such. And I have already alluded here to the importance of the affective side of our personhood as being a strong theme both in Newman and Stein. The person unites the mental and sensate levels in his cognitive relationship with the world.

\footnotetext{
89 Ibid., 168.

90 Ibid.

91 S. Borden, Edith Stein, 40.
} 
And here is the difference between certitude and mere knowledge. Certitude is "the repose in self and in its object," it is "the consciousness of having that knowledge." ${ }^{22}$ In other words, I am certain of something, and I know that it is I who am certain of it. For Newman, then, the subject is present in the moment of knowledge; certitude is not an external relationship and correspondence between the object and the subject. It is not a theoretical distance from the object under consideration, but rather a commitment to what I am certain of. In the classical philosophy of Thomism, the proper object of the intellect is to know the truth, and Newman goes further: the second element is the sense of possession. I perceive the truth and this truth becomes mine; I can see the truth and I am in the truth. This is like being embraced by the object of knowledge. It is interesting to note that Newman also uses such terms as "a half-assent," "a faint and languid assent," phrases which seem contradictory to his claim as to the unconditional character of assent. We must remember, however, that when we call something "a half-assent" we mean the circumstances of a given assent rather than its nature. It is the specific condition of the knower, not the object.

There is yet another issue that calls for a commentary. One may wonder what is the difference between the acquisition of ideas in Locke's empiricism and Newman. Locke argued that man could furnish his mind only with such ideas that he can account for, i.e. the ideas that can be elicited from inferences. And because indubitable premises lead to certain conclusions, the rational man must be aware of what he allows to enter the composition of his mind. In both Locke and Newman we are masters of our mental possessions. The main difference between the two British scholars we find in the nature of our acquisition. In Locke, the appeal is made to some universal logic, whereas in Newman we refer to a personal acquisition. Therefore, if, for Locke, those who hold something they cannot prove are censored as enthusiasts deprived of toleration, for Newman, they are governed by their personal logic, the logic of the heart in which the acquisition is more subtle and hidden, and therefore hard to expose. To sum up, there is this experience of possession in Locke and in Newman, but there is a marked difference when the mind is considered to be a universal construction or a personal centre. In Newman, the person not only possesses the truth, but is also possessed by it, or in fact primarily possessed by it.

The main point of Newman's analysis of certitude was that it is a natural state of mind. At times, he seems to be inconsequent in his claim that certitude 
is distinct from assent. In the Grammar of Assent we read: "That Certitude is a natural and normal state of mind, and not (as sometimes objected) one of its extravagances or infirmities, is proved indeed by the remarks which I have made above on the same objection, as directed against Assent; for Certitude is only one of its forms." ${ }^{93}$ How can assent be distinct from certitude if it is "only one of its forms"? On the other hand, Newman would have a point here, if we say-following his way of thinking - that there are some common elements between assent and certitude. We know that certitude is the endpoint of many assents, therefore although assent as such is not certitude, an accumulation of assents is. Certitude, therefore, is an assent at the meta level. Numerous assents followed by reflections, hence a complex assent, bring about certitude. To be precise, assent, especially complex assent, is the core of a certain network of reflections. They revolve around this assent, feed on it, trying to raise something solid on its grounds. Assent is not yet certitude, nevertheless there are some common traits. The person who has assented to something real is then on a quest for the source of this object of assent.

\section{The Power of Simple Assent as Confronted with Certitude}

Simple assent, for instance, may also be called virtual, material or interpretative certitude. ${ }^{94}$ It is true that assents can turn into certitude, but it is also trueNewman argues - that certitude is of a permanent nature, whereas assents may come and go. They may disappear when subjected to reflection. Then we can withdraw our assent. At the same time, we have to observe that simple assent, although it is not certitude, is more powerful than complex assent, which is notional. Newman is therefore inclined to approve of simple assent as the more apt to lead to action because "the force of simple assent can be, viewed apart from its reflex confirmation," a real operative force when it is, for instance, "exemplified in the primitive Martyrs, in the youths who defied the pagan tyrant, or the maidens who were silent under his tortures." Here we have assent, "pure and simple, which is the motive cause of great achievements; it is a confidence, growing out of instincts rather than arguments, stayed upon a vivid apprehension, and animated by a transcendent logic, more concentrated in will and in deed for the very reason that it has not been subjected to any intellectual development." ${ }^{\prime 5}$ I think that we find here a very important

\footnotetext{
93 Ibid., 172.

94 See ibid., 174.

95 Ibid., 177.
} 
phenomenological moment, which, for Edmund Husserl, meant to "get at the being of things through an intuitive perception of their essence."96 Of course, the crucial addition introduced by Newman is the aforementioned "transcendent logic."

We must admit that Newman has indeed taken us through the very complex labyrinth of his intricate thoughts. We can even feel somewhat confused. He suggests that we aim at certitude and that the person is capable of attaining it, and it is true that simple assent is not certitude, it calls for a reflex act, and only the latter leads to certitude, which seems to be the proper purpose of our mental activity; nevertheless we now learn that simple assent is the most suitable and efficient state that leads to action. This apparent contradiction notwithstanding, we may attempt to account for it. I think that Newman'a reasoning runs as follows: rather than relying on the capacity of our minds for reflection, we should strive towards the prompt readiness of our persons. Reflection can blunt this readiness and lead us astray from respective action. We learn from the above quotation that we need an instinctive knowledge, a "vivid apprehension" and a "transcendent logic," phrases that are very imprecise. They appeal to our intuition rather than demonstrative argumentation or to a kind of spiritual readiness when illumined by the splendor of the truth. There are different kinds of definition. Here, we can propose a demonstrative (ostensive) definition, i.e. the kind of definition in which we define something by pointing at examples. ${ }^{97}$ Our apprehension of suffering is most vivid when we are dealing with concrete people who suffer. The suffering of humankind, for that matter, is most vague because the object of suffering is too large and anonymous. The suffering of a close relative is more vivid. And the suffering of someone who is lying in front of me, and at the same time is my close relative must be most vivid. We are called to respond to these circumstances; and we respond to them to the degree we are engaged in them. Now we may have problems with defining "transcendent logic." In our postmodern and disenchanted world transcendent logic would denote the use of terms that go beyond the explicit form of argumentation, or, rather, transcendent logic is akin to such a mode of conduct which cannot be accounted for by reference to well-tried schemes of behaviour.

To use a negative example, Locke's criticism of enthusiasm smacks of antitranscendent logic. I think the Bible is full of such transcendent logic in which, for instance, to save one's life means to lose it, and thus it is apparently illogical. ${ }^{98}$

\footnotetext{
96 W. Herbstrith, Edith Stein: A Biography, 34.

97 See P. J. Hurley, Logic, 88.

98 Cf. Lk 9, 24.
} 
Simple assent, when given to an imagination, is real. Such is Newman's main message, as we already know. The reflex assent, "which is characteristic of certitude, does not immediately touch us; it is purely intellectual, and, taken by itself, has scarcely more force than the recording of a conclusion."99 The vividness of an assent is personalized and usually takes place in the case of those who are well-acquainted with the subject. As regards religious matters, Newman observes that those who approach them in a theoretical manner are often "too intellectual to be spiritual," although we may find examples to the contrary. ${ }^{100}$ It seems that we cannot have both, i.e. depth and vividness; that is, to be occupied with reality rather than with a theory of reality.

Newman is indeed undertaking a very difficult task, for on the one hand he encourages introspection, but on the other he seems to be saying that too much introspection is misleading. He is trying, so to say, to reconcile fire with water. Simple assent is not certitude, yet we need complex assent, i.e. reflection upon simple assent, whereas it is simple assent that exhibits more personal alertness to a positive response. Certitude is to be sought after, but it seems to blunt the force and freshness of simplicity. The question arises: how to reach certitude and retain this readiness for simple assents? Especially since that certitude is a result of reflection and argumentation. Newman is wary of too much reflection and argumentation, for he is writing about "the litter of an argumentative habit" which "may beset and obstruct the intellect," and, when we are thus beset, we need "the exercise of good sense and [...] strength of will to put down [difficulties] with a high hand, as irrational and preposterous."101

\section{The Conditions of Certitude - Indefectibility versus Infallibility}

Certitude is important because it gives us persistence; assent is crucial because it signifies freshness. Or, to attempt yet another interpretation of Newman's analysis, we could say that certitude should be like preparation for a vivid assent, "a lifelong belief should be changed into sight, and things should be so near me, which hitherto had been visions." 102 Assents change, but certitudes endure. What we are talking about here is a special kind of dialectic which is composed of two elements: assent and certitude, i.e. change and duration. Assent is the readiness to respond to a truth, and certitude is the repose in

\footnotetext{
99 J. H. Newman, Grammar, 176.

$100 \quad$ Ibid., 177.

101 Ibid., 178

102 Ibid., 18o.
} 
possessing it. Certitude is indefectible; once certitude, always certitude. Certitude, as we already know, is not a spontaneous reaction but a thinking process related to respective faculties. And Newman, as previously mentioned, is not precise in this respect; sometimes two different terms mean the same. Once, he writes that the human mind is made for truth, and on the same page we find that it is the intellect that is made for truth. ${ }^{103}$

Indefectible as certitude can be, the problem is that there are true and false certitudes. It is impossible to discriminate between true certitudes and apparent certitudes. First of all, certitude is not the same as infallibility. Certitude is concerned with some concrete propositions, but infallibility-as regards persons - is a general faculty and concerns all propositions. We carry ourselves at times like a burden, especially when we know what we should be doing and our inclinations drive us from our duty, and at times we experience an easiness that carries us forward to its completion. Certitude is the relationship between the mind and the given propositions, the additional factor being "a sense of security and of repose." 104 We might say that the main criterion of a certitude's truthfulness is the satisfaction of these two factors: the person who experiences genuine certitude reposes in serene tranquility. Let me note in passing that one should never consider Newman's vision of certitude in isolation from other crucial elements of human integrity. Therefore, we cannot, for instance, imagine certitude without its attendant peace of mind.

It often happens, however, that what we once were certain of we now find as doubtful, or straightforwardly false. Whatever the outcome, we can do nothing but use ourselves as we are and use whatever faculties we have, i.e. there are no external authorities to which we can have recourse. I mean that we should naturally look up to good examples and great characters, but we cannot replace our personal decisions for theirs, we cannot replace our selves for theirs! Such seems to be Newman's lesson, especially that the purpose is to possess and enjoy the truth - an exceptionally individual task. In other words, there is no general certitude; certitude is always someone's. Let us stress that certitude, which is a deliberate assent, follows the process of reasoning; hence, if certitude is false, then it is reasoning that is at fault, not assent. Therefore, as we can deduce from this statement, if I feel certain of something, then I feel certain; it would be futile to grow frustrated because of what we feel and we cannot help feeling it. Rather, let us examine the concrete steps that have led to this feeling. Our nature induces us to assent to something with proof attendant

\footnotetext{
103 Ibid., 181.

104 Ibid., 186.
} 
on it. Newman advises circumspection in assenting, and people are often rash and thoughtless (especially in notional assents). Assent is a valuable personal act, despite the fact that people may often assent to something that is different than they originally thought, therefore "antecedent objections to an act are not sufficient of themselves to prohibit its exercise; they may demand of us an increased circumspection before committing ourselves to it, but may be met with reasons more than sufficient to overcome them." 105

Newman holds the accumulative structure of our knowledge, therefore he was so committed to historical studies. Knowledge is passed on from one generation to another, and knowledge not only in the sense of data. In his historical approach, he goes counter to the rationalist-empiricist position of Locke's punctual self in the case of which our identity is primarily created by our momentous consciousness, not by our historical duration. Generally speaking, Newman's attitude is a revolt against the enlightened ahistorical approach. In his interpretation of Locke, Charles Taylor came up with this conception of the punctual self as an ability to objectify and distance oneself from one's self. This presupposes a disengagement from himself or herself, rational control, and "the re-creation of our habits, and hence of ourselves." ${ }^{106}$ In Newman, there is no such distance from oneself, for here we use ourselves, i.e. we move forward together with the whole of our being. The person is not a consciousness liberated from the body and let loose to float in the vacuum of indefinite existence.

This anti-teleological objectifying, or even reifying conception of the mind is destructive for the ultimate calling of the person. Locke treated the mind as being composed of simple ideas, like building blocks out of which the human being is free to build whatever construction it wishes. The mechanistic world proposed by the Enlightenment and the sentimental world proposed by Romanticism are both destructive for the human person. In the former the human being is a great constructor with an abandoned final cause and no blueprint of what is worth building, except the immanent project. In the latter, the human being is lost amidst a blind quest for ever new expressions of his insatiate psyche. The so-called "new men" and "new women" are excellent examples of what we are talking about. The lone wanderer, treading the ruins of foregone traditions, cannot build anything lasting when deprived of the transcendent foundations.

The human being liberated from the meanderings of his own self, subdued to Reason, becomes a master of his world. He sets off to rebuild it on a

\footnotetext{
105 Ibid.

106 C. Taylor, Sources of the Self, 171.
} 
more solid foundation, "by following reliable rules of concatenation," based on "probable evidence [...] we wrest the control of our thinking and outlook away from passion or custom or authority and assume responsibility for it ourselves." Here we have "an ideal of independence and self-responsibility, a notion of reason as free from established custom and locally dominant authority."107 Here is the essence of rationalist reasoning: pure reason, the transcendental I floating in the void, free from what might thwart it: passion, custom, authority. The question is whether such a human being exists, or whether it is just another ideal type.

If we have made a mistake in our past, we are obliged to reason with greater caution, not to abandon reasoning (and suspend our assents) in general. As in Descartes, assent is an act of the intellect, which should be measured or, to be more precise, portioned out in line with what is clear and distinct; in Newman, assent is "a free act, a personal act for which the doer is responsible [...]."108 In the latter case, therefore, we take assent as it is in the concrete being. The initial situation, however, is that of chaos, of what our author calls "functional disarrangement," which is characterized by "disorder" in which man's "faculties have their rudimental and inchoate state," and they must be "gradually carried on by practice and experience to their perfection." 109 Reason is always someone's reason, not Reason (which, in the rationalist-empiricist context, is often capitalized) armed with universal rules of logic. The human being is in the process of growing. He must bring himself round to true knowledge, i.e. to the harmony between the inner self and assent to the object of knowing. This is what we have already called the state of preparedness. In his metaphorical description, Newman calls the sense of certitude "the bell of the intellect" which may at times strike when it should not. ${ }^{110}$ This fact, however, is not a sign that the clock should be rejected, but that it should be adjusted. In this sense of a need for regulation, both the intellect and conscience are similar, i.e. they need adjustment. The moral and intellectual "sanction[s] are liable to be biassed by personal inclinations and motives; both require and admit of discipline; and, as it is no disproof of the authority of conscience that false consciences abound, neither does it destroy the importance and the uses of certitude, because even educated minds, who are earnest in their inquiries after the truth, in many cases remain under the power of prejudices or delusion."111

\footnotetext{
107 Ibid., 167.

108 J. H. Newman, Grammar, 189.

109 Ibid.

110 Ibid., 190.

111 Ibid.
} 
As we can see from the above, Newman does not consider man's faculties as such, in their ideal disposition, but considers them as they are found in the concrete human beings entangled in their idiosyncratic circumstances. Our mindsets all too often depart from what is required of us and we fail to live up to the standard, that is, what we recognize as our duty. People can barely precisely distinguish between various types of notional assent and what is only credence or opinion they take for certitude, or else they rarely feel any need to do so.

Let us repeat: certitude is indefectible, which does not mean that it is infallible. Once certitude, always certitude, and those who claim they have lost their certitude are simply proving they have never had it. As Newman writes: "Certitude ought to stand all trials, or it is not certitude." 12 Assent given to something can often be understood as a prejudice. In such a case, we are obviously in danger of making a mistake. Certitude, we must remember, is "an assent given expressly after careful examination."113 Naturally, we can always ask: what if, despite careful examination, I fail in my certitude? Newman provides three conditions of certitude: "that it follows on investigation and proof, that it is accompanied by a specific sense of intellectual satisfaction and repose, and that it is irreversible."114 This point is yet another counterargument to all those who claim that Newman was anti-intellectual; such a claim is especially contradicted by the fact that the Cardinal constantly stressed the importance of rational grounds.

Let us emphasize again one important moment. Sometimes, people claim to have been certain of a doctrine, but in fact they have not accepted this doctrine in its entirety. For instance, some converts from Protestantism to Catholicism, especially in the nineteenth century, left the Catholic Church when new dogmas appeared, i.e. the dogma of the Immaculate conception and the dogma of papal infallibility. Newman rightly observed that they had never had certitude with regard to the Catholic Church, if they had been selective as to her doctrine. What they held, rather, was their private opinion about the Church. Therefore, indeed certitudes remain unimpaired while people may move from one religion to another, the problem being that these certitudes may be placed within different wholes. The Catholic Church, Newman intimates, contains all the truths, which is why she attracts so many converts. Thus, those certitudes found in other regions in Catholicism are found in their integral composition — complete melody, yet still developing-if I may say

\footnotetext{
112 Ibid., 206.

113 Ibid., 207.

114 Ibid.
} 
so. Newman is also trying to account, I guess, for his decision to convert from Anglicanism - without losing his certitudes, but gaining others because this admixture of truth is found in all religions. We may say that, eventually, he found the right system.

Now, why do some certitudes perish if, while being certitudes, they should remain? How is that possible, if Newman claims that the inherent property of certitudes is that they remain? I understand it that the formal conditions for certitude always remain, and then they must be filled with material certitude. And he must have been thinking about himself when he wrote that one might travel through the landscapes of many religions without losing his certitudes, "but with a continual accumulation of truths, which claimed from him and elicited in his intellect fresh and fresh certitudes." ${ }^{115}$ We may explain this apparent contradiction - that certitudes perish—by referring to systems in which they function (I shall write about this further on). They perish not in the sense they were not subjectively felt, but that they were placed within "distinct wholes." When we build a wall, we use bricks. Bricks in themselves are just bricks, yet I may replace one with another, without this particular brick being replaced ceasing to be a brick. Bricks do not perish, although they may be-and often are-differently arranged. We should not, therefore, concentrate on one brick, if we wish to learn the whole construction of a building, of its designer's idea, or - as in our case here-of a system.

If I make a mistake, argues Newman, and "my certitude is unfounded, it is the reasoning that is in fault, not my assent to it."116 This experience of unfounded assent should be all too familiar to any reader of these words. Yet, the fault is not in the personal process of giving assent, but in the object to which one has decided to give assent. This kind of reasoning shows Newman as a critic of scepticism, because a sceptic, as we commonly define him, is someone who, having failed to reach the truth, says that the truth does not exist.

When we look briefly at the Carmelite saint's individual path, we can observe a similar growing in certitude. In quest of her inner certainty (certitude) Edith Stein documented her path in letters which "show the gradual confluence of a painfully sought solution to the problem of inner uncertainty, the problem of friendship with Ingarden, and the emergence of a different kind of peace."117

Perhaps we could summarily understand Newman as follows: looking at various religions we can indeed find the same truths, but in different contexts-in distinct wholes. The point is not to focus on one truth in isolation from others,

\footnotetext{
115 Ibid., 202.

116 Ibid., 186.

117 H.-B. Gerl-Falkovitz, Introduction, in: E. Stein, Letters to Roman Ingarden, 2.
} 
that is, in isolation from the whole of the system. Only then can one feel at ease, in repose when one can sink into safe ground. It is like sinking into a comfortable armchair, without having to look back in fear of finding sharp stones which might hurt us. Finding the right system, as I have already said, has, in itself, both intellectual and emotional components.

\section{$15 \quad$ Religion as a System}

Newman argues on behalf of the existence of certitude in the following manner. First of all, the fact that a true doctrine is not generally received is not proof against certainty. When I accept something as certain, I cannot expect other people to do the same. Reception is not a proof or a condition sine qua non of a doctrine's truth. The teaching of the Catholic Church then, just like the truths of modern science, may continue, although neither the Church nor science is universally received. The validity and legitimacy of the truth is distinct from its acceptance. We must focus rather on the certainty of truth, for the problem is not in the variety of religions, "but in the contradiction, conflict, and change of religious certitudes." 118 The truth must be certain in order to endure, but it does not have to be universally received. Our assents to propositions vary, as we have been arguing throughout this work; they can be weak or strong, premeditated or emotionally biased, but just as the human being cannot be considered under one aspect, likewise "a religion is not a proposition, but a system; it is a rite, a creed, a philosophy, a rule of duty, all at once; and to accept a religion is neither a simple assent to it nor a complex, neither a conviction nor a prejudice, neither a notional assent nor a real, not a mere act of profession, nor of credence, nor of opinion, nor of speculation, but it is a collection of all these various kinds of assents, at once and together, some of one description, some of another $[\ldots . .]^{\prime \prime 19}$

I think that this conception of religion as a system that I am now putting forward and to which I have already alluded can be well defended. The human being does not exhaust his essence in one proposition; he is multifaceted and should be considered from many sides. In like manner, no one aspect exhausts a religion; indeed, it is "a rite, a creed, a philosophy, [and] a rule of duty." The point is that man starts from a different element he has assented to, and then endeavours a free variation focused on that element; we learn about reality

\footnotetext{
118 J. H. Newman, Grammar, 196.

119 Ibid., 197.
} 
by studying its various aspects. It can be an opinion, credence, or profession. In other words, one starts from various places of a certain doctrine. These places taken together, which often requires a considerable amount of time and patience, make up the whole of the doctrine, but taken separately they fall short of it (one element does not make up the whole of it). Therefore, from the same element some become Catholics, Protestants, or subscribe to atheism. This single aspect, isolated from the rest, and developed into a series of variations, leads to the oblivion of the others, i.e. to the oblivion of the whole system from which they have been abstracted. Let me remind the reader that the human being is originally immersed in "functional disarrangement"; each individual person must come to grips with himself. A single aspect is only a reflection of a larger whole, but the inchoate self may try to use this aspect to build up his own theory that suits him, rather than the truth of the religion in question. Therefore, these variations are easily carried out by man's free deliberation in which one conclusion follows another. Without a fulcrum, they come to a dissipation. Such a fulcrum could be the Church, with her solid dogmatic system. Newman is excellently showing his stance on evolution in like manner. Inasmuch as science calls for development, personal certitude in the area of religion is subject to the same, mutatis mutandis, principles of evolution. In this process, the human person must embrace all the implicit and explicit elements always seeking to accommodate what can separately be understood as a conglomeration of loosely connected pieces.

Or let us take another example. Human life can also be imagined as a system composed of a series of episodes unfolding throughout its course. Now, if you pick one episode, and forget that it is just an element of a larger whole, you are in danger of making a fatal mistake. Separate episodes are often in glaring contradiction to each other. Rudolf Höss was the notorious commandant of the concentration camp of Auschwitz. ${ }^{120}$ He lived with his family in a comfortable and spacious house surrounded by a large garden adjacent to the fence of the camp. Therefore, each morning he would open the gate to his place of work where oppression, pain, hatred and death ruled; and each afternoon he would go back through the same gate into a world of flowers, music, and paintings. Like a ghastly Alice in Wonderland, he switched his life back and forth. Should someone pick one frame of his life's film and concentrate on it, they would say: here is a tender father, a connoisseur of paintings, and a lover of music; but then another person might pick another frame and say: here is a

120 He was commandant of Auschwitz-Birkenau in the years of 1940-1943, i.e. at the time when Edith Stein was brought to Birkenau in the memorable year of 1942. 
bloody torturer, a blind ideologue, and cold executioner. And they would both exclaim: these two frames certainly do not show the same person! But they do, and the solution is that we should not focus on isolated episodes and generalize them.

Any discovery or invention can be interpreted with regard to its effects on those who are vitally interested in it. A new discovery in science may, in itself, be just a solution to a concrete problem, but in combination with other discoveries it can bring about a long-awaited remedy against, say, a series disease; what was not originally planned then resulted in unexpected offshoots. Not only in religion, then, do we need to approach it as a system whose specific elements emerge in time and are revealed to successive generations. The same is true about science, a fact that should be a lesson of humility to individual scientists. A concrete discovery is only one aspect; we do not yet know what other practical results will be brought to reality in the future. This approach in the area of science is, at the same time, a warrant that individual scientists will not give up when their personal endeavours fail. It may happen that only future generations will cherish the unveiling of a scientific mystery. Above all, we should avoid rash generalizations; in the past, they often resulted in anathemas or revolts.

In like manner, the same truth in different individuals may produce different results. Therefore, the three people described by Newman who ended up being a Catholic, a Protestant, or an atheist started from one certitude and carried it into a new system. Nevertheless, the original certitude remained, but with other elements being added; it was placed within a transformed whole. To use another metaphor, we can imagine a patch of colour which in itself is just a patch, but may become part of Leonardo da Vinci's Virgin and Child with Saint Anne or Modigliani's Gypsy Woman with Baby. The same shade of green, for instance, can remain as it is, but be placed in different surroundings. Or, to take still another example, the same sequence of notes can be found in various melodies. Now, the point is that when one loses his certitude, it turns out that, in fact, he never had it. Likewise, in each religion there is something in common with other religions. Therefore, it may happen that "a man might travel in his religious profession all the way from heathenism to Catholicity, through Mahometanism, Judaism, Unitarianism, Protestantism, and Anglicanism, without any one certitude lost, but with a continual accumulation of truths, which claimed from him and elicited in his intellect fresh and fresh certitudes." 121 The sad point about this unfortunate outcome is that, once we cling 
to one aspect and make it the central one while ignoring the others, we may in like manner, go in turn from one religion to another, and never reach the right one; in fact, never become a religious person. Let us note in passing, speaking somewhat metaphorically, that the example of a single note can be compared to a simple assent, but then we need to find the whole of the melody. Or we may have a string of notes that are in perfect harmony. In that case, we still need to place them within their melody, i.e. within their system.

And just like in the case of the patch being a part of different paintings, the same certitude may be an element of a different whole. Indeed, a similar example can be taken from language. We have the same words placed in various contexts and syntactic wholes. Various truths are incorporated in individual systems in which they occupy different places. The same word, say, expressive of friendship may be incorporated into various systems.

The area of certitude is fairly limited. In many spheres, we are satisfied with mere opinions that vary, that keep us adrift with what is generally shared by our community at large. Therefore, here comes another of Newman's principles which reads that "probability [i.e. not certitude] is the guide of life."122 (Let us note in passing that John Henry Newman might just as well be considered a philosopher of language. His analyses in this area have brought many new insights. Later on, they were developed by professional analytical philosophers.)

Because the province of certitude is so limited, it is commonly assumed that "probability is the guide of life," that we are satisfied with what is only probable. Newman stipulates, however, that we should not carry this maxim to an extreme. Generally, then, the claim that probability as the guide of life should be treated as a kind of intuitive generalization on the basis of daily empirical data. ${ }^{123}$ I understand this claim as follows: it is presupposed in probability itself that truth does exist, for we call something probable in relation to what is certain, otherwise we would not be able to call something probable. Probability therefore in its essence is an approximation to the truth. Moreover, we need more than probability, than the weighing of arguments, to be committed to religious devotion, to endure and stand firm amidst adversities; we

\footnotetext{
122 Ibid., 192.

123 Let us observe that this conclusion is very much in line with what contemporary physics declares about the nature of subatomic structures.
} 
are inclined to know what is certain. Here is the difference between what he called nominal Christianity and vital Christianity. ${ }^{124}$ In other words, one needs the firm ground of certitude to be a real Christian in whom words are consistent with deeds. The earnestness of our religious life must be animated by certitude. Hence, the perception that "probability is the guide of life" should be treated as a kind of popular belief on the basis of daily experience.

Another argument against certainty comes from the area of science. Because there are numerous creeds and religions, hence-some argue - there is no truth, there are only subjective opinions. Rationalists hold that religious truth should be laid down like a scientific truth — universal and generally accepted. Newman says that there is a common agreement as to the certainty of universal and cardinal truths. But even here one could argue that there was a time when philosophers held different opinions with regard to the origins of the universe, i.e. when they, for instance, sought the arche of the world. This would contradict the common intuition concerning the first principles, namely that they are commonly shared. I wonder if we could apply the same principle in the area of morals. Conscience is said to be composed of three elements: synderesis, sapientia, and scientia. Now, if synderesis can rightly be called the first principle, for it announces that there is a right and a wrong, so perhaps we could say that there is at least certainty with regard to this principle shared by all rational human beings.

The fact that we have so many religions and numerous creeds is perhaps proof that certitude does not exist, in the same way as it was missing in the origins of human learned development. One cannot deny that there are dedicated upholders among those who stick to false doctrines. Thus, perhaps the question of certitude should still be held as a disputable matter. The Cardinal, however, renounces such a conclusion. We acquire reality by learning its numerous aspects. The thing is to place them within the right system, i.e. the system to which we are not only subjectively attached, but which has historically evolved in its complete (and still open to be completed) entirety.

\section{$17 \quad$ Formal Inference}

It is natural that in our formal reasoning we seek to fix a common standard between one mind and another. Otherwise, we would not be able to maintain communication, let alone learned communication. The common standard is a

124 See J. H. Newman, Grammar, 193. 
precondition for our intelligibility. Like Descartes, Newman finds the epitome of such a standard in mathematics, which, by its self-evident symbols, holds all considerations together. In language, this role is played by words; each language being a different system. Therefore, words in turn can be organized into meaningful structures by the inherent logic of the system, one model of which is Aristotelian syllogistics. Such a logic is adequate within the milieu of very general and abstract terms, and thus departs from concrete things. Hence, it can correctly be used in the case of notional apprehension. Formal inference feels at home, if we may say so, amid abstract symbols.

Logic, then, simplifies reasoning, so that it is not led astray by the idiosyncratic nature of the concrete objects; it substitutes words for symbols in order to "circumscribe and stint their import as much as possible, lest perchance A should not always exactly mean A, and B mean B; and to make them, as much as possible, the calculi of notions, which are in our absolute power, as meaning just what we choose them to mean, and as little as possible the tokens of real things, which are outside of us [...]."125 This is the price we have to pay for precision, i.e. the departure from reality. Symbols are easier to handle. We need to have deprived the words - to use Newman's metaphorical parlanceof "their poetry, their rhetoric, and their historical life, to have starved each term down till it has become the ghost of itself, and everywhere one and the same ghost [...]."126 Indeed, the same ghost because we want to be intelligible and comprehended. Logicians put reality into well-ordered and ideal structures, i.e. into "ghosts," so that concrete objects can be efficiently manipulated. In like manner, we use such terms as suitable for mathematical equations.

Newman points to the fact that, out of necessity, we have to abstract names from reality for the purpose of logical requirements. Thus "man" is only "man in general" - turned into one aspect or taken for granted as one, indistinct, mass, a mere representative of the set of elements, or, to take another illustration, only a sketchy outline of a human figure. It is true that, in order to communicate ideas, we have to translate them into a language devoid of real references. Then, by way of this universal tool of communication, we can exist

\footnotetext{
125 Ibid., 214.

126 Ibid. Antoine de Saint-Exupéry with a brilliant touch of his pen painted a beautiful picture of the nonsensical decomposition of reality when man seeks in vain to find sense in separate elements. We read in his Wisdom of the Sands, "Too well I know that the man who has anatomized a body and weighed the bones and entrails is none the wiser, for bones and entrails serve no purpose in themselves-no more than ink or paper. What counts is the wisdom the book bestows, which is of an essence different from that of these material things." (A. Saint-Exupéry, The Wisdom of the Sands, trans. by S. Gilbert, London: Hollis \& Carter, 1952, 20).
} 
within the world of science, but cannot reach into reality, for "abstract can only conduct to abstract; but we have need to attain by our reasonings to what is concrete; and the margin between the abstract conclusions of the science, and the concrete facts which we wish to ascertain, will be found to reduce the force of the inferential method from demonstration to the mere determination of the probable."127 Quite naturally then, we need a kind of personal reasoninga point I have been all the time driving at in this book—a subtle instrument which resonates with reality.

In view of the above, indeed, our formal inferences can only reach what is probable in the concrete (i.e. probability is the guide of life). They are adequate tools for the consideration of abstract thinking. What has been found as a general conclusion, when applied to a particular case, is only probable. I think that an example in point here may be found in medicine. Let us say that, as a result of scientific research, a drug has been found to cure a lot of diseases. It is composed of active substances whose results are well-tested; nevertheless, the person to whom this drug is supposed to be administered is always concrete. And the effect upon his expected recovery can only be probable, or it may fail entirely. There are many elements that we take for granted, i.e. we treat them as premises, in order to facilitate our reasoning. And if we go back to the sources of our knowledge, we arrive at the recondite first principles-truths that we need to accept - without "any common measure of minds," ${ }^{28}$ which is a very strong theme in Newman. We are all linked by a thin network of humanity with each element deeply immersed in our individual worlds. And this is the main problem for Newman, namely, that we fail to accept the original truths from which we individually depart. Then, when formal inferences are carried out from those truths to a conclusion, we renounce the conclusion because we have rejected the reality from which it started. Thus, for instance, if someone fails to respect the sanctity of human life from its conception till its natural death, any argumentations against abortion, providing ever newer data, are of no use because there is fundamental disagreement from the very beginning.

Let us refer here to Stein's revelatory remark made in her letter to Ingarden about the "limits of reason" (which I shall be discussing further in the next chapter), which can be interpreted as the barrier of formal inference when applied to the concrete. For in the concrete, the human being must employ something more adequate and specialized than mere abstract formulas. The sources of knowledge are recondite, i.e. they are hidden in the abyss of

127 J. H. Newman, Grammar, 215.

128 Ibid., 216. 
primeval life, as Stein called them. The direction of Newman's analysis seems all too obvious. We must go back to the point from which we start. If we miss this point of departure, there is no sense bewailing the wrong conclusions.

Let me remind the reader that all this time we are discussing the romantic response to rationalism and sentimentalism, all of them-as we can understand our heroes-reductive views of the human being. The responses were sought in existentialism and phenomenology, and, above all, in personalism. Such were the romantic revisions of the enlightened quest for universalism. The nineteenth century focused on the incompatibility between conceptual knowledge and personal experience, and the twentieth century followed suit. While analyzing Newman, we touch upon the component elements of personalism, phenomenology, and existentialism. Generally, we stand in confrontation with the romantic revision of the enlightened quest for universalism. We stop in respect before the limits of our ratio, and have to subdue ourselves to the mystery of the human person who can accept more than he can comprehend or demonstrate. Edith Stein, who herself experienced the mystery of her own person, naturally must have felt endeared to Newman's thinking. The point was to observe that social life is carried out on the one hand within the confines of a legal (i.e. logical) order, i.e. the rational construction of any political system, and on the other it is buttressed in human daily endeavours by non-political institutions, enmeshed in a complicated and powerful network of traditions, customs, and religions. If we rely only on the state and its law, which is general, we find it inadequate to cope with the dynamic variety of the concrete. One needs something more akin to, and connatural, with the idiosyncrasies of individual circumstances and that pertains to one's personal character. Something that, from within, empowers the person to action. In essence, we need a metaphysics in the singular-metaphysics translated into the singular fortune of the person. In the Philosophical Notebook we read: "Granting that the whole science of metaphysics is esoteric [...] treatises on it should always be written in the first person singular, still it may be true that a continuous meditation may bring out to a particular mind a truth in the way of intuition, I mean as something perceived without reason of middle term - as eyes long accustomed to gaze upon darkness see objects for which others would require more light."129 Newman is indeed consequential in his thinking, as we shall see here. There is something fascinating in his hesitation between simple assent-which comes from a spontaneous response to a given value, and certitude-which is the effect of reflection. It seems that this spontaneous reaction is more important,

129 E Sillem (ed.), The Philosophical Notebook, vol. 2, 29. 
yet it depends on someone's spiritual preparation. Spiritual preparation also denotes a readiness to act duly. (Let us note in passing that the biblical stories about the call of the first Apostles, mentioned before, are very much to the point).

Therefore Newman defends the individual (egotistic) position-examining one's own self. And he goes on to explain that "[i]n most departments of writing, to speak of self is egotistical - not so in metaphysics. In it the writer cannot propose to do more than record his own opinions, the phenomena to which he appeals and the principles which he assumes being within his own breasts. He has nothing in common with others in the sense in which he may assume a community with others as regards external objects. His hermit spirit dwells in his own sphere. All then I propose to do is testify my own notions, as a psychological fact, \& a contribution to psychological science.

All I aim at is to draw out a case, or a «probable —» and I think this enough, because there is very little teaching in this subject matter, which is much more than probable, though one system or theory may be more probable than another. I am not speaking of particular doctrines, but of a system or philosophy.

Why I think it enough <worth while $>$ to aim at what is probable, is, because, if I am only recognised so far, unbelievers \& others who hold false views, or Catholics who hold views which I do not relish, cannot put me down."130 We start from our selves as from facts, with which we are most familiar. If we begin with a general theory, its application to a concrete event only reaches probability.

Metaphysics - because Newman is all the time referring to facts and reality (i.e. the way the person is), and the singular-because the general must be translated into the particular. In order to understand this, I propose the following example: "love thy neighbour" is part of metaphysics, and an answer to the question: "who is my neighbour?" is the singular. ${ }^{131}$ Newman's message, therefore, is also an authentic apology on behalf of human freedom. He himself found in his own person an example of a very intricate and meandering path to personal growth which no external system could preplan or outline in detail.

Logical reasoning must admit a multiplicity of assumptions and the uncertainty of its conclusions. Each person's act bears its own personal mark. Notional arguments, being general, can never reach the particular, therefore there is nothing personal in them; what in abstract looks like proof, in the

$\begin{array}{ll}130 & \text { Ibid., vol. 2, 87. } \\ 131 & \text { Cf. Lk 10:25-37. }\end{array}$ 
concrete reaches only as far as the probable. What can thus be shown as true in inanimate matter can hardly be identified with animate objects. Here we need the living mind to detect what is otherwise hidden in obscurity. I think Newman makes this area of discreteness the special object of his interest. There are things that rely on individual expertise and personal endowment, rather than judgement by rule. Newman seems to find no reason to praise someone for their theoretical predictions when they turn out to be true. The movements of planets, for that matter, must have been prearranged and then they were only reflected in mathematical equations. Therefore, his well-known conclusion reads as follows: "Science, working by itself, reaches truth in the abstract, and probability in the concrete; but what we aim at is truth in the concrete."132

\section{Units before Universals}

Units should come first before universals. Concrete things are alike, not identical. Therefore, although all human beings share one trait, namely humanity, they are different in their personal individuality, in their sameness, and in their selfhood. Abstract sameness does not exist, and even as regards rationalitythe trait we often treat as common and identical to all men-is, in each case, entirely different. ${ }^{133}$ Thus, Newman was a personalist who stressed the incommunicability and incomprehensibility of each human being. God the Creator is incommunicable and incomprehensible, so likewise His creatures are incommunicable and incomprehensible; we, so to say, inherit the traits of incommunicability and incomprehensibility from the Creator. I mean that we may understand certain aspects of their being, but we never completely reach someone's mind, or enter someone's interior. We have access only to what is externally manifested. And even the acting agents, who, naturally, are in touch with their own interior, can only imperfectly grasp the full meaning of their own beings. Newman is often accused of nominalism, but we should not think that he decides about the existence or non-existence of universals. He merely states, and rightly so, that there is a discrepancy between general notions (universals, i.e. man) and concrete beings (this here John). And in our daily experience concrete units have priority over universals; we are dealing with units, not universals.

\footnotetext{
132 J. H. Newman, Grammar, 223.

133 This conclusion refers us to MacIntyre's text Whose Rationality?
} 
In the sciences, we form abstractions, but we begin with things, and they are treated as wholes. Only then are we able to understand them. "The individual man before my mind may be viewed in relation to his anatomy, his organic nature, his intellectuality, his religiousness, but in each case it is he who is viewed, and he is one. Each abstraction then retains with it the idea of unity. "134 We experience ourselves as wholes, a unity, and this knowledge is "gained from sight," and this idea of unity "acts upon the mind, and kindles the thought or discovery «Why, I declare, I am one, I am one and the same,» [- when I am] <as seen in my> consciousness, in thinking, in existing." ${ }^{\prime 35}$ The elementary and primary principles of thought are not innate, the soul would not think without some external stimulus, and - having been roused - it reflects upon itself. "And first, when it contemplates itself, it will at once gain the notion of unity and of individuality — and of independent existence."136 Newman defines his starting point as follows: "My point is, not to deny that our knowledge comes from experience, not to advocate innate forms, but to say that our experience is not so much of external things, but of our own minds."137 Indeed, external objects are like images in our minds. And each mind views them differently. Each mind, so to say, touches upon them in its own individual manner.

Our originality consists not in how we can appear to other people, but how differently we look at different things. And abstraction, of necessity, must simplify what is incommunicable and immeasurable.

If we thus inherit incommunicability and incomprehensibility from God, we must approach each human being, including our own self, accordingly, i.e. never taking it for granted, but always with respect to his or her individual history and development. Taking something for granted is the natural feature of all inferential processes as expressed in language. We are doomed to use general terms, otherwise we would not be able to communicate at all, nor would we be able to construct general knowledge. And when such reasoning, which uses general terms, is applied to concrete situations, the knowledge that is thus gained is - as we already know — only probable.

Newman's considerations obviously touch upon a well-known distinction between entropy and redundancy. What is individual is often entropic, for it contains information that is highly unpredictable; and what is general contains predictable information, that is redundant. Since our knowledge about reality is never perfect and complete, but is composed of various aspects, we can only

\footnotetext{
134 E. Sillem (ed.), The Philosophical Notebook, vol. 2, 17-18.

135 Ibid., vol. 2, 97-99.

136 Ibid., vol. 2, 23 .

137 Ibid., vol. 2, 22.
} 
therefore be satisfied with the accumulation of aspects. They cannot be converted into syllogisms because they are too circuitous and elusive; we have to give them abstract names. Newman rightly observes that, in order to grasp the human being in the concrete, we need a more adequate and more sensitive instrument, namely another human being. Thus, we arrive at this mysterious principle which reads cor ad cor loquitur (heart speaks unto heart); only one heart can speak unto another heart. If heart, as we shall see further, denotes the broader (and more adequate) faculty of the person, it can enter into fruitful communing only with another heart-this conclusion sounds logical. And, naturally, a conversation of hearts metaphorically symbolizes here a conversation of persons who are not reduced to intellects, i.e. an exchange of general information. The intellect merely uses the general notions and addresses the general processes. They express only certain aspects of the general character of the individual being, but are never exhaustive or complete. They resemble a sketchy portrait of a person. Now, in order to consider Newman's personal decision we can ask: how did he come to know that the Catholic Church was the true Church and that he should join it? How did Edith Stein come to know that Christianity was the true way for her even up to the moment of entering a contemplative order? From Newman's biographic facts we learn that he studied the primitive Church, yet - as he himself noted - there is a discrepancy between the knowledge we gain and the formal inference we employ to elicit some conclusions and a personal decision we make. There is a discrepancy between the mere statement that a proposal holds true and the decision that I should follow it. Therefore his studies could have prepared him for his final decision, but, ultimately, he was the only person to make it not on the basis of self-evident premises, but on the basis of his personal result, on his personal fiat.

Informal Inference

Let us now consider the characterization of Newman's informal inference. He was well aware that, in order to reach the complexity of the concrete, one needs to find a much more subtle instrument, a point I have already stressed, than the general method of syllogistic reasoning, which makes use of general terms. Rather than summing up all the aspects, we need to approach the being in its wholeness. This conclusion reminds us of the manner in which we understand the transcendental sphere (in Rousseau or Kant), i.e. the general will (Rousseau) and the transcendental I are not a mere enumeration of particular cases; the general will and the transcendental I are rational hypotheses. 
They suffice in general considerations; therefore, the main fruit of modernity is the independent and autonomous being in the context of negative liberty, i.e. liberated from any arbitrary intrusions. The thinking and acting agent would rather get lost amid all the minute aspects and would find the conclusion lacking. He needs to grasp "by a clear and rapid act of the intellect, always, however, by an unwritten summing-up, something like the summation of the terms, plus and minus of an algebraical series." ${ }^{138}$ This quote shows the constant tension in Newman's writings between what results from the tedious process of reasoning and what is due to an intuitive grasp. Reasoning can be understood as formal and informal: the formal is subjected to some external and universal rules, the informal pertains to the person. Intuition is natural, which does not mean that it is not subject to development. To the degree to which the person grows in obedience to internal duty and conscience, the intuitive instrument is made more sensitive to assenting to moral values.

Newman calls reasoning "the very breath of my existence." ${ }^{139}$ Consciousness and reasoning are essentially bound up with the idea of existence. I cannot be conscious of something that does not exist. Obviously, we may dream, especially daydream, about something that does not exist, but what Newman understands by the phrase "to be conscious" is that something operates somehow on our mind and sets it in motion, i.e. into thinking and reasoning. In other words, operation speaks of existence.

As we can see, the intuitive grasp is not a physical summation of welldefined units, but rather a hidden process by which we get to know the concrete. It must be remembered that, as we have said, this knowledge is not formal, but personal — which means that it lacks an explicit form, and remains only implicit. We reach the concrete by way of a kind of instinct. Informal inference does not replace formal inference-as I have remarked above, the two currents-formal and informal - coexist in the one person. If I were to portray its essence, I would compare it to a visit to some friends or relatives. The visit has its formal elements such as a concrete appointment, knocking at the door, greeting the person, and the informal elements are composed of all the words and gestures that can never be predicted beforehand, so they are informal. They are responsive to individual circumstances (assuming that we are sincere in this encounter). Or, to take another example, let us look at surgery. The surgeon knows the general principles of surgery, but in each case it is different, so he must apply or modify his general knowledge to this particular

138 J. H. Newman, Grammar, 232.

139 E. Sillem (ed.), The Philosophical Notebook, vol. 2, 37. 
case. His successive conduct then relies not so much on his theoretical acquaintance with medical rules, at least not exclusively, but very often on his intuitive and implicit experience. Instead of following the individual elements of his medical knowledge, resultant from other cases and made general, the surgeon knows what to do with the internal and implicit certitude which depends on his personal acquaintance with the case in question and his intuition of what should be done. For some, this particular procedure may arouse in a concrete case to certitude and proof depending on the constitution of the individual mind. The surgeon's knowledge can here be identified with what he feels that is right at a given moment. This feeling should not be mistaken for an emotional state. Rather, it is his mental and personal certitude as to what should be done. Let me remind the reader of Gauss's example. Indeed, the mathematician's inference in one act grasped the conclusion.

\section{Personal Knowledge versus Inference}

Thus, our procedure in knowing reality is an intricate intermixture of explicit elements-the conditional inferences from which we arrive at conclusions from premises - and implicit elements, from which we unconditionally assent to given propositions. Aside from principal knowledge, we need personal experience of the matter at hand in order to issue the right judgements. Instead of focusing, for that matter, on the objective truth of the Church, Newman emphasizes the fact that in his honest, inward-looking approach, man is capable of grasping this truth in his person. Therefore, he concentrates on our personal endowment, on our instinctive acquaintance with a particular case and the testimonies of others, rather than on formal argumentation. This is the groundwork of our belief. We should adhere to this personal faculty of our very person and trust it, rather than try to seek general knowledge and then apply it to our lives. Newman proposes that the person rely on his "own living personal reasoning, [his] good sense, which is the healthy condition of such personal reasoning, but which cannot adequately express itself in words [...]."140

Thus, for the person who is steeped in practical knowledge, a formal ergo in a conclusion comes to life with reality. This term, $\operatorname{ergo}$ (i.e. then) in implication, has a different meaning in each case, depending on who is undertaking the reasoning. Speaking somewhat metaphorically, ergo can be alive and creative, arousing the individual to action, or else dead and formal, hardly ever

140 J. H. Newman, Grammar, 239. 
personally efficient (see the case of my Lazarus). In an abstract and formal situation, when we consider the well-known logical implication that if $\mathrm{X}$ is greater than $\mathrm{Y}$ and $\mathrm{Y}$ greater than $\mathrm{Z}$, then $(\operatorname{ergo}) \mathrm{X}$ is greater than $\mathrm{Z}$, we may find it difficult to resist the obvious or else may become personally involved. The personal manner of understanding ergo in an implication does indeed deserve a more thorough examination, for-judging by the external manifestationsit is not at all easy to discriminate between notional assent and a real one. A person engaged in the subject in question grasps the whole proposition with one act; a person who is only theoretically acquainted with it follows the formal procedures. For such a person, the word ergo is a mere logical symbol, like the symbol " + " in a series of numbers. He is simply arbitrarily told that the element that follows ergo results from the element that precedes it, but, unless he really understands the reality of the components, the ergo has no power of conviction, no power of eliciting real assent. Recapitulating what we have said so far, we can come up with two meanings of the word ergo: logical and existential (or personal). The logical meaning is a mere inference on the basis of the premises in question (inference inherent in the terms under consideration), the existential (personal) meaning is the response of the person. Obviously, we may be dealing with both meanings, and for the external observer it is difficult to discern which of them is present. Only introspection can provide an answer and a respective action.

The main point of our considerations here is to stress the intrinsic relationship between action and its author, i.e. whether I am myself really and truly the agent. If ergo is a mere repetition of implication, I can be completely absent from what I (notionally) declare an implication. On the contrary, I am a self, an effective person in whom acts originate; they do not pass through me as if they were passing through an inanimate object, but they emerge from me. Let me observe in passing that the problem of understanding ergo is similar to the word "last" from Randy Pausch's "last lecture." We have here the same, let us say, transition from notion to reality, from a mere notional apprehension to the illumination of reality. This is what we describe in English as dawning, i.e. it dawned on me.

We do not have to prove our existence by formulating cogito ergo sum. "I am conscious that I am,"141 argues Newman. I learn about my existence through the operations of my faculties: "I feel pain. I have not faith in the feeling, but the feeling is part of me, or bound up in my «I am». Consciousness indeed is not of simple being, but of action or passion, of which pain is one form. I am

141 E. Sillem (ed.), The Philosophical Notebook, vol. 2, 33. 
conscious that I am, because I am conscious I am thinking (cogito ergo sum) or feeling, or remembering, or comparing, or $\leq$ exercising $\geq$ discourse.

I repeat, if it be improper to speak of «faith in one's being», it is improper to speak of faith in <certain> other things besides being — being is not known directly, but indirectly through its states (just as the eyes do not see the substance of bodies, but the qualities) and these states, which convey the notion of being, are such as feeling, thinking, remembering \& c. Certain faculties then, or rather their operations, are a part of the initial idea of existence.

This view of the subject brings us a step further, as revealing an important principle. Sentio ergo sum. To call this an act of argumentation or deduction, and that it implies faith in that reasoning process which is denoted by the symbol of «ergo» seems to me a fallacy. I do not advance from one proposition to another, when I know [- am conscious] my existence from being conscious of my feeling but one and the same act of consciousness brings home to me that which afterwards at leisure I draw out into two propositions, denoting two out of many aspects of the one thing. What is called reasoning then is in its essence not a deduction, but it is the perception of certain complex ideas, or the modes or the dress of things. Thought and being, or sensation \& being, are brought home to me by one act of consciousness, prior to any exercise of ratiocination, though I may afterward, if I wish, survey the complex idea by means of that exercise."142 Newman suggests that the word "ergo" should be replaced by "for," e.g. "I am for I think," “I am for I reason." It is not deduction in the form of that well-known scheme of implication: if $\mathrm{p}$, then $\mathrm{q} \rightarrow$ if I think, then I exist. Rather, I grasp my existence by one act. My consciousness informs me about my existence through sensations.

In reality, therefore, the circumstances are entirely different. Reality, so to say, opens up to this particular person. If we resolve, however, to apply some formal rules to individual cases, we are in danger of falling victim to circuitous arguments and never reaching a satisfactory conclusion. There is a correlation between certitude and implicit proof and such is "a law of our minds." ${ }^{143}$ Newman always stresses this requirement of a connatural relationship between the mind and the thing that this mind is supposed to consider. Understanding, in its primary sense, is a personal effort, not a logical puzzle, especially in concrete circumstances. Therefore, apart from our general knowledge of some problems, we need to have personal experience with the objects under consideration.

\footnotetext{
142 Ibid., vol. 2, 34-35.

143 J. H. Newman, Grammar, 239.
} 
In concrete reasonings, we cannot help but rely on ourselves; we have to use ourselves, as we have often repeated here, "judge for ourselves, by our own lights, and on our own principles," or, in other words, the criterion of truth is "not so much the manipulation of propositions, as the intellectual and moral character of the person maintaining them and the ultimate silent effect of his arguments or conclusions upon our minds."144 Newman always stresses this living faculty of judgement in the individual person: not only intellectually, but also morally. This is another strong theme in Newman which shows his view of human integrity. And this is also an excellent reference to St Augustine, namely the fact that morality, or the purity of the heart, is a precondition for our correct thinking. Newman stresses this personal and practical endowment in which "an ounce of common-sense goes farther than many cartloads of logic $[\ldots] . " 145$ The processes of reasoning that lead to action and assent are multiform, subtle and omnigenous in the concrete, so they cannot be measured by rules; they are personal. Here, verbal argumentation must become subordinate "to a higher logic."146 And this higher logic comes from the person, the person who must be prepared intellectually and morally to face the challenges of reality.

All in all, Newman intimates that it is personal knowledge-a combination of logic, personal experience, and historical encounters with the subjects in question - that can assess the value of some practical implications. All of these elements come together to form this higher logic of the person. In this logic, the explicit and implicit elements appear to be on the same footing, and in concrete judgements the implicit ones become prevalent.

This silent incorporation (of implicit knowledge) is of the utmost importance. The mind should not be garrulous and noisy, a phenomenon which often takes place when ignorance is clumsily masked with a proliferation of words. It becomes so when it is involved in a busy consideration of arguments which happens when a person thinks he is master and constructor of reality (the mechanistic treatment of reality). When reasons are measured out, and appear to be of equal value, what conclusion is there to result from this strenuous job if moral character is lacking? The condition of silence smacks of contemplation. We repose in certitude as we repose in reality. And this repose is stronger than any formal conclusion which can be demonstrated. The person feels at home, a feeling that is difficult to lay out in formal terms. I have often repeated the feelings of repose and contentment, manifest signs of

$\begin{array}{ll}144 & \text { Ibid., 24O. } \\ 145 & \text { Ibid. } \\ 146 & \text { Ibid. }\end{array}$


certitude. For both Newman and Stein, their personal choices were associated with peace and contentment; let us remember that the aforementioned states of mind have nothing to do with some passive and Stoic acquiescence. Once she arrived at her new spiritual home, i.e. feeling certain about her decision, Stein "found complete peace and contentment in her hidden life of prayer and sacrifice." 147 She found herself within a spiritual castle and "difficult concepts" became simple, and the Carmelite Rule was "all alive in her own person."148 What originally, with her natural reason, could have been approached only with reluctance or pitifulness, was now accepted without any reservations. The virtue of obedience was viewed through the eyes of her renowned spirit. And, likewise, Newman, when he joined the Roman Catholic Church. He had to concede that another kind of logic must be at work in the person's individual life.

In concrete matters, verbal logic is subordinated to, say, personal logic, i.e. to what kind of character we are. Two minds may, and often do, look at the same thing in two different ways, for they approach them with their different intellectual and moral beings. As I have already said, Newman doubts the plausibility of sudden conversions. He believes, instead, in a gradual process in which knowledge is mingled with the ingredients of character. It is a process which resembles the spontaneous accumulation of data rather than enforced deductions, "a calm contemplation and gradual understanding of their premisses."149

The person must grow in understanding. It is the kind of knowledge that becomes one with the person who holds it, or is even held by it (as we remember about being possessed by an idea), rather than being a mere manipulation of notions. The knowledge that is meant here is like the Image of God that comes via the conscience. Newman compares it to the process in which the eyes become accommodated to the details of a landscape. Layers upon layers settle in the mind, thereby allowing the person to grow in individuality. This process of settling and growth is characteristic of Newman's and Stein's developments. Newman refers to "the trained imagination," which is capable of seeing "the representations of things" behind the notions. ${ }^{150}$ Indeed, when we understand reality and concrete events as being messages from someone, through their authors we make them personalized. All human acts are marked with personal intentions. We should be able to read them as personal communication, and transmit them in the same way we send communiques to other persons. And he eventually concludes "that methodical processes of inference,

\footnotetext{
147 M. L. Hill, Saint Edith Stein, 91.

148 Ibid., 93.

149 J. H. Newman, Grammar, 249.

150 See ibid., 25 o.
} 
useful as they are, as far as they go, are only instruments of the mind, and need, in order to their due exercise, that real ratiocination and present imagination which gives them a sense beyond their letter, and which, while acting through them, reaches to conclusions beyond and above them. Such a living organon is a personal gift, and not a mere method or calculus."151 Edith Stein also has this practical bias, as I have pointed out in Chapter 1, i.e. knowledge translated into practical acts on behalf of others, as an important element to create a personality, not a mere way to accumulate information.

Following Locke's suggestion, Newman agrees that there are cases which are sufficient for scientific proof, although they rise only to probability. But what are these propositions which rise to probability? And Newman proposes an answer, namely that they are to be found in concrete matters. It is here that we are guided by supra-logical judgment, and this judgment-as Newman intimates- "is not mere common-sense, but the true healthy action of our ratiocinative powers, an action more subtle and more comprehensive than the mere appreciation of syllogistic argument."152 Obviously, we arrive here at the world of the virtue of prudence. And prudence is "a personal endowment"; indeed, virtue, according to Aristotle, is not part of our nature, but something that we accomplish as a result of hard work. After all, virtue is the outcome of what we do against our natural inclinations. This personal logic does not exclude logic in abstract matters, but supplements it.

Thus, we have outlined-speaking in political terms-a conservative context of human action in which there are legal structures within which is placed a virtuous man, contrary to, for instance, the theological principle of ex opera operato, which means that the sacraments are valid, irrespective of the agent, but depending on our own minds, "by our own individual perception of the truth in question, under a sense of duty to those conclusions and with an intellectual conscientiousness." ${ }^{153}$ Newman's approach is clearly laid out in these words - we use ourselves in our integrity, the intellect and the will united together to bring forth a personal result, that well-known phrase from the Cardinal's University Sermons that has already been mentioned here. The person, thereby, is a living cognitive institution, if I may use such a phrase. All faculties of this institution are of high value, for they all participate in cognition and action. The only kind of certitude we can attain is moral certitude and moral evidence, and that - as the British Cardinal claims—not only in spiritual subjects but also in other, terrestrial, questions. Newman claims that

$\begin{array}{ll}15^{1} & \text { Ibid. } \\ 15^{2} & \text { Ibid., 251. } \\ 153 & \text { Ibid., 252. }\end{array}$


even in mathematical science the principles of concrete reasoning - in which the intellectual prowess must go hand in hand with the moral characterare valid. And he compares this case to the famous lemma from Newton's Principia. As we know, if we multiply the number of sides on a regular polygon inscribed in a circle, it will ultimately (i.e. in infinity) become a circle. But, in fact, it disappears before it becomes a circle. Likewise, in reasoning we accumulate premises, so that they ultimately turn into a conclusion. We anticipate and predict the conclusion in concrete matters, rather than attain it by way of accumulation. The arguments converge, but do not translate into the conclusion, for, after all, they only lead to it, and no single argument is a conclusion, since, in such a case, the conclusion would be illogical. Therefore, it is not the ergo in an invincible syllogism that brings about the conclusion, but the personal absorption of the numerous (uncalculated) premises which are laid out in their complicated relationships.

A good example of the coalescence of explicit and implicit reasons can be taken from the area of criminal cases. Judges must rely not only on the evidence to bring in a verdict of guilty, especially if the evidence is only circumstantial. The point is that in concrete matters we often are certain, but fail to provide respective argumentation on behalf of our certitude. The reasons are too subtle and invisible to be demonstrated as we proceed from conditional inference to unconditional assent.

To sum up my considerations on personal knowledge and informal inference, let me go back to Newman and quote an important statement. In the Philosophical Notebook we find his personal reflection: "I doubt whether what is called reasoning be in its essence a process." 154 This depicts his basic hesitation between intuition and reflection as the fundamental sources of knowledge. Indeed, when we compare thinking with reasoning, the former term is broader than the latter. Now, if reasoning is a process, it is subjected to the well-known rules of logic, i.e. we pass from indubitable and incontrovertible premises to a conclusion. We can thus suspect Newman's reservations and his fundamental anxiety about the intervention of the imperfect intellect with its natural predilection for speculation. Newman even writes about "the wild living intellect of man"155 and goes on to outline his great programme of Catholic defence-by outlining his concept of the person. The intellect is at home with the explicit elements of our knowledge. Newman recapitulates all the typical accusations that were levelled against him as follows: "[I make] profession

\footnotetext{
154 E. Sillem (ed.), The Philosophical Notebook, vol. 2, 73.

155 J. H. Newman, Apologia, 164.
} 
to hold doctrines which I cannot possibly believe in my heart, but that I also believe in the existence of a power on earth, which at its own will imposes upon men any new set of credenda, when it pleases, by a claim to infallibility; in consequence, that my own thoughts are not my own property; that I cannot tell that to-morrow I may not have to give up what I hold to-day, and that the necessary effect of such a condition of mind must be a degrading bondage, or a bitter inward rebellion relieving itself in secret infidelity, or the necessity of ignoring the whole subject of religion in a sort of disgust, and of mechanically saying every thing that the Church says, and leaving to others the defence of it."156 All of these are simply the main items on the deistic agenda and inspired by Locke's modern philosophy: the Church is like a foreign idea imposed on the mind; man holds ideas he cannot account for; the claim to infallibility is against human autonomy; and the ultimate conclusion that, under such a state of affairs, the individual mind must either secretly (i.e. slavishly) revolt or yield submissively to it. The result is, as we know, enthusiasm or irrationality. (Interestingly enough, let us observe that it somehow did not occur to Locke and his followers that being forced to join the state (Anglican) Church could lead to the same line of accusations). And the solution for Newman is very simple-you pick up only certain aspects out of something which is a whole. Only by learning the whole system can you understand its separate elements.

Newman understands faith in two ways: religious and natural. Naturally, we have to believe in many things we cannot, nor do we feel any necessity to, check. There are things within us and without us. He applies the word "faith" to "our reliance <certainty> of things without and not within us."157 Hence, the world within us is what we actually feel. Intuition is prior to faith. In the Grammar of Assent he writes about instinct. It would be absurd to say that we have faith in intuition, hence intuition is the real starting point, and it concerns the things within us. Intuition pertains to three things that precede the knowledge of myself: (1) consciousness, (2) thought, (3) a certain analysis, which becomes, afterwards, the principle of reasoning. The knowledge of my existence is the fourth act. All of them are "one complex act of intuition. Here we have real intuition, but I have faith, not intuition, of the external world."158

\footnotetext{
156 Ibid., 165.

157 E. Sillem (ed.), The Philosophical Notebook, vol. 2, 71.

158 Ibid.
} 
The phrase "cogito ergo sum" is therefore a complex act consisting of four elements. First, I intuit about my consciousness, then about my thinking, then I reflect on my thinking, and ultimately combine them into a complex idea, a complex intuition.

The original point in Newman's approach is that ratiocination can be treated as an act of the mind rather than a psychological process. Let us recall Stein's confession after having read the mystic text. At the same time, however, before we lay a charge against Newman for his inconsequence (between ratiocination as an act and as a process), we must observe that certain processes in the mind are tacit. Consequently, even though a decision may sound like an act of the mind, it has, nevertheless, been preceded by some implicit and hidden internal process. Thinking is a personal life. Even the subject involved finds it difficult to trace all its paths. Saint-Exupéry puts it beautifully in his Wisdom of the Sands where we read: "inasmuch as the heart and soul have no concern with the rules of logic or the science of numbers-this is where I step in and impose my will."159

Newman argues, as I have already alluded to, that reasoning in the concrete can be understood as a simple act that has the nature of instinct. He calls it natural inference. And thus we have arrived at the key point of Newman's doctrine. The human person integrates within himself the intellectual and moral resources to arrive at an instinctive manner in which to accept the truth. We may call this informal inference, natural inference, or Illative Sense. These terms describe the mode in which we react to reality, i.e. we react according to the way we are. And we are a coalescence and convergence of various personal faculties. The person opens himself to truth inasmuch as he has worked on his true self; the true self is responsive to the truth of reality. In this sense, it becomes clear that cor ad cor loquitur (heart speaks unto heart), and in this personal communing we descend on to the firmer and more solid ground of understanding than when we are involved in argumentative exchange. This communing is conscious and unconscious, explicit and implicit, relies on what is told and what is untold, it ultimately refers to the primeval depth which Edith Stein discussed and of which we shall be talking further. The human person makes use of his illative faculty and thus grasps the truth in the way of

159 A. Saint-Exupéry, The Wisdom of the Sands, 21. 
unconditional assent, instead of following the external rules. Such rules subdue the intellect, but they hardly reach the innermost centre of the person.

Our most natural mode of reasoning is ultimately "not from propositions to propositions, but from things to things, from concrete to concrete, from wholes to wholes." ${ }^{160}$ We deal with them with our intrinsic and personal power, for we can never learn all the aspects of the objects in question. We may say that Newman proposes a most "democratic" endowment of the human person, for it does not depend on the amount of theoretical knowledge we have acquired. Newman advocates this spontaneous activity. Some of his comments, however, may initially raise some doubts, but on second thoughts they become clear. He is writing, for instance, that true poetry is "a spontaneous outpouring of thought" and that "no one becomes a poet merely by the canons of criticism."161 It is true that by reading critical essays on poetry no one becomes a poet, but it is also true that a mere spontaneous outpouring of thought will not make one a poet. These quotes are examples which show Newman at his best, that is, they depict his consequence and cohesion. Poetry understood as "a spontaneous outpouring of thought" reminds us of simple assent, and reading "canons of criticism" resembles certitude. And we know that, for Newman, assent is a precondition of certitude.

At the same time, however, let us observe that Newman is right in claiming that anyone, irrespective of his intellectual capacity, may learn the truth and act accordingly. Such a person may know what to do without being able to formulate the reasons why, because his knowledge is implicit. He may not be able to give intelligible reasons. He feels all at once that he is certain of what he says or does. We have here natural acuteness and personal idiosyncratic modes of recognition. People well-acquainted with the matter in question instinctively grasp the solution without going from antecedents to consequents. Indeed, we even deal with this kind of spontaneous knowledge improved by practice and habit in the area of the natural sciences. There were truths in the past predicted by scholars which could not be proved, let alone demonstrated. The examples we could mention here are gravitational radiation or the fact that bodies of enormous masses can bend light. It must be noted that Newman's instinct should not be treated as a natural sense, one and the same in every person, "but a perception of facts without assignable media of perceiving."162 It is a spontaneous perception of the truth. Obviously, there are cases of supernatural intervention in which someone is suddenly struck

\footnotetext{
160 J. H. Newman, Grammar, 260.

161 See ibid., 261.

162 Ibid., 263.
} 
by the inappropriateness of his behaviour. Such was St Paul's conversion. We have to admit, however, that we do not know anything about some hidden processes of doubt that might have made their way into Saul's mind before he was struck by supernatural intervention. In the case of Saul, it was like a revelation, like light that had broken in upon him. But before the final act of his personal drama had taken place, however, he might have become astonished by the manner in which Christians faced persecution. All these moments of heroism that seemed to have defied suffering were indeed mind-boggling for pagans throughout the Old Testament and for Pharisees at the threshold of the New. That experience of wonder at the other person's inexplicable conduct would parallel the situation of Reinach's widow that I have already described and the way Edith Stein perceived it.

Newman is seeking to provide natural grounds for apprehending and holding fundamental truths. It seems that, for him, the whole of human nature is inclined to these truths and the more we try to demonstrate them by means of logical rules, the more we meddle with the natural sources of their accommodation. In fact, when subjected to analysis we distance ourselves from them, since we can never convey the contents of our internal experience, nor is it necessary. The point is to open up the natural avenues to the human inmost centre, the avenues each person must walk himself. They spring up from the very constitution of our minds. This point must be properly understood, because we have already said that knowledge is acquired like virtue, i.e. we have to grow to learn. In personalism, we understood the person as the being which is and, at the same time, is becoming. Now we learn that it is the natural constitution of the mind to be open to knowledge; nature and art seem to enter into combat. Our natural view of things is connatural to our minds; Newman means "a power of looking at things in some particular aspect, and of determining their internal and external relations thereby." ${ }^{163}$ We are potentially endowed to know the truth by personal acquaintance with a certain subject. This gift can be subtle and versatile, and it is peculiar to some minds. They gain this natural and spontaneous gift of ratiocination. Newton, therefore, was inclined to different matters than Napoleon. The reader may be reminded of Gauss's example mentioned before. Newman seems to be pointing at Aristotle's phronesis, but for him it is not an instrumental art. ${ }^{164}$

We make use of this spontaneous cognition via a sense that is proper to ourselves. In other words, our discretion and judgment are exerted spontaneously

163 Ibid., $265^{-266 .}$

164 See ibid., 266. 
and we cannot give an account of how they proceed or whence they proceed. It is an act in which the agent and the observer become one; they move forward in much the same way as they breathe. Obviously, we may analyze them afterwards. Discretion and judgement proceed from concrete to concrete and are attached to a definite subject-matter. This is the key point in Newman's theory of knowledge in the concrete, where our natural and spontaneous ratiocinations are at work. They resemble taste and invention in other contexts.

Newman wants man to be transparent. In concrete matters, the question of good and bad is often at stake, and it is here that "yes" (a word) must mean yes (reality) and "no" must mean no. Otherwise, the person becomes unreal (the question of real and unreal words will be dealt with further on). This ratiocinative faculty is not a general instrument of knowledge; rather, it can be called departmental. It is, in fact, a collection of faculties. A good example in point here would be memory, which, in respect of different persons, varies. We should trust persons then, not logical science, since, apart from their specialized knowledge, they have personal experience of the matter in question. Aristotle intimates the same idea in his Nicomachean Ethics: "Therefore we ought to attend to the undemonstrated sayings and opinions of experienced and older people or of people of practical wisdom not less than to demonstrations; for because experience has given them an eye they see aright."165

In Aristotle, phronesis (practical wisdom) characterizes the sagacious man, a man of practical wisdom able to deliberate well about what is good and expedient for himself, not in some particular respect, e.g. about what sort of things are conducive to our health or strength, "but about what sorts of thing conduce to the good life in general."166 So, it seems that we can establish a common measure between two persons endowed with practical wisdom, something that is not possible for Newman. Two minds are incommensurate. In concrete circumstances, two minds are working entirely differently. One may pose a question here. Namely, if we are to trust persons on account of their long acquaintance with the subject-matter under consideration, how do we know that their view is not biased, for instance, by political expedience? How are we supposed to know that their intentions are morally noble? Are they not leading us astray? Therefore, without the issue of conscience these questions rightly give rise to doubts. And, let us add, consciences are shaped under appropriate conditions. Yet another thing is of utmost importance-Newman points to the individual histories of those who are supposed to be consulted. If we follow

\footnotetext{
165 Aristotle, Nicomachean Ethics, trans. by W. D. Ross, Kitchener: Batoche Books, 1999, ch. VI, 102.

166 Ibid., Bk. VI, ch. v.
} 
their history and find them wanting in honesty or impartiality, we are evidently right to abandon them. We take the person together with his history, in case we might spot some false steps. After all, we need to obtain a clear picture of what we are looking at. In that case, it is someone's life that is speaking to us. By following our masters we become prepared to lean on ourselves and draw on our intellectual and moral resources. Thus, judgement is not merely a result of skill in argumentation, but it is - as Newman calls it-"the architectonic faculty" with the Illative Sense (right judgement in ratiocination) as its branch.

Newman is constantly trying to show that, despite the fact that experience leads to probabilities when put in the form of a syllogism, certitude does exist. People feel certain. He is obviously referring to Kant when he writes that there are philosophers who "grant the à priori principle assumed in the argument, and in consequence are obliged, in order to vindicate the certainty of knowledge, to have recourse to the hypothesis of intuitions, intellectual forms, and the like, which belong to us by nature, and may be considered to elevate our experience into something more than it is in itself."167 The intellectual forms, however, were designed by Kant to arrive at pure knowledge, the kind of knowledge that is independent of experience. In the Kantian option, man arrives at certainty in a world distilled from the erroneous testimony of the senses, in the area of the transcendental I. For Newman, the very fact of certitude, to which those who experience it testify, is sufficient for its existence. His aim is practical and he does not want to be a metaphysician, i.e. he shrinks from appealing to some theoretical premises. ${ }^{168}$ The mental state of certitude is enough for the truth of a proposition because the most important thing is that something is true to this particular person; in other words, that this person is living the truth. The person may "objectively" be wrong, but there is no denying that he does experience something as true and about which he is certain. Let us remember that certitude is not passive, it does not come from outside but from within, it is "an active recognition of propositions as true, such as it is the duty of each individual himself to exercise at the bidding of reason, and, when reason forbids, to withhold."169

As we have already shown, there is no common measure between minds. We are our own centres when we reason. We have at our disposal the ratiocinative faculty whose perfection is the Illative Sense.

167 J. H. Newman, Grammar, 270.

168 See ibid., 271.

169 Ibid. 


\section{The Sanction, Nature, and Range of the Illative Sense, or the Power of Integration}

We live among various things and we have to use ourselves to know them, i.e. our faculties and our abilities. As Newman writes: "I am what I am, or I am nothing." 170 I need to suffice myself, but the main purpose is to ascertain myself. We need to know who we are in order to put ourselves to use. Obviously, there are many faculties in man whose capacity is still not fully realized and ready to develop. Man is, therefore, somewhat incomplete and open to perfection, a point I have already alluded to. In this sense, Newman is a realist. He takes reality as it is. We are potential beings. There are many inchoate and rudimental elements in our nature which we gradually, by recurrent efforts, seek to bring to perfection. The human being, as Newman observes, is "the creator of his own sufficiency; and to be emphatically self-made."171 And, let me repeat, we have this great task of integration at work here. I, a person, am a very complicated instrument whose principles of operation I learn throughout my life. In other words, I am given to myself as a concrete being and at the same time am assigned to myself as a concrete task. There are infinite dimensions inside and infinite perspectives outside I have to master. The explicit and implicit zones are mingled together. As the implicit zone is, naturally, not well-defined-I believe in it rather than know it by way of intellect - the explicit instrument is often abstract and inadequate to precisely describe the interior. I need to master the elusive world of emotions, rules, and requirements. Therefore, in order not to be lost amidst the intricate paths of argumentation, as seems to be Newman's claim, it is safer to develop a habit of correct thinking, in which we accept the truth in much the same way as we breathe. Real assent then comes out naturally from man.

What we obtain, let us repeat, is a personal result. In this process, nothing is deterministic or mechanical. It is a personal task. We acquire knowledge by means of inference and assent. Newman reads like a metaphysical realist when he writes that we must appeal to man and his nature as a fact. I have already mentioned this point when writing about metaphysics in the singular. It is of no use attempting to devise a science of reasoning in the concrete, i.e. a kind of universal logic which would bring any mind, in the form of a mechanistic procedure, to the required solution. We need to rely on ourselves and "confess that there is no ultimate test of truth besides the testimony born to truth by

\footnotetext{
170 Ibid., 272.

171 Ibid., 274.
} 
the mind itself, and that this phenomenon, perplexing as we may find it, is a normal and inevitable characteristic of the mental constitution of a being like man on a stage such as the world. His progress is a living growth, not a mechanism; and its instruments are mental acts, not the formulas and contrivances of language."172

Newman does not seek universal schemes of knowledge, which anyone could master at the bidding of some expediency; rather, he takes aim at persons capable of gaining certitude. Thus, it is not structures from outside, as it were, which decide for us, but it is the personal inside that paves the way. Certitude grows together with the person in whom questions, decisions, and actions form a deposit - if I may say so - thereby creating character (personhood). We gain knowledge by the rightful use of inference and assent. Inference is obscure and assent is distinct and definite. And we can see how the mental and sensate levels coalesce in Newman's proposal, as they coalesce in Stein's.

The personal knowledge thus gained relies on the integrated capacities of the person, explicit and implicit. This integration resembles a kind of readiness worked out in a person to respond to the demands of the truth. I think that the best instantiation of what we are talking about here is Edith Stein's testimony of her experience of certitude. She writes in the bookJüdische Familie: "I could not proceed with anything except on the basis of some inner drive. My decisions emerged from a level of depth which I myself was unable to grasp clearly. But once something had emerged into consciousness and taken on a definite shape in my mind, then nothing could hold me back. Then it became almost a game to accomplish the apparently impossible."173

This process of "emerging from a level of depth" addresses exactly the implicit character of human knowledge. The internal truth of the human person renders him a living instrument of certitude. Certitude is not co-equal to understanding. I may be certain of something as a whole, although I cannot explain the detailed grounds of my certitude. ${ }^{174}$ There is something powerful in the human person, in respect of his degree of integrity, that, despite the intricacy of verbal argumentation which he may be too awkward to render, he can stand firmly by what he claims as certain. We are talking here about the law of progress that man gains in real assent and action. It is a living growth, in which man is "born to truth." There are different paths to it, all of them connatural to us, whether we call them demonstration, testimony, speculation or

\footnotetext{
172 Ibid., 275 .

173 E. Stein, Judische Familie, quoted in: W. Herbstrith, Edith Stein. A Biography, 30-31.

174 Cf. J. R. Connolly, John Henry Newman. A View of Catholic Faith for the New Millennium, Lanham: Rowman \& Littlefield Publishers, Inc., 2005, 56.
} 
evidence. The point is to discern at which moment we find ourselves. Newman then steps in with his, naturally Augustinian, proposal, i.e. we need overruling Providence to guide us safely through all these intricate paths. I understand this as follows: man should not place too much hope in his solitary efforts in finding the way. I mean it is our personal task, but we are never alone, we are surrounded by numerous exemplars and inspirations in the bosom of the Church.

And the final stage of our faculty of judging and concluding is the Illative Sense. In his rendition of the latter, Newman not only refers to Aristotle's phronesis, but also to the logic of transcendental phenomenology. As we know, in phenomenology we focus on a double manner of understanding objects. First, we have the natural world, that thing of nature that is "one and the same for all individuals who encounter it," and then "the thing as it presents itself to the individual encountering it at the moment."175 I think there is a parallel between what Stein calls the coherence of constituting consciousness and constituted objects and what Newman called connaturality. This coherence or connaturality exists differently with respect to whether the mind is considering the physical world or the spiritual world. Newman rightly observed, apart from the objective existence of a given object, there is, parallel to it, its subjective presentation, i.e. the object is somehow present to me, and its presentation (not to be mistaken with its existence) is unlike that to someone else.

Newman defines this personal path in the following manner: "The authoritative oracle, which is to decide our path, is something more searching and manifold than such jejune generalizations as treatises can give, which are most distinct and clear when we least need them. It is seated in the mind of the individual, who is thus his own law, his own teacher, and his own judge in those special cases of duty which are personal to him."176 The Illative Sense is akin to an acquired habit. This habit, matured by practice and experience, is not a theory of what duty is and how it should be understood, but "it is a capacity sufficient for the occasion, deciding what ought to be done here and now, by this given person, under these given circumstances." 177 Therefore, it is very personal, concrete, and individual. Each individual has this ruling principle in himself, and if he is still uncertain, he appeals to someone else. Newman claims that we follow living examples rather than theoretical conclusions. There are as many kinds of phronesis as there are occupations. One person may excel in

\footnotetext{
175 E. Stein, Philosophy of Psychology and the Humanities, trans. M. C. Baseheart, M. Sawicki, Washington D.C.: ICs Publications, 2000, 4.

176 J. H. Newman, Grammar, 278.

177 Ibid.
} 
one area and turn out to be a complete failure in another (and we remember the examples of Newton and Napoleon, as given by the Cardinal). As Newman rightly observed: "A good man may make a bad king; profligates have been great statesmen, or magnanimous political leaders." ${ }^{178}$ In all these areas of practical activity, we use our skills and sagacity. He even calls them instinct or inspiration. In concrete matters, we follow the logic of thought rather than the logic of language, the logic of thought being more subtle and elastic. And Newman compares its procedure to modern mathematical calculus. The essence of the latter is that we sum up the infinitesimal parts (those elements that cannot be measured) into one whole.

\section{Intuition versus Reasoning}

I think that we may be right in claiming that there are similarities between the way Newman interprets intuition, simple assent, and conscience. I would like to put this forward as a kind of thesis, namely, that there is a parallel between obedience to conscience and intuition. In conscience, the first thought is always right, says Newman, and in intuition we grasp the matter at hand in one moment. I do not want to say that intuition is always right, but in like manner Newman does not hold that conscience is infallible, either. The similarity between intuition and conscience consists in their functional immediacy. In intuition, we grasp something in one act, and in conscience we should instantly obey; the main point is the danger of reflection and its attendant rationalization. We know that in conscience rationalization eliminates its dictates and categorical character. The thing is that the person should grow in such functional immediacy, in such readiness to the call of what is right. Any intrusions from reflection may interfere with this readiness. We read in his Philosophical Notebook "that one man sees what another does, that A \& B are alike arises from no comparison \& discrimination of outlines, complexion, feature etc. but it arises from the way in which he, (\& not another perhaps) looks at them. It is a kind of intuition, and hence it is very difficult to separate what is called reasoning from intuition." ${ }^{179}$ Hence, we are constantly reminded that we think and reason with the whole of our person. It is not merely an individual intellect that sifts through separate elements of the problem being studied, but the whole person who intuits about it.

\footnotetext{
178 Ibid., 279.

179 E. Sillem (ed.), The Philosophical Notebook, vol. 2, 75 .
} 
Counter to the rationalist-empiricist view, Newman observes that minds are exposed to "unperceived impressions" (I shall talk about these further on) and such impressions often constitute their composition. Indeed, we have in our minds unperceived impressions which we cannot explain, as well as concepts which we can account for. The religious idea, the living idea, appears in our mind not primarily as a concept, but as a reality. For example, we could say that the situation resembles a hurried glance at something: we have seen it, but do not know precisely what it was. Certainly, we know it was real. We come to meet it half-way by being open to it, via an intensive quest for that which we have thus cursorily perceived. Something impresses our mind, arouses it, alarms it, and takes possession of it. The living idea touches the mind, penetrates the mind from the inside and is entirely different from a mere report of sense data, or from a response to sense data. It is profound, it is reliable, although we may not be able to give an account of it. Even Edith Stein, after having assented to the truth of what she had read, would not have been able to explain why, or to define what actually was the truth. Growth in this sense would mean a readiness and openness to be thus possessed. In order to avoid misunderstandings, as the word "openness" has become very fashionable these days, that openness in Newman's context is openness to God's words.

The "activity of our reflexive powers" implies a process by which to arrive at secondary ideas, i.e. the creation of our minds, but, unlike for the empiricist, for Newman an explicit form is not necessary. Locke would call it enthusiasm and, in fact, an irrational attitude. Newman thereby postulated his own form of the objectivity of the religious idea: it is objective although not conceptually apprehended. What is necessary for true growth in religious matters is realisation and possession on the part of man. The religious state of mind, if I may say so, is thus akin to mysticism and poetry. It seems that Newman alludes to the mystic experience of the desert, of emptiness, and of impenetrable darkness. Despite this state of confusion and conceptual obscurity, the religious person moves forward.

Our inward knowledge is real and permanent and distant from confession, it "unconsciously supplies the mind with spiritual life and peace."180 An unperceived impression, we may infer, stands in opposition to a perceived impression. The latter is an impression that is derived from a well-known experience and has been processed by our reflexive power. Newman challenges the wellknown rationalist-empiricist paradigm of the origin of knowledge reduced only to scientific knowledge, which is especially inadequate when applied to

$180 \quad$ J. H. Newman, University Sermons, 322. 
human nature. Such principal terms as "Person," "Substance," "Incarnation" are hidden to us, that is, we use them in our language, but their contents are hidden. We come to anticipate them darkly through our senses, but we can never entirely grasp their meaning. For Kant, as we know, they are also hidden and incomprehensible, therefore he postulated them as categories of practical reason. Kant's proposal is, here, a special kind of ruse. The sphere which theoretical reason fails to reach can become a postulate of practical reason. When Newman distances himself from reason, he does not refer to that which is irrational, but rather he is aware that, due to the insufficiency of reason, the reality of the person transcends what pertains to reason. Thus, Newman distinguishes the world of notions and the world of reality, not in order to set these two worlds in opposition, but in order to show their essential otherness and, at the same time, complementariness. Man uses notions he defines since, otherwise, he would not be able to develop science. Science, by its nature, should be an area of intersubjective comprehension or intelligibility, as the metaphysician would say. Otherwise, common research would not be possible for those people who pursue science; it would not be possible to know it.

\section{$25 \quad$ Faith and Reason}

The world of reality is different than the world of science and theory, especially in the area of faith and morality. It eludes the reductive function of notions; it calls not so much for knowledge and definition, as for an answer, action, experience, and commitment. It is a world that cannot be ignored with aloof or despondent neutrality, a world that has absolute claims to its truths, for it concerns the whole of man, his ultimate goal and destiny. There are realities here that are impressed on our minds, but not in the form of clear-cut concepts, categories or judgements in the first place. Rather, we approach them when we react like children, "for what is short of truth in the letter may be to them the most perfect truth [...]." 181 If we were to compare Kant and Newman in this respect, we might imagine that Newman's response to Kant's dilemma would be the following: yes, this is true, our reason is helpless to conceive of such things, but it is not reason that confronts them but the person. We do not have to posit anything, we have to open our minds and hearts. It is not the capacity of our mind, or the vastness of our imperatives that make up for the insufficiency of our knowledge in religious and moral matters, but the extent to which we

181 Ibid., 341. 
can confide in Him who is the Person. It matters much to what extent we can unfold ourselves and allow ourselves to be possessed. Likewise, we are always called upon not to reason, but to trust, to follow, and to bear witness. Reason is ultimately guided by Faith, when "it is content to be a little child [...]."182 The line of progress in Newman runs towards simplicity. His concept of simplicity, however, is completely different to Rousseau's. Newman does not assume that human beings are primarily pure and innocent. On the contrary, man is primarily weak and sinful, a creature that is apt to rebellion and in need of conversion. Conversion is supposed to occur not by dismantling the whole social order in a revolutionary coup, but through self-transformation. Metaphorically speaking, Rousseau is presented as starting as a child; Newman is ending as a child. In his view, man strives towards childhood till the end of his life. I think we may call Rousseau's ideal childishness, and Newman's humility.

This is a very interesting point. As we can see, for Newman, unlike for Enlightenment thinkers, we arrive at certain knowledge-in practical matters - individually, not when we rise to the universal level of reasoned notions. And certain knowledge is co-equal in Newman with persons who are certain of something, and this, in turn, does not mean that they rise to the point of clarity and distinctness of concepts. On the contrary, they often fail the test of notional clarity and distinctness, as we expect them to give reasons why they hold to some truths. Therefore in our interpersonal relationships we have to always take it as a matter of fact that, aside from the universal fabric of what is commonly shared by virtue of universal logic, there are principles and values which other people hold, but which are incommunicable and yet remain the source of their inner life. In reasoning, they then appear more important than impersonal rules. (If two people from the same house or the same street are so different, so much more different are those who belong to two different cultures). The end-process of progress for Newman would be persons who are certain of how to act well, not persons who can define a good act. Newman's reasoning in these matters borrowed much from the romantic school, the Alexandrian Fathers, Augustine, the Oriel Noetics, and, above all, the phronesis tradition that went back to Aristotle. In this tradition was grounded Newman's illative sense, which has already been mentioned, according to which, in our thinking, we rely on "implicit reasoning" and "implicit inference," "natural inference." To be more precise, we might even speak of personal reasoning and personal inference. ${ }^{183}$ Newman literary calls it "personal reasoning" in his

\footnotetext{
182 Ibid., 351 .

183 Cf. E. E. Kelly, Identity and Discourse, in: G. Magill, Discourse and Context, Southern Illinois University, 1993, 47.
} 
Grammar of Assent, of which mention has already been made. As we can see, we are elaborating here on Newman's phenomenology (or hermeneutics) of thinking.

This spontaneous process of development that has been discussed here is derived from the fact that, as individual persons, each of us reasons differently. We have different, "cogitative methods," as Newman called it, and "the territory of thought is portioned out in a hundred different ways." 184 Much of our mental endowment depends on the principles we hold, rather than on the universal rules of reasoning. Thus, different people may interpret the same facts of experience differently. This does not mean that we are completely in the dark as to what is true or false in development, that our cogitative method cannot be put to the test. In other words, much can be said about the value of life, but words are always inadequate and far inferior to one simple deed of courage when, for instance, someone offers his life for someone else.

This state of affairs is aptly rendered by Edith Stein's phenomenological analysis. I mean here especially her thoughts on the relationship between belief and faith (fides) and this particular situation where belief is transformed into conviction and becomes close to fides. The latter term means to take a stance, one's own act, a thing that ideally corresponds with Newman's term realize; it is not an established opinion, but a personal response.

\section{The Explicit versus the Implicit and Being Possessed}

This thrust of ideas and their realization are closely related to another of Newman's term, namely that of possession, or rather of being possessed. The state of being possessed is, in turn, related to the two levels existent in the person: explicit and implicit. I have already alluded to this issue numerous times in this work. I mean the essential discrepancy between the person's belief and his capacity to account for this belief in an intersubjectively comprehensive message.

As we know from this text, in order to assent to the truth we do not have to acquire a complete command of the idea that is presented, for the obvious reason that the idea is often too complex to be grasped in toto; furthermore, it may be of a dynamic nature and, under the process of development, it contains elements which are there and elements which are to become. Certain aspects wait to become unfolded by personal experience, discovered rather than conceived.

184 J. H. Newman, University Sermons, 344. 
It is not the intellectual structure of the idea, however, that determines our assent, but its life-such is Newman's definite conclusion. Undoubtedly, Christianity is such an idea, therefore it is capable of possessing people's minds, to enflame them and to be conveyed from one person to another. Our comprehension, being more or less clear, can facilitate our assent, but does not necessitate it. If it did, only those who were intellectually knowledgeable would stand a chance at accepting what is presented to them. Newman is obviously referring to his text about consulting the faithful in matters of doctrine. ${ }^{185}$ This consulting does not mean actually asking the faithful, but rather observing their genuine experience of faith, especially in its historical context. Newman was amazed at the fact that in the past, when various heresies would put the educated divines off their orthodoxical doctrine, the simple believers could stand firmly by their faith.

In his University Sermons, he observes that "the inward idea of divine truth [...] passes into explicit form by the activity of our reflective powers, still such an actual delineation is not essential to its genuineness and perfection."186 A simple and uneducated believer may not be able, and he often is not, to provide a formal demonstration on behalf of that to which he has assented. Newman adds a yet more radical characterization: "But what is remarkable at first sight is this, that there is good reason for saying that the impression made upon the mind need not even be recognized by the parties possessing it. It is not proof that persons are not possessed, because they are not conscious, of an idea. Nothing is of more frequent occurrence, whether in things sensible or intellectual, than the existence of such unperceived impressions." ${ }^{187}$ And here we arrive at yet another key term in Newman, i.e. being possessed. When we possess something, we can retain a certain safe distance between the thing possessed and the possessor. It is an intellectual distance filled in by reflection. But in the case of being possessed by something, such a distance disappears. We are in the hands of an idea, if I may say so somewhat metaphorically. Indeed, Stein's confusion after having read Teresa of Avila's book or seen Mrs

185 I mean the revolutionary text published in the Rambler (July, 1859 - interestingly enough, in the year of Darwin's publication), entitled On Consulting the Faithful in Matters of Doctrine. Monsignor George Talbot (1816-1886) should be especially mentioned here as the person always rushing to report to Rome on what was going on in England. The Church was not ready yet for the elevated role of the laity (she had to wait until the Second Vatican Council). And to Bishop Ullathorne's impertinent (with a marked aloofness) question "Who are the Laity?" Newman answered "that the Church would look foolish without them" (See M. Trevor, Light in Winter, 201).

186 J. H. Newman, University Sermons, 320.

187 Ibid., 321. 
Reinach or noticed the simple woman praying in the church—all of which are unperceived impressions - leaves the reader, the onlooker perplexed but not knowing why. A living idea exerts such impressions; they are powerful but not comprehensible, because they are not products of an individual mind!

When a living idea gets into one's mind, it begins to operate within, but it is too rich to be grasped. It is "commensurate with the sum total of its possible aspects," which vary "in the separate consciousness of individuals." 188 Various minds react to it in different ways. In respect of this idiosyncratic compliance, the idea, for some minds, appears to be real, for others, not. Indeed, we perceive an individual mind inasmuch as we perceive an object, i.e. from its various sides. Then, after an examination of its numerous aspects, they are consolidated and brought into one object, i.e. the dogmatic structure of the Catholic faith, for instance.

A real idea cannot be exhausted. If it is complex and contains many aspects, they can be, in turn, analysed separately. Christianity, for instance, contains a plethora of aspects, as I have already said, for it is "dogmatical, devotional, practical all at once; it is esoteric and exoteric; it is indulgent and strict; it is light and dark; it is love, and it is fear."189 A living idea may contain elements which, on analysis, are even contradictory; its task is to give life, not to satisfy the intellect. When an idea is capable of arresting and possessing the mind, it is said to have life, "to live in the mind which is its recipient." 190 Mathematical ideas cannot be said to be called living, although-let us admit - there are mathematical problems, e.g. the theory of prime numbers, which have held many minds in their grip. Newman claims that only great ideas which concern human nature can be called living. He writes: "when some great enunciation, whether true or false, about human nature, or present good, or government, or duty, or religion, is carried forward into the public throng of men and draws attention, then it is not merely received passively in this or that form into many minds, but it becomes an active principle within them, leading them to an ever-new contemplation of itself, to an application of it in various directions, and a propagation of it on every side." 191

Only to such ideas are we ready to devote much time by returning to their original thrust in contemplation. Such are the great philosophical ideas on human nature or the rights of man. They arouse interest and stir up emotions; in a word, they create commotion. Let us look at how the author beautifully

188 J. H. Newman, The Development of Christian Doctrine, 34.

189 Ibid., 36.

190 Ibid.

191 Ibid. 
characterises Christianity which-as he says- "differs from other religions and philosophies, in what is superadded to earth from heaven; not in kind, but in origin; not in its nature, but in its personal characteristics; being informed and quickened by what is more than intellect, but a divine spirit."192

Persons are often baffled about the ideas they have. Their minds remain under a gradual and tranquil expansion. There is no abrupt revolution, but a steady process of "the development, in explicit form, of what was already latent within it." ${ }^{193}$ Indeed, our hesitation about Newman's being a mystic or not can readily be solved by this quotation from his University Sermons, in which the future Cardinal describes what is otherwise well-known from mystical experience: "Moreover, it is a question whether that strange and painful feeling of unreality, which religious men experience from time to time, when nothing seems true, or good, or right, or profitable, when Faith seems a name, and duty a mockery, and all endeavours to do right, absurd and hopeless, and all things forlorn and dreary, as if religion were wiped out from the world, may not be the direct effect of the temporary obscuration of some master vision, which unconsciously supplies the mind with spiritual life and peace." ${ }^{194}$ This picture perfectly fits that which, in other contexts, is described as the mystical night. A person who is supposed to assent to the truth is actually going through darkness in his life. Therefore, Newman concludes that "the reality and permanence of inward knowledge [is] distinct from explicit confession." 195

Let us also observe in passing that in the case of divine truth, all minds are simple and uneducated. This seems to me to be simply a logical conclusion drawn from the consideration of the nature of what is divine. If a finite being is confronted with what is infinite, there is no gradation. No matter how many steps a person takes towards the palace of knowledge, he has barely managed to comprehend it. Therefore, I would like to put forward the following theses: when Edith Stein really assented to what she had read, it was not her intellectual prowess that helped her assent, but the simplicity of her personality. It was not her educational preparation that had set the scene for acquiescence, but her personal transparency. This point will be discussed at greater length when we talk about the abyss of existence.

\footnotetext{
192 Ibid., 57.

193 J. H. Newman, University Sermons, 321.

194 Ibid., 322.

195 Ibid., 323.
} 
Edith Stein excellently and succinctly explained how she understood the place of reason in concrete matters in her letter to Roman Ingarden. We read in this letter: "It seems that first, using the intellect, you have to approach the limits of reason and then come to the door of mystery. Perhaps Newman can help you with it, although his point of departure is quite different. In any case, I will send Letters and Diaries as soon as it is printed.

I hope it is perfectly clear that it is not my intention to describe my way as the way. I am fundamentally convinced that there are as many ways to Rome as there are human minds and hearts. Perhaps the intellectual way comes off badly with the representation of my way. In the years of preparation for my conversion it had a strong influence on me. However, realistically considered, not 'feelings' but real events, along with the concrete image of Christianity in the words of witnesses (Augustine, Francis, Teresa), were decisive for me. However, how shall I describe for you in a few words an image of each 'real event'? An infinite world opens up something entirely new when you once begin to live the interior instead of the exterior life. All prior realities become transparent; the genuine sustaining and motivating strengths become perceptible. Previous conflicts become trivial! The individual comes to understand a life filled with passion and blessedness that those living a worldly life do not know and cannot grasp, something that from the outside appears as the most uneventful day in a totally inconspicuous human existence. And how strange it appears when you live among those who see only the superficial and never notice anything else in the world around them."196

Let me stress several points from Stein's letter. First, she does not want "to describe her way" as "the way." This is a very Newmanian approach in which every person is responsible for his own choice, which he must realize in himself, rather than blindly following someone. Second, despite the importance of the affective side of the human being, it is not "feeling" that drove her on, but a "real event," another beautiful recapitulation of the strong theme shared by Newman and Stein. And, third, the "real event" can hardly be rendered in the form of an intellectual representation. Indeed, Newman expressed his helplessness to describe what drove him on by simply asking: "What have I done thus to be deserted, thus to be left to take the wrong course, if it is wrong?"; nor was Stein able to explain why her emotions were aroused on seeing peace in Reinach's widow's face, the simple woman sunk in prayer, or when reading

196 E. Stein, Letters to Roman Ingarden, 259-26o. 
Teresa of Avila's text. Such were their real events and such were their personal responses, but it would be impossible to precisely account for their place and time. They were lone wanderers under the burden of their personal responsibilities. Of course, she could not describe in words what struck here as unperceived impressions - it was real, but incomprehensible.

Newman, for his part, reflected on the question of reason and its limits in the Philosophical Notebook. There is an entry under the symbolical date of 1859, the year in which Charles Darwin published his renowned Origin of Species. The point was to distinguish between things which are against reason and those which are beyond reason. He opens his considerations with a quote from St Thomas Aquinas. Things that are against reason cannot be "repelled," and things that are beyond (above) reason cannot be "solved or explained." Now, an objection that is unrepellible is against reason, and a question that is insoluble is above reason. We need to distinguish between the questions that are unrepellible and those that are insoluble. The insoluble question is above reason. There is nothing in the Christian Faith that is against reason, therefore there are no objections against it which cannot be repelled. At the same time, there are many things which are above reason, therefore there are many questions about it "which cannot be solved or explained." 197 Moreover, Newman argues that we need to distinguish between "unanswerable" and "perplexity." There are no questions which cannot be answered, hence there is nothing in Christianity that is repelling, although it may be difficult to understand. Here, again, we meet the fundamental word "system." When talking about Christianity, we should not be dealing with its fragmented elements in isolation from the whole of it. Therefore, in the sense of "answer" any objections against Christianity can be "answered." If it were not possible to "answer" them, they would be against reason. At the same time, "there are many $[\ldots]$ < questions about $>$ the Christian faith which cannot possibly be answered, and if they all could be answered, there would be nothing in the Christian Faith above reason." This problem results from the imperfection of our human intellect. The intellect cannot reach "those truths by which the questions about the Faith are duly explained or solved." Therefore, Christianity is not against, but rather above, reason: supra and non contra rationem, the token of the insoluble question and the untenable objection. ${ }^{198}$

197 E. Sillem (ed.), The Philosophical Notebook, vol. 2, 101.

198 Ibid., vol. 2, 103. 
We have inside us this "instinctive sense" of, or faith in, other testimonies "on which to ground our certitude."199 The reason for this is that we confide in what we hear, rather than doubt everything until a clear and distinct demonstration is granted. Our natural condition is that we are not faced with clear or distinct ideas, but with antecedent probabilities, as we have already said. We can assent to truth despite mere probabilities, owing to our personal sense of integrity. Chaos or disintegration is not necessarily something entirely negative. We can always treat it as a chance to grow, to pull ourselves together no matter what happens, because we can confront the unpredictability of events with the vastness of the abyss of our existence.

Newman has often been accused of egocentrism, that he is writing only about himself. I think such an objection is incredibly oversimplified and based on a complete misunderstanding. I would rather talk about his, almost religious, respect for the sanctuary of the human person and regard for human limitations. How could he have learned respect if he had ignored his own limitations? And, examining his own life, he had learned patience and humility. We can most adequately summarize his position in the following question: what could we be, if we only realized what we are? But the point is that each person is placed within his own ethos. He needs to comprehend it in order to respond to a given circumstance. Because we do not know exactly the basic structure of someone else's ethos, we may rightly call it a shadow or a being hidden in his own shadow. Therefore, Newman writes "that every being in that great concourse is his own centre, and all things about him are but shades [...]. He has his own hopes and fears, desires, judgments, and aims; he is everything to himself, and no one else is really any thing. He has a depth within him unfathomable, an infinite abyss of existence; and the scene in which he bears part for the moment is but like a gleam of sunshine upon its surface."200 This beautiful passage perfectly renders what Edith Stein defined as primeval life, and of which I shall talk later. What is this centre from which decisions come? Is it our good nature, as Rousseau put it? Is it practical reason, as Kant wanted it?

If the individual is "the abyss of existence," as Newman claims he is, how can this abyss express itself through a concrete form? And how can the infinite find a concrete form? A form that is, of necessity, finite. The abyss of freedom is in quest for a form. Only through a frame, imposed on chaos, can the individual

199 J. H. Newman, Grammar, 237.

200 J. H. Newman, Parochial and Plain Sermons, 779. 
make his or her life meaningful. And if the individual is "an abyss," nothing short of an abyss can give it the form. The abyss, by definition, is unnameable. It is indeed a great challenge to place the abyss of existence within frames. They must be co-equal to the task at hand. The conclusion is logical enough: the human abyss of existence must be placed within the frames of God's abyss. Otherwise, the infinite can never be squeezed into a finite form. Man is a mystery to himself. This mystery can be grasped only by Someone who is capable of penetrating all the intricate, idiosyncratic pathways of the unfathomable human abyss.

The American Newman scholar, John Crosby, who comments on this passage in his book The Personalism of John Henry Newman, refers to the infinite number, in itself a proper analogy in the context of Newman, as the Cardinal was interested in mathematics. Nothing can be added or deduced from the infinite number. Therefore, the human being, in his relationship with the world, is like the infinite number in relation to the finite numbers. Everything that we experience, everything within the range of the empirical I- to use Kantian parlance-is indeed nothing in relation to human infinity. It is "like a gleam of sunshine." In order to bring this infinity round to action the centre must rule over the vast area of hidden (implicit) shadows. Speaking somewhat metaphorically, we can say that the infinite actor plays a finite role. How can one rule over infinity? Or, does one have to? Not by accomplishing certainty from without, but by arriving at certitude within. Infinity, by its nature, cannot be placed within finitude. We are surrounded by a set of infinite existences. For matters of simplicity, we treat each human being as a set whole, but it is a composite rather than a solid figure (a welldefined exemplar of a larger whole). When Newman uses the word "whole" in the context of the human being, what he means is that man can make himself a whole when integrated. Again, let me resort to mathematical or even physical analogies. We are dealing here with quantum mechanics, with infinitesimal magnitudes. They can be expressed by mathematical formulae but cannot be measured.

Certainty cannot grasp "an infinite abyss of existence," because the former contains a rigid formula; it is the Newtonian world. The abyss, for its part, flows out, exceeding the limited frames; it belongs to the medium of infinitesimal magnitudes. Its shapes overflow.

Which of these cases fits Stein's assent to the Christian truth after she had read Teresa's book? What is the precondition for her assent? I think that the foundation is the fundamental simplicity and inherent reality that create the potency for the act of real assent. Any person who has been real has a chance to thus assent. I understand inherent reality as internal undividedness. 
And the phrase "has been real" must be understood as "using real words" in Newman's sense.

\section{The Real versus Unreal Words}

This section studies the discrepancy between the words and images, between the notions and reality. Jean Guitton perfectly characterises our times when he writes: "Our civilisation oversaturated with knowledge and means of knowledge offers so many masks and false supports that man no longer knows what he knows and does not know."201 The French philosopher is naturally writing about the twentieth century, but these negative tendencies diagnosed then are even more pronounced today. The old revolutionary battle cry écrasez l'enfâme, which, during the French Revolution, was aimed at the absolutist aristocracy, in the twentieth century was turned against the bourgeoisie and erupted in the 1968 revolt. As it usually happens with all revolutions, they are based on several naïve presumptions among which one prevails: it is enough to remove the wrong form in order to dig out the good man from under the rubble of falsehood and pretence. Such is Rousseau's immortal illusion. Newman's response to that would be simple: it will do no good to change the external form, man must bring out his true self. The revolutionaries go by way of opposites, which is hardly ever a good solution. If the old (bourgeois) society respected certain codes of behaviour, let us have no codes; if they venerated tact, shame, and secrecy, let us proclaim openness and shamelessness. If they insisted on limitations, let us opt for absolute freedom (even though they call it licence). In such circumstances, false words abound, and lofty declarations are plentiful. It is true that abuses must be denounced, there is no doubt about it, but they cannot be cured by the method of substitutive oppositions.

Since we are immersed in shadows, it is only right to ask about our real whereabouts: where are you talking to me from? Are you really there? And the words you are formulating, are they really yours? Do they belong to your interior, to your true self, or are you merely repeating foreign words? What do the words reflect? Are they someone's words or merely general opinions? What is their context? Their ethos? Does the speaker live in reality, or only aphoristically — to use Kierkegaard's term? Such are the words designed to test the reality and place of the speaker. They tend to settle whether the speaker is

201 J. Guitton, Le travail intellectuel : conseils a ceux qui étudient et a ceux qui écrivent, Paris: Aubier, 1951, l, 14. 
really present in the reality he is telling us about. Or else he is merely looking at something which, for him, is inaccessible because he himself does not believe that he could stand by the reality he is talking about. And even if he criticizes something, i.e. he is expressing a negative opinion about a reality in which he would not like to participate, we still do not know whether he means what he is saying. When we speak words that give lie to what we really think, we pronounce unreal words.

The history of mankind can be viewed in this way that, for instance, original sin, the first fall, can be regarded as the first moment of unreality. The story of the first fall is paradigmatic unreality - the ideal type of all unrealities. The first man wrought a kind of cleavage between words and their meaningthe essence of how Newman understands unreality. Adam heard the question: 'Adam, where are you?'. And he answered, contrary to the facts: 'I have hidden myself because I am naked. ${ }^{202}$ Such is the origin of paradigmatic unreality and paradigmatic lying for all the future generations to come. Adam knew that nakedness was not the main reason for his hiding (as if man could hide from God!), nor did he know the meaning of nakedness, that it was something to be ashamed of, something that should be hidden. With this unreality, man came to the false conclusion that he could cover all embarrassing situations with unreal words. Thus, he ushered onto the stage of human history deception, distortion, and equivocation. As his behaviour was censored for that, he ultimately invented a non-judgmental attitude and political correctness as the mark of obligatory decorum. And he learnt not to treat his life too seriously. Life is just a game to be played for others or for oneself. To have fun, to amuse oneself, and to amuse others, other actors. In this manner, the story of unreality unfolded.

The gap between the real and unreal words may come from the fact that we often hear that sublime doctrines should correspond to the like feelings. And, in this context, the Romantic poet writes down the accusation of the false poet: "Thou playest to strange ears of unconceived delights ... Thou drawest forth tears. But thou thyself, what feelest thou? What dost thou create? Through thee floweth a stream of beauty, but thou art not beauty. Woe unto thee! The child that weeps on its nurse's bosom, the flower of the fields that is unconscious of its fragrance, have more merit before the Lord than thou."203

\footnotetext{
202 Cf. Gn 3:8-10.

203 Z. Krasiński, The Undivine Comedy, quoted after Monica M. Gardner, The Anonymous Poet of Poland Zygmunt Krasinski, Cambridge: At the University Press, 1919, 95-96. A classic example here is Jean Jacques Rousseau, who sent all five of his children to an orphanage, whereas, at the same time, he produced sublime, noble treaties on education in which he stressed the importance of sacrifice, self-sacrifice. And no wonder that Rousseau comes
} 
These words come from the pen of one of the great Polish romantic poets, Zygmunt Krasiński (1812-1859). In his The Undivine Comedy we find this clash, this inadequacy between words and deeds. The Philosopher from Krasiński's drama is a porte-parole of the Enlightenment encyclopaedists who ardently believed in human progress. It is interesting that the Polish romantic poet calls his belief "self-willed belief," 204 a phrase that emphasises human self-will, rather than religious belief. ${ }^{205}$ We must remember that, for Newman (and this places him outside the circle of fideists), the act of faith is a special (personal) intellectual act.

We sooner learn the doctrines than their attendant feelings. Newman was well aware of this psychological regularity. This is one of the reasons why professions are often not accompanied by attendant feelings. In the Parochial and Plain Sermons we read that man knows about the necessary association between doctrines and feelings. "But in truth he perhaps does not really believe them absolutely, because such absolute belief is the work of a long time, and therefore his profession of feeling outruns the real inward existence of feeling, or he becomes unreal." And then the author formulates his warning: "Let us never lose sight of two truths, - that we ought to have our hearts penetrated with the love of Christ and full of self-renunciation; but that if they be not, professing that they are does not make them so." ${ }^{206}$ In like manner, people speak about the shortness and vanity of life, using commonplaces because so they think this is expected of them. Profession outruns our emotions because real feelings take time. We should look at things, not words. "There is but one right way; it is the way in which God looks at the world." ${ }^{207}$ This conclusion is very Augustianian in nature. Newman calls for sincerity and authenticity, in which we say what we mean and we mean what we say: "Let us aim at meaning

across here as a negative example, because he himself stressed the importance of loving the group at the expense of the individual.

204 Ibid., 203.

205 I am proposing here the phrase "self-willed belief," because the 1875 English translation "intuitive conviction" does not render exactly the meaning of the Polish phrase, which is "samowolna wiara." This phrase perfectly fits Newman's criticism of the general tendency to be guided by pain or pleasure, and his criticism of the counterfeit of conscience, which has already been mentioned. Furthermore, the phrase "wilful belief" may suggest here the Protestant understanding of Christian faith in which the principle of sola fide is dominant and the process of the privatisation of religion is well under way. The "self-willed belief" can only be present where the individual relies on his own private opinion rather than on the teaching of the Church. It was extremely important for Newman to always think within the bosom of the Church.

206 J. H. Newman, Parochial and Plain Sermons, 975.

207 Ibid., 978. 
what we say, and saying what we mean; let us aim at knowing when we understand a truth, and when we do not."208 In Grammar of Assent, Newman's accusatory voice resounds in his words when he writes: "We sometimes find men loud in their admiration of truths which they never profess." ${ }^{209}$ And in one of his sermons he notes that people "do not really dwell on what they profess to believe." 210 There are two reasons for this: we can blame the agent for his superficiality and ignorance, or else this inadequacy results from the very nature of the matter given to consideration. What we can deduce from the importance of real words is that the most important thing is to avoid the dubiousness that sneaks in between the subject and the object. The subject can be in error, but should never be divided inside, i.e. he should never intentionally lie as to his real attitude. Inasmuch as we elaborate on the sacrifice of expiation and account for it in many words, we still do not know why this was necessary.

I would like to explain what I mean by way of illustration. Let us imagine a ladder. Each rung of the ladder denotes a word. The real word is the rung on which we are actually putting our foot. This rung is my reality. Not only do I pronounce a single word, as I am ascending the ladder, but I am physically touching it, feeling it or, rather, feeling the reality hidden behind it. Some rungs are below me - they are no longer mine; some rungs are above me-they are not yet mine. The past should not be mixed with the future, and the present must be acknowledged. Obviously, the past is present in memory; the future is present in hope. Memory and hope must not be replaced. The difference between real and unreal words resembles our considerations on the use of the word ergo in inference. When ergo is used merely in its logical sense, barely touching the person, it can be actual without being real; it is formally present, but is devoid of any substance. Therefore, ergo (like the unreal word) can be only superficial (notional) without being real.

That is why he delved into himself, devoted himself to writing letters, and committed his literary talent to Apologia pro Vita Sua. This particular introspection into oneself had nothing of a display or a showcase. Rather, Newman sought to probe whether he was real in what he was saying, whether he had realized what he decided to teach. Newman wrote his Apologia not to prove he had never made any mistakes; such a task would be futile and, in fact, dangerous, for it would bring forth the poisonous fruit of pride. He wrote in order to find out whether he had been hypocritical in his words or deeds. And he found no guilt in his conduct (which does not mean that it was infallible); let

\footnotetext{
208 Ibid., 979.

209 J. H. Newman, Grammar, 142.

210 J. H. Newman, Parochial and Plain Sermons, 1227.
} 
us repeat again that it is better to be the sincere persecutor Saul than the false apostle Judas.

John Henry is thus trying to bring this message home to his former Anglican brethren who accused him of betrayal and opportunism, and to his actual Catholic fellow-believers who might doubt his sincerity. ${ }^{211}$ Prison wardens say that the most difficult thing is to witness change in petty thieves; it is easier for murderers. The thieves have a tendency to belittle their guilt, to explain it away, or even justify it. After all, they stole from those who had too much, as they themselves reckoned. Therefore, in the New Testament those who are most harshly reproved are not, if I may say so, sincere sinners, but hypocritical devotees, those who falsely regret what they have done.

\section{0}

\section{Real Adherence (Not Notional), Personal Adherence to the Word of God}

The worst thing is when we use unreal words, an outcome typical of the situation in which one says words contrary to the actual state of one's mind. In one of Fulton Sheen's books we find an apt description of this condition: "Very harmful effects can follow accepting the philosophy which denies personal guilt or sin and thereby makes everyone nice. By denying sin, the nice people make a cure impossible. [...] By refusing to admit to personal guilt, the nice people are made into scandalmongers, gossips, talebearers, and supercritics, for they must project their real if unrecognized guilt to others. This, again, gives them a new illusion of goodness: the increase of faultfinding is in direct ratio and proportion to the denial of sin. [...] It is a fact of human experience that the more experience we have with sin-our own sin-the less we are conscious of it. In all other things, we learn by experience; in sin, we unlearn by experience." ${ }^{212}$

Contemporary man, to use the Kierkegaardian metaphor, is always shrinking from his tomb, from the tomb of his duty, of his authentic existence. He can fulfil his fortune, but he shuns it, always finding excuses. The tomb is the way of the cross for the individual, not Hegelian History or the State. That is the essence of human despair. Hegel claimed that man can fulfil his destiny by

211 When Newman claimed that the Thirty-Nine Articles (the Anglican creed) could be interpreted in a "Catholic" sense, he thereby declared open apostasy and invited revolt on the part of the queen. (See G. St Aubyn, Queen Victoria. A Portrait, London: Sinclair-Stevenson Ltd., 1991, 310).

212 F. J. Sheen, Peace of Soul, New York: Permabooks, 1954, 64. 
being buried in the objective being of the State, i.e. his whimsical individuality can be mastered and controlled within the confines of the objective legal system. Does it suffice? Kierkegaard (1813-1855) protested against this outcome. In order to fulfil our destiny, we need to enter the tomb of our individual fortune, and we can do this. That is why the tomb in the East is filled and happy and the tomb in the West is empty and unhappy. Kierkegaard, therefore, had an excellent insight into all the consequences of what we are confronting at the moment. As Alasdair MacIntyre mentions, the attempts are made "to diminish central Christian doctrine in a way that would make it acceptable to post-Enlightenment culture, the culture of encyclopedia." Such was the post-Cartesian and post-Kantian heritage which, in the late-nineteenth century, sought to subject theology to rationalist standards; this subjection meant "rejecting, modifying, and truncating theism until it became a doctrine acceptable within the framework imposed by the encyclopaedist's unitary and ahistorical conception of rationality [...]." Such attempts must have been taken seriously by Kierkegaard in the first half of the nineteenth century and by Newman almost throughout the whole century. MacIntyre writes: "these recurrent attempts evoked a variety of theological restatements, of which Kierkegaard's and Newman's were among the most notable."213

Let me present an example of this ahistorical approach, an example that appears to be quite common today. There are people who are silent about the orthodoxy within the Catholic Church — for the sake of fear or political correctness - a tendency that is characteristic of a peculiar type of aggiornamento, especially popular with some parts of the western hierarchies in their openness to the contemporary world. Therefore, they resort to some linguistic games instead. Because the word "Catholic" is derived from the Latin "catholicus," they say, and the latter means "general," then "Catholic" can be reduced to "all-inclusiveness," "instant culture," "latitudinarianism," "comprehensiveness of belief." It must be noted that such an attitude had brought the Anglican Church to a deadly standstill in the nineteenth century and created what was later labeled as the "Broad Church." And we come to a paradoxical hybrid, a strange qui pro quo, where all opinions are accepted and the question of truth is suspended. Like in Macbeth, we have a mixture of many elements: fair is foul and foul is fair. A mere linguistic foundation for the Church seems to be a very insecure foundation for a solid edifice as the Church undoubtedly should be. Too broad an approach may certainly satisfy the requirements of a fashionable

213 A. MacIntyre, Three Rival Versions of Moral Enquiry. Encyclopaedia, Genealogy, and Tradition, Notre Dame: University of Notre Dame Press, 2006, 68, 69. 
tolerance, but shall not establish a dogmatic institution. In this maelstrom of proposals, set against the vast panorama of ideas, skepticism may have the final say.

The notional assent introduces us into what Kierkegaard called the aphoristical way of living. He called it "the religion of the aphoristical and the accidental"; we "live aphoristically, we who live withdrawn and segregate, like aphorisms in life, without community of men, without sharing their griefs and their joys; we who are not consonantal sounds in the alarums of life, but solitary birds in the stillness of night, gathering together only occasionally, to be edified by considering the wretchedness of life, the length of the day, and the endless permanence of time; we [...], who have no faith in the game of happiness or the luck of fools, who believe in nothing save misfortune." ${ }^{214}$ Living in aphorisms is living a non-committal life, as Michael Novak calls it. Those who are forever absent live either in hope or in memory. Only those who are present to themselves are happy. The unhappy man can be absent in his hope or in his memory. This penetrating psychological insight into the human psyche is indeed worthy of the most profound consideration.

The most important purpose of our life is to "obtain a correct knowledge of [ourselves]" - such is the fundamental direction of our life. ${ }^{215}$ When we profess great doctrines, we must be well aware whether we really mean what we thus pronounce, for "all those who neglect the duty of habitual self-examination are using words without meaning." 216 The point is then to know, i.e. to realize, the language I am using. Otherwise, "assent to a form of words which declares those doctrines [...] is the same as a real holding of them, and belief in them, then it is equally possible to believe in a proposition the terms of which belong to some foreign language, which is obviously absurd."217 Nevertheless, similar situations are very common. People think that when "they are familiar with words, they understand the ideas they stand for."218 In like manner, some think that the mere repetition of the word "conscience," a word which belongs to common language, makes those who repeat it people of conscience. Selfknowledge is especially crucial in the case of religion and morals. Newman stresses the fundamental importance of examining one's heart first in order to use these words with meaning. He explains it thus: "For it is in proportion

214 S. Kierkegaard, Either/ or. A Fragment of Life, trans. D. F. and L. M. Swenson, Princeton: Princeton University Press, 1949, 179-180.

215 See J. H. Newman, Parochial and Plain Sermons, 31.

216 Ibid.

217 Ibid.

218 Ibid. 
as we search our hearts and understand our own nature, that we understand what is meant by an Infinite Governor and Judge; in proportion as we comprehend the nature of disobedience and our actual sinfulness, that we feel what is the blessing of the removal of sin, redemption, pardon, sanctification, which otherwise are mere words." ${ }^{219}$ We should go inside and "read ourselves," to set about a profound introspection. To know oneself is to plant religion inside. We should rather believe things, than words; "without self-knowledge you have no root in yourselves personally,"220 and to know oneself does not mean to achieve the transcendental level. Professing without understanding is of no avail, and the correct form of understanding is realizing. I shall talk about this at greater length when writing about Stein's primeval life and man's inmost depth. Now let us focus on the question of conscience, one of the strongest themes in Newman, and, naturally, an important point in the issue of the reality-unreality of words.

\section{The Voice of Conscience}

Our natural experience does not lead us automatically to belief, because it may just as well lead us to unbelief. We must start from faith, unless we wish to claim that external circumstances are capable of determining our belief. Therefore, Clive S. Lewis (1898-1963), in the introduction to his book The Problem of Pain, brilliantly recapitulates the time when he was an atheist. Then, his interpretation of the world was entirely different than when he became a believer. And the interesting turning point was the moment of belief, which helped him gain a totally different view of the same experience. The conclusion for Lewis was obvious: it was not his experience that had brought about this change, but his transformed approach. And he notes: "The spectacle of the universe as revealed by experience can never have been the ground of religion: it must always have been something in spite of which religion, acquired from a different source, was held."221

Conscience, for Newman, is such a mysterious faculty that, while heard inside the agent, it is, at the same time, a telling sign of the supernatural. And the conscience is concerned with the particular. Any considerations of Newman are incomplete if there is nothing about the pivotal role of conscience in his pursuits. Conscience is this special place where the natural is

\footnotetext{
219 Ibid., 32.

220 Ibid., 39.

221 C. S. Lewis, The Problem of Pain, London and Glasgow: Collins Fontana Books, 1965, 3.
} 
mysteriously combined with the supernatural, and it is the place of personal encounter, in fact, the most important encounter between man and God.

Conscience is not "a rule of right conduct, but [...] a sanction of right conduct."222 It does not say how to do something, but evaluates whether our action is good or bad. Therefore, conscience does not provide any general rule on how to behave, but is a judgement attendant on our behaviour. We can make errors in our judgements, but this does not mean that we always behave in the same way. The sense of moral obligation and duty is shared by all, but it may be associated with different actions. As Newman stresses, the knowledge that there is a right and wrong is notional, but its application is practical. Conscience depicted as a triangle with the innate element of synderesis and two acquired elements - science and wisdom-is individualized in each case. In other words, as Newman explains, "this sense of a particular judgment or sanction on the quality of [an] action is part of myself in the same way that existence, in the same that sensation, consciousness, reasoning, memory are part of myself, and it is as unmeaning to say that I have faith in it, or blind faith in it, or that it is a law of the mind, as to say that existence is a law of the mind. It is bound up in the very idea or fact of my existence." And the author is not interested in individual differences, with regard to the acquired elements, but in it being "a sanction or command." 223

Conscience is primarily a faculty of judging. Newman enumerates its characteristic features, among which we find "a phenomenon of $<$ my $>$ existence, one of those phenomena, thro' which as I have said, my existence is brought home to me." But, unlike existence, which is brought home to us by virtue of faith, "the accuracy or truth of the praise or blame in the particular case, is a matter not of faith, but of judgment." And he concludes by discriminating two senses of conscience: "the act of moral judgment, or for the particular judgement formed." And, consequently, we have "the foundation of religion" (when the act of moral judgement is meant) and ethics (when the particular judgement is formed). ${ }^{224}$

The moral sense differs from the sense of beautifulness, for instance, for the moral sense is primarily concerned with persons. Yet one more fundamental characteristic of conscience must be mentioned here, namely, the fact that its ultimate authority reaches beyond the self, i.e. the voice of conscience, although it is heard within the self, does not come from the self. Therefore, we commonly speak of conscience as a voice, which is uncommon in the case of

\footnotetext{
222 J. H. Newman, Grammar, 99.

223 E. Sillem (ed.), The Philosophical Notebook, vol. 2, 49; see also J. H. Newman, Grammar, 98.

224 See, E. Sillem (ed.), The Philosophical Notebook, vol. 2, 47.
} 
some aesthetic judgements. Here, the voice usually comes from someone. The voice of our conscience in our decisions "dimly discerns a sanction higher than self for its decisions, as is evidence in that keen sense of obligation and responsibility which informs them."225

Another fundamental element of conscience is that its voice dictates and commands. The voice of conscience has nothing to do with the sense of the expedient or the beautiful. It is authoritative and minatory. Conscience considered as the moral sense is unlike the sense of the beautiful because it is always emotional, whereas the sense of the beautiful is emotional only in some cases. It fills us with awe, remorse and shame. It is something more than a moral sense. In its dictates it is interpersonal, i.e. another person is always presupposed. Conscience stirs our affections, because in its voice another person is being revealed to us, "this implies that there is One to whom we are responsible, before whom we are ashamed, whose claims upon us we fear."226 In the voice of conscience, we have within us the image of some person; we listen to someone speaking inside.

The existence of moral obligation, therefore, is conditioned by the existence of God: "there is a God, because there is a moral obligation." 227 In the same manner, he examines the existence of conscience. "I have a certain feeling on my mind, which I call conscience. When I analyse this, I feel it involves the idea of a Father \& Judge - of one who sees my heart \&c. \&c."228 In like manner, conscience is not impersonal — there is Someone speaking to us — nor is it my private point of view-how could I feel ashamed of my own private opinion?

Indeed, Newman's intuition seems correct here. It would be rather odd to experience any remorse when hearing sounds echoing from somewhere and having no personal sender. And we feel remorse even when in solitude, when there is actually no one around to talk to us. We may even have some Platonic associations when we read in Newman that "the presence of unseen individual beings is discerned under the shifting shapes and colours of the visible world."229

Newman holds that we have this initial knowledge of God, and it is present in children. This knowledge is latent in the mind, it is pre-reflective, but it is difficult to determine how much of it comes from within or without. It depends on each individual and individual circumstances whether this primordial

\footnotetext{
225 J. H. Newman, Grammar, 99.

226 Ibid., 101.

227 E. Sillem (ed.), The Philosophical Notebook, vol. 2, 31.

228 Ibid., 2, 31.

229 J. H. Newman, Grammar, 102.
} 
(residual) knowledge will be strengthened or distorted and obliterated. And even though distortion or obliteration might not take place, these initial sentiments could still turn into mere notional apprehension. The point is, therefore, how to keep this premeditated image of God alive.

As in the case of conscience, we combine fear with shame-the elements present in its voice-so here we seek to join strength with delicacy. Dogma symbolizes strength; it is a stronghold around which there may revolve a personal response. This personal response is obviously called upon to be translated into certitude, and this response is strength, but unlike the original and objective strength; certitude - as we have seen-calls for time. In this sense, it may be identified with virtue. And here we have arrived yet one more time at the point that is most intriguing for Newman, i.e. how is a dogma in each particular case given a personal shape. As in the example with the fan vaulting (in Chapter 2), this dogma is capable of upholding different personal constructions without changing its essence. Each person is constructing his or her personal shapes throughout his or her lifetime. Reason and the heart are conjoined in a most spectacular dialogue. They are placed under one roof-yet another of Newman's metaphor.

We must constantly bear in our mind that Newman is always striving for the integral view of the human person. He is neither inclined towards a rationalism of modernity nor towards a sentimentalism of romanticism. As I have already said, imagination (the power creating images) is important as the initiator of action, but nothing here comes about automatically. Reason is not rejected, but it must be placed within all other personal dimensions. As the Cardinal concisely summarizes his point: "Impassioned thoughts, high aspirations, sublime imaginings, have no strength in them. They can no more make a man obey constantly, than they can move mountains. [...] Conscience, and Reason in subjection to Conscience, these are those powerful instruments (under grace) which change a man. But you will observe, that though Conscience and Reason lead us to resolve on and to attempt a new life, they cannot at once make us love it." ${ }^{230}$ Thinking, and whatever results from its processes, is an area of open options in which when it can be argued in favour of something, it can be made real. Reason is subdued to conscience. Indeed, in his way of comprehending Conscience is not the voice of practical reason (since in that case we would have reason subjected to reason, which would make a tautology), but the voice of God, who is seeking to bring the person onto the right path.

230 J. H. Newman, Parochial and Play Sermons, 76. 
By calling conscience the voice of God, Newman wishes to stress that it is not "a creation of man." 231 Conscience is in us as a judgement, but at the same time not out of us when we evaluate something convenient, fit or beautiful. Newman criticises the claims of psychoanalysis that conscience is but a twist in primitive people, that it is irrational, that the very sense of guiltiness is irrational. If man is but an element in a deterministic series of causes and effects, there is no talking about freedom of will. And if such is the case, there is no responsibility. Consequently, conscience cannot make man responsible for his acts. Certainly, Newman's view of conscience stands in glaring contradiction to conscience viewed as our private and sovereign opinion which cannot be subjected to any sanction. And Newman states that "Conscience has rights because it has duties [...]."232 This is a very important point, for it says that conscience is not a mere private opinion, that it does not refer to itself but to Something else, or, to be more precise, to Someone else. Private opinions have no duties; their duties are enclosed in themselves, and they refer to no one except the self. Conscience, understood in this manner, brings the self back to order; the order that is not conceived nor invented by the self. Conscience therefore, as I have already said, is a sanction because it does not confirm the individual in his belief, i.e. in no way is it a sense of self-complacency. Obviously, since it has duties, it must be reared in duties. And the best context of rearing the conscience in duties is, for Newman, the Decalogue, the Bible, the Sacraments, and the tradition of the Church. But even in this context, conscience, as the voice of God, is not limited or determined. I mean, for instance, those situations of heresy, when lay people saw in their conscience that the hierarchs were wrong.

Conscience's worst enemy is its counterfeit, which Newman calls "the right of self-will." ${ }^{233}$ And Newman defends Pope Pius IX who, in his encyclical Quanta cura, criticises the so-called "liberty of conscience." The Pope obviously did not mean literary conscience, but its counterfeit; therefore, in fact, licence which in certain circles was (intentionally or ignorantly) called conscience.

Newman holds that conscience reigns supreme even when set up against the Pope's infallibility, because the "Pope is not infallible in that subject-matter in which conscience is of supreme authority [...]."234 Moreover, conscience "is not a judgment upon any speculative truth, any abstract doctrine, but bears immediately on conduct," whereas the Pope's infallibility "is engaged on

231 J.H.Newman, Certain Difficulties Felt by Anglicans in Catholic Teaching, London:Longmans, Green, and Co., 1891, 247.

232 Ibid., vol. II, 25 o.

233 Ibid. The term "self-will" reminds us of "self-willed belief." (see a previous footnote).

234 Ibid., 257. 
general propositions and given errors." ${ }^{235}$ Outside of this area, the Pope may announce his decisions, e.g. administrative, but they are not infallible.

Yet one more thing must be mentioned in this characterisation of conscience, as we find it in the pages of Newman's writings. He observes that each science has its certainty in itself. We proceed from undeniable premises to general truths by way of induction. Indeed, this is what we do, in particular in the natural sciences. The sense of right and wrong, another name for conscience, "is the first element in religion, is so delicate, so fitful, so easily puzzled, obscured, perverted, so subtle in its argumentative methods, so impressible by education, so biassed by pride and passion, so unsteady in its course, that, in the struggle for existence, amid the various exercises and triumphs of the human intellect, this sense is at once the highest of all teachers, yet the least luminous [...]."236

This is an excellent diagnosis of conscience and an insightful analysis of its position in human moral knowledge. Important as conscience is, Newman realistically assesses its capacity, and, therefore, the Church and her institutions in supplementing its inadequacies. Conscience does play an essential role in Newman's grammar of knowledge, but we are constantly reminded - as we can see in this quote - that many other elements must come into play for human integrity to prevail. We can understand his hesitation with regard to certitude and intuition, his concession on the part of conscience-as he jokingly remarked that he would drink a toast first to conscience and only afterwards to the Pope-and at the same time his claim that conscience is the least luminous. In order to avoid confusion, let me remind the reader that Newman is always concerned with a concrete, real, and unpredictable being in a concrete situation. Therefore, few things can be theoretically decided in advance. And conscience is the last candidate for a thorough theoretical description.

Let us turn now to the question of habit. All of Newman's analyses seem to converge on this point - the person's habitual readiness to promptly respond to the call of the good of a given situation.

\section{Habit— the Way of Action}

Newman clearly draws on Aristotle when he describes virtue as "a mean,that is, as considering it to lie between things that are wrong. We know what is

$\begin{array}{ll}235 & \text { Ibid., } 256 . \\ 236 & \text { Ibid., } 253^{-254}\end{array}$ 
right, not positively, but negatively; - we do not see the truth at once and make towards it, but we fall upon and try error, and find it is not the truth. We grope about by touch, not by sight, and so by a miserable experience exhaust the possible modes of acting till nought is left, but truth, remaining. Such is the process by which we succeed; we walk to heaven backward; we drive our arrows at a mark, and think him most skilful whose shortcomings are the least."237

It follows from the above passage that the way to the truth is hard work. We need to try and show discipline. "We do not know what we mean by a habit, except as a state or quality of mind under which we act in this or that particular way; it is a permanent power in the mind [...]."238 This power in the mind is not effected by merely intellectual activity.

It is important because unreal words bring us away from our personal growth, from the true unity of our persons. Being true to oneself is of utmost importance. Being true also means to be at peace with one's conscience. Therefore, this does not mean to primarily have one's own way. Another thing is that when we apply the Aristotelian way to virtue we act in a negative mannerby avoiding extremes, i.e. by saying "no" to each extreme. By going back and rejecting all the extremes, we finally arrive at the truth. In other words, we first departed from the truth at the moment when we took for the truth something that was merely its false reflection.

Habit as a permanent state of mind can be positive or negative. In other words, it acts in such a way as to prompt the agent to good deeds or to deaden him to the awareness that he is doing something bad. Therefore, Newman resorted to introspection, that phenomenological tool with which to examine one's mind and find out where it is located in relation to the matters at hand and how it evaluates them. The mind can be, respectively, resolute on something good or in the grips of doing wrong. He lay down his individual model of introspection in Apologia pro Vita Sua, a very personal diary on someone's spiritual and intellectual journey, an attempt at a justification of one's life. What kind of justification was it? For sure, it was not a justification with a view to some objective criteria. This type of justification would be especially foreign to Newman, and would go against the grain of his guiding principle that "egotism is true modesty." His justification was meant to show his personal consistency between his person and the choices he had made throughout his life. The most important thing is to be real, i.e. not to rationalize one's conscience. It is better, one might conclude, to act and make mistakes than to pretend.

237 J. H: Newman, Parochial and Plain Sermons, 1019.

238 Ibid. 
The negative aspect of habit has the following effects upon the acting agent. It blurs his ability to assess his condition and entail despair. Fulton Sheen (18951979) put it wonderfully when he wrote: "The condition of despair induced by unrepented sin often reaches a point where there is a positive fanaticism against religion and morality. He who has fallen away from the spiritual order will hate it, because religion is the reminder of his guilt. Husbands who are unfaithful will beat their wives who are faithful. Wives who are unfaithful will accuse their husbands of infidelity." ${ }^{239}$ Is it not here that we find the contemporary interest in the gloomy recesses of one's mind? People like watching negative characters on television because, by way of contrast, they can think of themselves as someone better; and because they are given an opportunity for worse actions. Newman speaks about "secret faults" (secret sins). Conscience ceases "to upbraid us" when we refuse to listen to its reproaches. We can thereby become accustomed to sins (or faults) and desensitized, i.e. "the more guilty we are, the less we know it; for the oftener we sin, the less we are distressed at it." And the Cardinal adds his own practical observation: "I think many of us may, on reflection, recollect instances, in our experience of ourselves, of our gradually forgetting things to be wrong which once shocked us. Such is the force of habit. By it (for instance) men contrive to allow themselves in various kinds of dishonesty. They bring themselves to affirm what is untrue, or what they are not sure is true, in the course of business. They overreach and cheat; and still more are they likely to fall into low and selfish ways without their observing it, and all the while to continue careful in their attendance on the Christian ordinances, and bear about them a form of religion. Or, again, they will live in self-indulgent habits; eat and drink more than is right; display a needless pomp and splendour in their domestic arrangements, without any misgiving; much less do they think of simplicity of manners and abstinence as Christian duties." 240

In the quotation above we can see two elements. First, we find Newman's consistency in carrying out his introspection. Second, his acute sense of observation. All the aforementioned negative symptoms of human behaviour can, in turn, be enhanced by the ethos in which we live. Once certain shameful deeds are accepted, let alone recommended, the agents readily resort to soothing excuses. Newman does not propose any revolutionary solutions. If one cannot change the ethos, one should leave it. Ethos can be related to what Newman calls custom. Habit is what comes from within, and custom is what

239 F. J. Sheen, Peace of Soul, 66.

240 J. H. Newman, Parochial and Plain Sermons, 37. 
comes from without. Certain bad practices may grow very deep roots. People have a tendency to look with an approving eye at what should be eliminated. They "will feel the sway of the fashion of their age,"241 Hence Newman was right in claiming that one should be jealous of one's own person.

Newman, for his part, stresses the fact that my primary responsibility is myself. I carry myself throughout my life, e.g. through the political ostracism of Great Britain in the case of Newman, and through the suffering of the Holocaust in the case of Edith Stein. I am not called upon to save the world, nor capable of doing so. My first and foremost duty is to save myself. This is an individual and a social task at the same time. It is social in the sense that each authentic human being remains a pattern of behaviour for the generations to come. Here is someone who has managed to retain his personhood. Then, in his unique introspection, he tested his own position, whether he committed himself, whether he was real in what he was saying and doing.

In 1859, Newman rejected Ward's view that we have to trust our faculties first, as it is our first speculative certainty. Therefore, his later philosophy is "no mere psychologism - it is a metaphysics of being as known in experience."242

241 Ibid., 38.

242 E. Sillem (ed.), The Philosophical Notebook, vol. 2, 33. See also A. J. Boekraad, The Personal Conquest of Truth According to J. H. Newman, Louvain: Editions Nauwelaerts, 1955, $255^{-272 .}$ 